\title{
8. »LA VÉRITÉ EST EN MARCHE, RIEN NE L'ARRÊTERA PLUS «: DAS LICHT DER WAHRHEIT IN DER DREYFUSAFFÄRE
}

\author{
8.1. »Les puits qui parlent «: Der Gefangene, das Individuum \\ und die Masse auf dem Weg ans Licht
}

Kaum ein anderes Ereignis offenbarte die vielfältigen Spannungen und Konflikte innerhalb der republikanischen Gesellschaft deutlicher als die Dreyfusaffäre ${ }^{1}$. In die jahrelangen Auseinandersetzungen bezüglich der Revision des im Januar 1895 als Verräter verurteilten und auf die Teufelsinsel deportierten jüdischen Hauptmannes sahen sich verschiedenste politische und gesellschaftliche Gruppen involviert. Früher oder später, so schien es, war jeder gezwungen sich in das verabsolutierende Schema dreyfusard contra antidreyfusard einzugliedern ${ }^{2}$.

Gerade in bezug auf die Tagespresse bietet diese Klassifizierung ein sehr verzerrtes Bild, das kaum in der Lage ist, das in Wirklichkeit wesentlich feiner schattierte Meinungsbild zu reflektieren, zumal im Hinblick auf die unterstellte Parallelität von Antisemitismus und dreyfusards sowie Revisionismus und antidreyfusards ${ }^{3}$. Die Erklärung ist nicht zuletzt in der Bildpublizistik zu suchen ${ }^{4}$, die ihren Elan aus dem vergröbernden Schema zweier konkurrierender

${ }^{1}$ Die Publikationen zum chronologischen Verlauf der Affäre sind Legion. Vgl. stellvertretend Jean-Denis Bredin, L'Affaire, Paris 1985; Martin P. Johnson, The Dreyfus Affair. Honour and Politics in the Belle Époque, New York 1999. Einen anschaulichen Abriß bietet Michel Drouin, Précis, in: Ders. (Hg.), L'affaire Dreyfus de A à Z, Paris 1994, S. 23-112.

2 Diese gesamtgesellschaftliche Komponente tritt in neueren Untersuchungen in den Vordergrund. Vgl. bes. Laurent Gervereau, Christophe Prochasson (Hg.), Laffaire Dreyfus et le tournant du siècle (1894-1910), Paris 1994; Drouin (Hg.), L'affaire Dreyfus de A à Z; Norman L. Kleeblatt (Hg.), The Dreyfus Affair. Art, Truth and Justice, New York 1987.

${ }^{3}$ Speziell zu den Tageszeitungen vgl, die Untersuchung von Janine PoNTY, La presse quotidienne et l'affaire Dreyfus en 1898-1899. Essai de typologie, in: Revue d'histoire moderne et contemporaine 21 (1974), S. 193-220. Anhand von 55 Zeitungen (26 Pariser und 29 aus der Provinz) unterscheidet die Autorin allein vier Hauptkategorien der AntiDreyfus-Presse: "haineux et antisémite«; "haineux sans antisémitisme«; »sans violence«; "socialiste«. Darüber hinaus trennt sie scharf zwischen den Tendenzen »dreyfusard « und »révisionniste « (ibid., S. 198). Allg. zur Rolle der Presse vgl. Patrice Boussel, L'affaire Dreyfus et la presse, Paris 1960.

4 Zur Bedeutung der Karikatur in der Dreyfusaffäre vgl. John Grand-CarTeret, L'affaire Dreyfus et l'image. 266 caricatures françaises et étrangères, Paris 1899; F. Hermann, Die Dreyfusaffäre im Spiegel der Karikatur, in: Eduard HütTinger, Hans A. LüTHY (Hg.), Gotthard Jedlicka: eine Gedenkschrift. Beiträge zur Kunstgeschichte des 19. und 20. Jahrhunderts, S. 105-113; Gervereau, S'engager, se dégager; Phillip Dennis Cate, The Paris Cry. Graphic Arts and the Dreyfus Affair, in: KleEblatt (Hg.), The Dreyfus Affair, S.62-95; Christian Delporte, Images d'une guerre franco-française. La caricature au temps de 
Parteien zog. Die gewollt scharfe Absetzung von der jeweiligen gegnerischen Richtung 5 mündete zwangsläufig in ein extremes Gegensatzmodell, das in Licht- und Finsternismetaphern adäquate Ausdrucksweisen fand. Im Spiegel der Karikatur, und besonders im speziellen Fall der bildlichen Lichtsymbolik, wird darüber hinaus sehr deutlich, daß die Dreyfusaffäre allmählich zur Metapher für das Schicksal des um sein Recht kämpfenden Individuums im System der Republik wurde, die sich in der vielfältigen Rezeption schließlich zum Abbild des Kampfes der Masse um ihren Platz in dieser Gesellschaft entwikkelte. Die Dreyfusaffäre fungierte, wie Kedward völlig richtig präzisiert, als Katalysator für ungelöste Konflikte ${ }^{6}$ und kann als Gradmesser für Anspruch und Wirklichkeit der Republik und damit auch der lumières gelten. Tatsächlich spielte die Person Dreyfus selbst in der Karikatur eine untergeordnete Rolle $^{7}$. Während sich der Begriff "Affäre« für den scheinbar abgeschlossenen

l'affaire Dreyfus, in: French Cultural Studies 6 (1995), S.221-248. Zu den Reflexionen in den visuellen Künsten im allgemeinen vgl. Norman L. KLeEblatT, The Dreyfus Affair. A Visual Record, in: Ders. (Hg.), The Dreyfus Affair, S.1-24; Stephen Brown, Norman L. KleeblatT, Les arts visuels (1894-1908), in: Drouin (Hg.), Laffaire Dreyfus de A à Z, S.316-322. Was die innergesellschaftlichen Spannungen betrifft, so liegt der Akzent der Forschung bisher stark auf der Wechselwirkung von Aktion und Interaktion lediglich zweier agierender Gruppen - dreyfusards und antidreyfusards - was besonders durch das starke Interesse am kämpferischen Dialog der beiden Satiremagazine Le Sifflet und Psst!... ersichtlich ist. Dazu DelPorte, Images d'une guerre franco-française, und Tillier, Virulences. 5 Zur damit einhergehenden extremen Polemisierung des Sprachgebrauchs vgl. Richard Griffiths, The Use of Abuse. The Polemics of the Dreyfus Affair and its Aftermath, New York, Oxford, bes. S. 5: "So political debate in the years leading up to the Affair, and during the Affair itself, was marked by the bluntness and violence of the emotions expressed and by the unsubtle nature of the polemical attacks involved. Often, the accusations which were hurled, and which had started as imaginary exaggerations, took on a life of their own. Unreal splots assumed reality, bogey-man became solid threats, fear of the other side became almost more powerful than the hatreds that had created it. So it was that the rhetoric of late nineteenth-century politics, magnified by the Affair, in fact created even wider polarities between the participants «.

${ }^{6}$ H. R. Kedward, The Dreyfus Affair. Catalyst for Tensions in French Society, London 1965. Innerhalb der Presse wurde diese Entwicklung von den sich an ein intellektuelles Publikum richtenden revues dreyfusardes eingeleitet, darunter etwa La Revue blanche. Vgl. dazu Vincent Duclerr, Les revues dreyfusardes en France. L'émergence d'une société intellectuelle, in: La Revue des revues 17 (1994), S.11: „Ce sont en grande partie les revues dreyfusardes qui ont mené l'affaire Dreyfus à prendre une dimension d'événement considérable, à se déployer dans les domaines politiques mais également civiques, culturels, scientifiques, et intellectuels $\ll$.

7 Dennoch wird Dreyfus, stets mit eindeutig negativierenden, jüdischen Zügen dargestellt, zur Zielscheibe in der Bildpublizistik der antidreyfusards. Le Triboulet etwa zeigt ihn am 30.4.1899 hoffnungslos am Strand der Teufelsinsel, während die Sonne der Révision im Meer versinkt (D. OLA, Coucher de soleil). Am 4.6.1899 schlägt eine Karikatur im selben Magazin die Bonne révision à l'américaine vor, die darin besteht, Dreyfus zu hängen, während die nunmehr hoch am Himmel stehende Sonne das Geschehen mit einem breiten Grinsen quittiert. Der Henker in Gestalt eines vor Kraft strotzenden, muskulösen französischen Helden verdeutlicht durch den Gegensatz zur mageren, häßlichen Gestalt des degradierten Hauptmanns die Gleichzeitigkeit einer Ideologie rassischer Über- bzw. 
Fall langsam durchsetzte und die Ereignisse dem Wendejahr 1898 und Émile Zolas epochalem Artikel "J'Accuse ${ }^{8}$ entgegenstrebten, war Alfred Dreyfus als Person von der Bildfläche verschwunden. Als Verbannter auf der Teufelsinsel war ihm jegliche Handlungsfreiheit genommen. Gerade durch diese Machtlosigkeit wurde Dreyfus aber zur einflußreichen Symbolfigur für ein Klima der politischen Ungerechtigkeit. Aus diesem Grunde äußerten sich schließlich auch führende Sozialisten und Anarchisten zugunsten des Verbannten, der als Opfer nicht mehr zur Klasse der Privilegierten gehörte: Jean Jaurès unterstrich in Les Preuves Dreyfus' Schicksal als »exemplaire de l'humaine souffrance « und »témoin vivant du mensonge militaire, de la lâcheté politique, des crimes de l'autorité «9. Die Dreyfusaffäre war für Jaurès nur die Spitze des Eisbergs einer Verschwörung, undurchschaubarer Machtstrukturen, Ursprung alles sozialen und moralischen Unrechts:

Les socialistes qui veulent fouiller jusqu'au fond les secrets de honte et de crime contenus dans cette affaire, $[\ldots]$ s'occupent de toute la classe ouvrière. Qui donc est le plus menacé aujourd'hui par l'arbitraire des généraux, par la violence toujours glorifiée des répressions militaires? Qui? Le prolétariat. Il a donc un intérêt de premier ordre à châtier et à décourager les illégalités et les violences des conseils de guerre avant qu'elles deviennent une sorte d'habitude acceptée de tous. Il a un intérêt de premier ordre à précipiter le discrédit moral et la chute de cette haute armée réactionnaire qui est prête à le foudroyer demain ${ }^{10}$.

Auch Sébastien Faure vollzog in dem anarchistischen Magazin Le Libertaire eine explizite Gleichsetzung von politischer Affäre und sozialer Frage, und

Unterlegenheit. Das Motiv des Hängens findet sich noch einmal nach der Begnadigung, diesmal jedoch unter völlig anderen Umständen: Das am 13.8.1899 abgedruckte Blatt Seule solution possible von BALA D'ECHE versetzt die fiktive Hinrichtung nach Paris. Eine mit Sensen, Hacken und anderem Werkzeug bewaffnete Menge hat Dreyfus an einer Laterne aufgehängt und damit eine revolutionäre Tradition wiederbelebt. Die Laterne erscheint im Kontext des die Wahrheit bringenden Lichtes im Kampf um die Revision (vgl. dazu Kap.8.2.) wie ein höhnischer Kommentar. An der Schuld wird hier nicht der geringste Zweifel gelassen, wie der lateinisch-französische Bildtext belegt: Aspice Dreyfus pendu / Quod Patriam a vendu, / Si Pa-tri-am non vendisset / Dre-y-fus pendit non fuisse. Die umfunktionierte Laterne ist also zur stummen Zeugin einer Wahrheit berufen, die für die Dreyfusgegner ebenso unbestreitbar ist wie für die Gegenseite seine Unschuld. Der Kampf um die endgültige Rehabilitierung nach der Begnadigung 1899 stellt für die Dreyfusgegner eine obskure Bedrohung dar. Am 13.12.1903 zeigt Le Triboulet eine Karikatur von George EDWARD mit dem Titel Encore lui! - Pauvre France: Dreyfus nähert sich dem unter ihm liegenden Frankreich als unheilvoller schwarzer Schatten, bemüht, mit seinen ausgestreckten Armen einen möglichst großen Teil des hexagone zu verdunkeln.

8 Émile Zola, J'Accuse. Lettre à M. Félix Faure, président de la République, in: L'Aurore, 13.1.1898.

9 Jean Jaurès, L'intérêt socialiste, in: Ders. Les Preuves. L'affaire Dreyfus, Paris 1898 (Repr. 1981), S.12. Im Gegensatz zu Jaurès berharrte Jules Guesde, Gründer des Parti ouvrier, auf seiner Position des absoluten Klassenkampfes und lehnte jegliches Engagement für Dreyfus ab. Vgl. zu Guesde: Robert StuarT, Marxism at Work. Ideology, class and French socialism during the Third Republic, Cambridge 1992, sowie Hutron, Historical Dictionary, Bd. 1, S. 442-446.

10 JaURÈs, L'intérêt socialiste, S. 13. 
dies zu einem Zeitpunkt, wo er von der Unschuld des Verbannten noch keineswegs überzeugt war ${ }^{11}$ : "À l'heure actuelle, l'affaire Dreyfus n'est plus l'affaire Dreyfus. Elle porte à l'ordre du jour la question sociale tout entière avec ses complexités « ${ }^{12}$.

Seine Kritik richtete sich zunächst allein gegen die Mechanismen, die im Zuge der Ereignisse offen zutage traten, wobei er besonders den Militarismus anprangerte und das Schicksal der »foules abusées« herausstellte als »symbole et instrument des luttes internationales, nécessaires à la sauvegarde des dominations sociales ${ }^{13}$.

Am klarsten zutage aber trat die Vermengung von Dreyfusaffäre und sozialer Frage in der stets äußerst distanzierten Haltung des anarchistischen Schriftstellers und Publizisten Zo d'Axa, der in seinem von Juni 1897 bis März 1899 in 27 Ausgaben erschienenen Magazin La Feuille $e^{14}$ eine gleichbleibend kritische Haltung gegenüber der Person Dreyfus zum Ausdruck brachte. Noch in der letzten Ausgabe der La Feuille prangerte Zo d'Axa die dem Militär gegenüber unkritische Haltung des Verbannten an: "Et le capitaine Dreyfus lui-même qui reste, ses lettres en font foi, le type de l'officier chauvin, ne pensez-vous pas qu'il protestera en apprenant l'explosion d'antimilitarisme dont son cas fut l'heureux prétexte? «15 Dennoch korrespondiert der Erscheinungszeitraum von La Feuille keineswegs zufällig mit der brisanten Phase der Affäre. Die direkten und indirekten Bezugnahmen sind unverkennbar und verdeutlichen die weitreichende Rezeption der Affäre als eigenes Symbolsystem.

Besonders aufschlußreich ist die am 17.Dezember 1897 veröffentlichte Ausgabe mit dem Titel: Réhabilitation civile et exécution militaire. Unter der Überschrift Une erreur judiciaire berichtet der Leitartikel von der wahren Geschichte eines jungen Soldaten, dessen unmittelbar bevorstehende ErschieBung das Sujet von Théophile Alexandre Steinlens Illustration auf der Vorderseite ist (Abb.60). Der besagte Soldat hatte sich im Militärgefängnis auf

11 Faure selbst kam erst im September 1898 zu dem Schluß, daß Dreyfus unschuldig sein müsse. Vgl. Boussel, L'affaire Dreyfus, S. 172.

12 Sébastien Faure, Les anarchistes et l'affaire Dreyfus (1), in: Le Libertaire, 29.1.-5.2. 1898 .

13 Ibid.

14 La Feuille imitierte die Tradition des Flugblatts und sollte so vermutlich den Anschein einer spontanen Reaktion vermitteln, was sich auch in der losen Folge der erschienenen Ausgaben spiegelt. Die Vorderseite des Blattes zeigt unter dem Logo eine großformatige Illustration, die Rückseite ist den Texten des Herausgebers vorbehalten. Zu La Feuille vgl. auch DrrTMar, Steinlen, S.100-105. Die mitwirkenden Künstler waren neben Théophile Alexandre Steinlen auch Adolphe Willette, Charles Léandre, Hermann-Paul, Louis Couturier, Louis Anquetin und Maximilien Luce. Auch darin zeigt sich die kritisch-distanzierte Haltung Zo d'Axas zur Affäre: Neben Steinlen waren auch Hermann-Paul und Couturier überzeugte dreyfusards, während zumindest anfangs Léandre und besonders Willette zu seinen entschiedenen Gegnern zählten, wobei letzterer ein fast manischer Antisemit war. Davon zeugen seine Ausfälle in den von ihm gegründeten Zeitschriften Le Pierrot und Le Fifre. Vgl. dazu Cate, The Paris Cry, S. 67.

15 La Feuille No.25, 28.3.1899 (= Désarmement). 


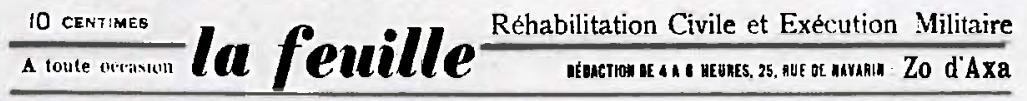

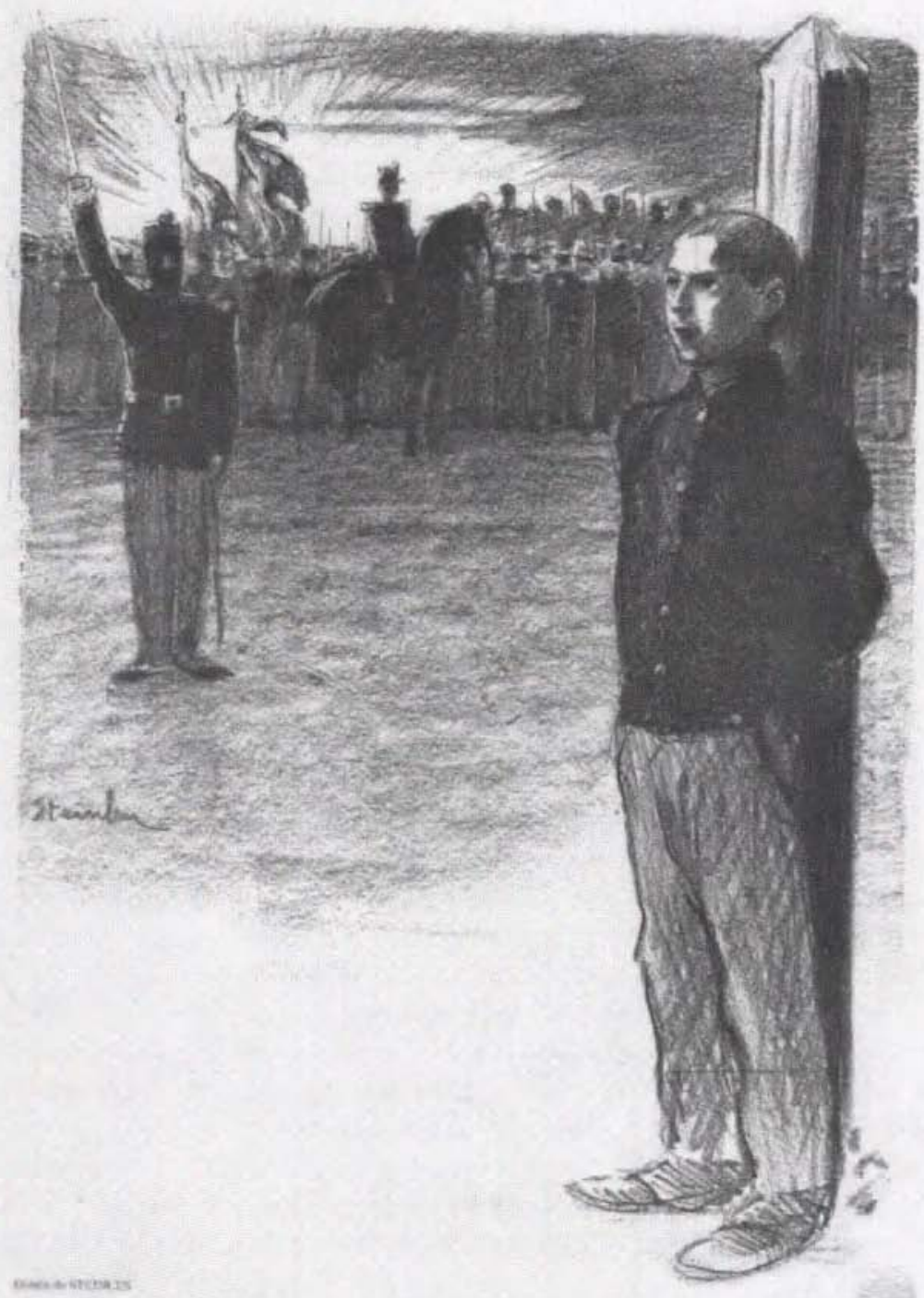

Abb. 60 Theophile Alexandre Steinlen: Rehabilitation civile et execution militaire, in: La Feuille, 17.12.1897. UB Frankfurt. 
einen Offizier gestürzt, der einen Mitgefangenen erschossen hatte, nur weil dieser um Brot gebeten hatte. Der junge Soldat selbst wird nur leicht verletzt, wegen des Angriffs auf einen Vorgesetzten aber zum Tode verurteilt. Der Titel des Artikels zitiert ganz bewußt denjenigen von Bernard Lazares Schrift über den Dreyfusprozeß, die nur einen Monat zuvor in Paris erschienen war: Une erreur judiciaire. L'affaire Dreyfus. ${ }^{16}$ Lazare stellte den Prozeß und seine Folgen als reines Konglomerat des Antisemitismus dar, als eine sorgfältige Konstruktion des Stereotyps eines jüdischen Verräters. Vor diesem Hintergrund tritt die Ungeheuerlichkeit des Falles, den Zo d'Axa schildert, um so deutlicher hervor. Der junge Soldat wird aufgrund einer mitmenschlichen Reaktion zum Schwerverbrecher stilisiert, der gleichsam symbolisch ausgemerzt werden muß:

"Pour clore cette ère de scandales où maints officiers se distinguèrent, il faut un exemple, c'est certain: Fusillez vite le petit soldat«. Die Schuld der Offiziere am trostlosen Zustand der Armee wird in dieser gnadenlosen Reaktion also völlig negiert und statt dessen am unteren Ende der Hierarchie gesucht. In seiner moralischen Tragweite greift die Botschaft dieses Vorkommnisses weit über die Affäre hinaus. Die Frage nach Schuld und Unschuld stellt sich hier gar nicht, und folglich ist die Formulierung erreur judiciaire völlig unangebracht. Hier ist niemand - ob gewollt oder ungewollt - einem Irrtum aufgesessen, sondern das Urteil wurde bewußt und bei klarer Sachlage gesprochen.

Im Gegensatz zu Dreyfus bleibt dem namenlosen Soldat nicht einmal die Hoffnung. Steinlens Illustration zeigt den Moment der Hinrichtung. Mit den Händen an einen Pfahl gefesselt, steht der Junge da, die Augen nicht verbunden. Der Befehlshabende hat schon seinen Säbel erhoben, um das Signal zum Schießen zu geben, auf das die Soldaten in Reih und Glied warten. Dahinter strahlt die eben aufgehende Sonne auf, wodurch die vom Erschießungskommando mitgeführten Fahnen optisch zentriert werden. Die Armee erscheint so als im Zentrum stehend und sich selbst glorifizierend. Das Individuum, das mit dem Licht keine strukturelle Verbindung hat, wird dagegen zum Feind erklärt. Das sich als undurchdringliche schwarze Front präsentierende Militär schottet das Licht ab und weitet seinen Führungsanspruch auf den umgebenden Raum aus. Tatsächlich scheint es, als wolle der Kommandierende mit dem Schießbefehl den endgültigen Sonnenaufgang abpassen und somit eine ideologische Indoktrination des Lichts inszenieren.

Die verzweifelte Lage des isolierten Individuums wird um so offenbarer, wenn man bedenkt, daß der amorphe Block der Soldaten, das Gewehr im Anschlag, aus den ehemaligen Kameraden des Todeskandidaten besteht. Eine

16 Vgl. Philippe Oriol, Bernard Lazare, in: Drouın (Hg.), L'affaire Dreyfus de A à Z, S. 221-225: Schon ein Jahr zuvor war die Broschüre unter dem Titel L'erreur judiciaire: la vérité sur l'affaire Dreyfus erstmals in Brüssel veröffentlicht worden, dies mit der Absicht, eventuelle Zensurmaßnahmen zu umgehen. 
Solidarität, wie dieser sie bewiesen hat, scheint hier nicht zu existieren. Das warnende Beispiel des Verurteilten trägt bereits Früchte, der Verrat der Mehrheit am einzelnen ist somit perfekt. In seiner Komposition erinnert die Szenerie nicht zufällig an die verbreiteten Darstellungen der Degradierung von Dreyfus (Abb.61) ${ }^{17}$. Der moralischen Hinrichtung steht hier jedoch die tatsächliche gegenüber. Zwischen Opfer und Täter findet kein eigentlicher Kontakt mehr statt, der Verurteilte wird vollends in die Rolle des auszumerzenden Feindes gedrängt. Dieses Beispiel militärischer Willkür muß gleichzeitig als Kritik an den vielfältigen Bemühungen um die Rehabilitierung von Dreyfus verstanden werden. Dem prominent gewordenen Fall stehen eine unüberschaubare Anzahl von anderen himmelschreienden Ungerechtigkeiten und Verbrechen gegen die Menschlichkeit gegenüber, die kaum öffentliches Interesse erregen. Das Ausmaß des Verrats der Gesellschaft am unterdrückten Individuum wächst somit ins Unermeßliche. Die Wahrheit zu sagen heißt, dieses Schema zu durchbrechen und damit den Opfern eine Stimme zu geben. Bewußt variiert Zo d'Axa in der vorletzten Ausgabe von La Feuille die Metapher der sich aus dem Brunnenschacht ans Licht emporkämpfenden Wahrheit, die im Rahmen der Dreyfusaffäre eine ungeheure Verbreitung fand ${ }^{18}$. Zo d'Axa allerdings nutzt die Doppelbedeutung des Wortes puits, das neben dem Brunnenschacht auch den Minenschacht bezeichnen kann und legt das Sinnbild der sich Gehör verschaffenden Wahrheit auf das gegen seine Lebensbedingungen rebellierende Proletariat um. Der Artikel Les puits qui parlent argumentiert, daß die gegenwärtige Krise der Bourgeoisie den Arbeitern erst ihre moralische Überlegenheit vor Augen geführt hätte ${ }^{19}$. Die Bergleute als besonders schlecht gestellte Schicht, denen sogar das Tageslicht vorenthalten bleibt, werden dabei vor dem Hintergrund einer Gewerkschafts-Demonstration zur idealen Substitution der Allegorie:

Ce sont les rudes gars de la mine, ceux qui pour un dérisoire salaire risquent le grisou tous les jours - y a-t-il même des jours pour eux! l'éternelle nuit sous les galeries - ce sont ceux des houillères sinistres qui réunis, dimanche passé, ont proclamé leur opinion. La parole de la Vérité devait sortir des puits profonds ${ }^{20}$.

Das Motiv des sich befreienden, zum Licht strebenden Gefangenen erscheint in der Karikatur als der Kampf, den das Individuum stellvertretend für die Masse führt. Das Licht als Symbol der zu erringenden Freiheit nimmt dabei selbst keine aktive Rolle ein. Ist dieser Kampf, wie im Fall des verurteilten Soldaten, bereits verloren, dann wird das Licht sogar zum stummen Attribut des triumphie-

17 Henri Meyer, Le Traître - Dégradation d'Alfred Dreyfus, in: Le Petit Journal, 10. 1. 1895. Vgl. auch Fréderic de HAEnen, La Dégradation du capitaine Dreyfus, in: L'Illustration, 12.1.1895.

18 Vgl. dazu Kap.8.2.

19 »es gouvernements exploiteurs ont donné ce qu'ils pouvaient commettre: le prolétariat exploité, conscient aujourd'hui, se redresse«. Les puits qui parlent, in: La Feuille No.24, L'honnête ouvrier, 15.2.1899.

${ }^{20}$ Ibid. 


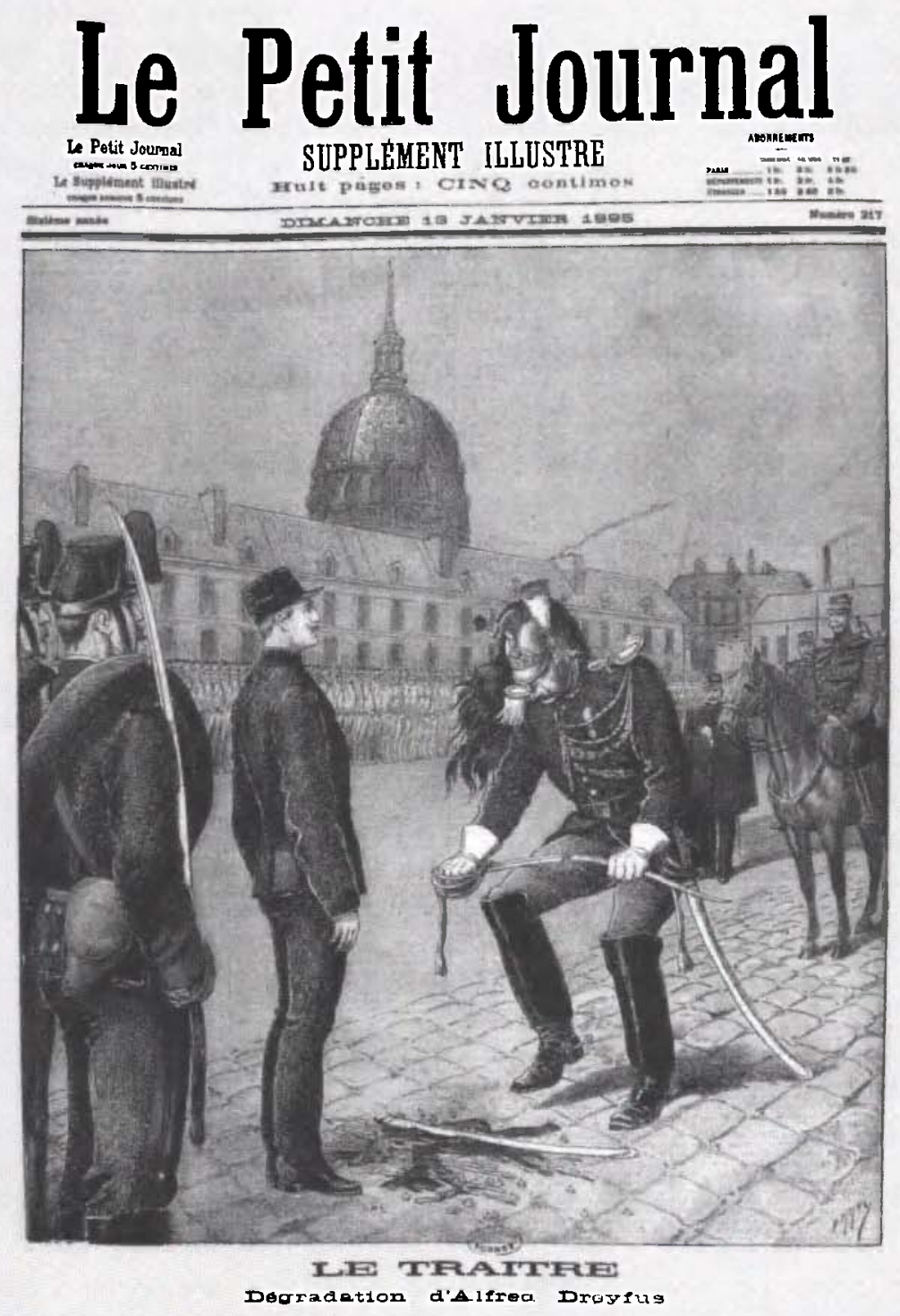

Abb. 61 Henri Meyer: Le Traitre - Degradation d'Alfred Dreyfus, in: Le Petit Journal 13. 1. 1895. Bibl. Forney, Paris. 
renden Unrechts ${ }^{21}$. Das Ideal des sich selbst schenkenden Lichts der Wahrheit verschwindet auch im direkten Kontext der Affäre sehr schnell ${ }^{22}$. Noch 1898 zeichnet Kab für die Lyoner Comédie politique das Blatt De la tombe à la lumière!... (Abb.62) ${ }^{23}$ : Angekettet sitzt Dreyfus auf der Pritsche eines Kerkers, aber ganz im Lichtschein der Revision, die durch die Gitterstäbe dringt.

Die ein Jahr später in Le Libertaire erschienene Darstellung La Grille (Abb. 63) ${ }^{24}$ thematisiert dagegen den vehementen Versuch eines Gefangenen, das mit dem Kreuz geschmückte Gitter aufzubrechen, um ins sonnige Freie zu gelangen: »Hardi, l'HOMME, encore un effort!«

Die von Dreyfus wiedergewonnene Freiheit gibt Hoffnung auf eine Veränderung der politischen und gesellschaftlichen Verhältnisse. An die Stelle des realen Handlungsträgers ist aber nun der Platzhalter einer ganzen sozialen Schicht getreten, der durch die typographische Hervorhebung im Bildtext sogar als Mensch schlechthin gedeutet wird. In den Vordergrund rückt vor allem der erbitterte Kampf gegen christliche Bindungen, die sogar zur alleinigen Ursache der Unfreiheit gemacht werden. Die symbolisch überhöhte Aktivität des Ausbrechers stellt, verglichen mit der fast märtyrergleichen Haltung von Dreyfus, das eigentliche Konfliktpotential dar: Die Furcht vor der revoltierenden Masse trug erheblich zur aufgeheizten politischen Stimmung bei. Die Dreyfusaffäre war ein entscheidender Faktor bei der paradigmatischen Veränderung der politischen Öffentlichkeit und ihrer Wahrnehmung ${ }^{25}$.

Die Ängste von Dreyfusgegnern und -anhängern hingen dabei gleichermaBen mit dem Bild der unkontrollierbaren Masse zusammen: Was auf der einen Seite die Erinnerung an die Commune war, löste auf der anderen Seite der entfesselte antisemitische Hass der Menge aus ${ }^{26}$.

Demonstrationen und Gegendemonstrationen waren an der Tagesordnung, und im Gegensatz zur sorgfältig kanalisierten Festkultur des 14. Juli waren diese Massenkundgebungen nur schwer zu kontrollieren. Die ständig wachsende Bedeutung der Massenkultur als politischem Faktor konnte spätestens seit der Boulangerkrise nicht mehr geleugnet werden ${ }^{27}$. Gleichzeitig war der

${ }^{21}$ Erst in Darstellungen, auf denen sich das befreite Individuum der Sonne am Horizont direkt zuwendet, ändert sich die indifferente Rolle des Lichts. Der Kampf wird in derartigen Darstellungen als bereits gewonnen vorausgesetzt oder aber aufgrund einer ideologisch notwendigen Überzeugung als zwangsläufig zu erfüllende Zukunft betrachtet. Vgl. dazu Kap. 9.3.

${ }^{22}$ Der Beleg dafür sind die zahlreichen Darstellungen, in denen die Wahrheit sich mühsam ihr Recht verschaffen muß und oft nur mit tatkräftiger Hilfe des Arbeiters ans Licht gelangen kann. Vgl. dazu Kap.8.2.1.

${ }_{23}$ La Comédie politique, 21.11. 1898. Zu Kab vgl. Kap.4.2.

24 Ausgabe vom 5.11.-12.11.1899.

25 Tartakowsky, Pouvoir, S. 34: »Pendant l'affaire Dreyfus, l'investissement de l'espace public à des fins politiques devient le fait des deux camps en présence «.

${ }^{26}$ Christopher E. Forth, Intellectuals, Crowds and the Body Politics of the Dreyfus Affair, in: Historical Reflections/Réflexions historiques 24 (1998), S. 63.

27 Vgl. dazu Kap. 7. 


\section{DE LA TOMBE}

\section{A LA LUMIERE!...}

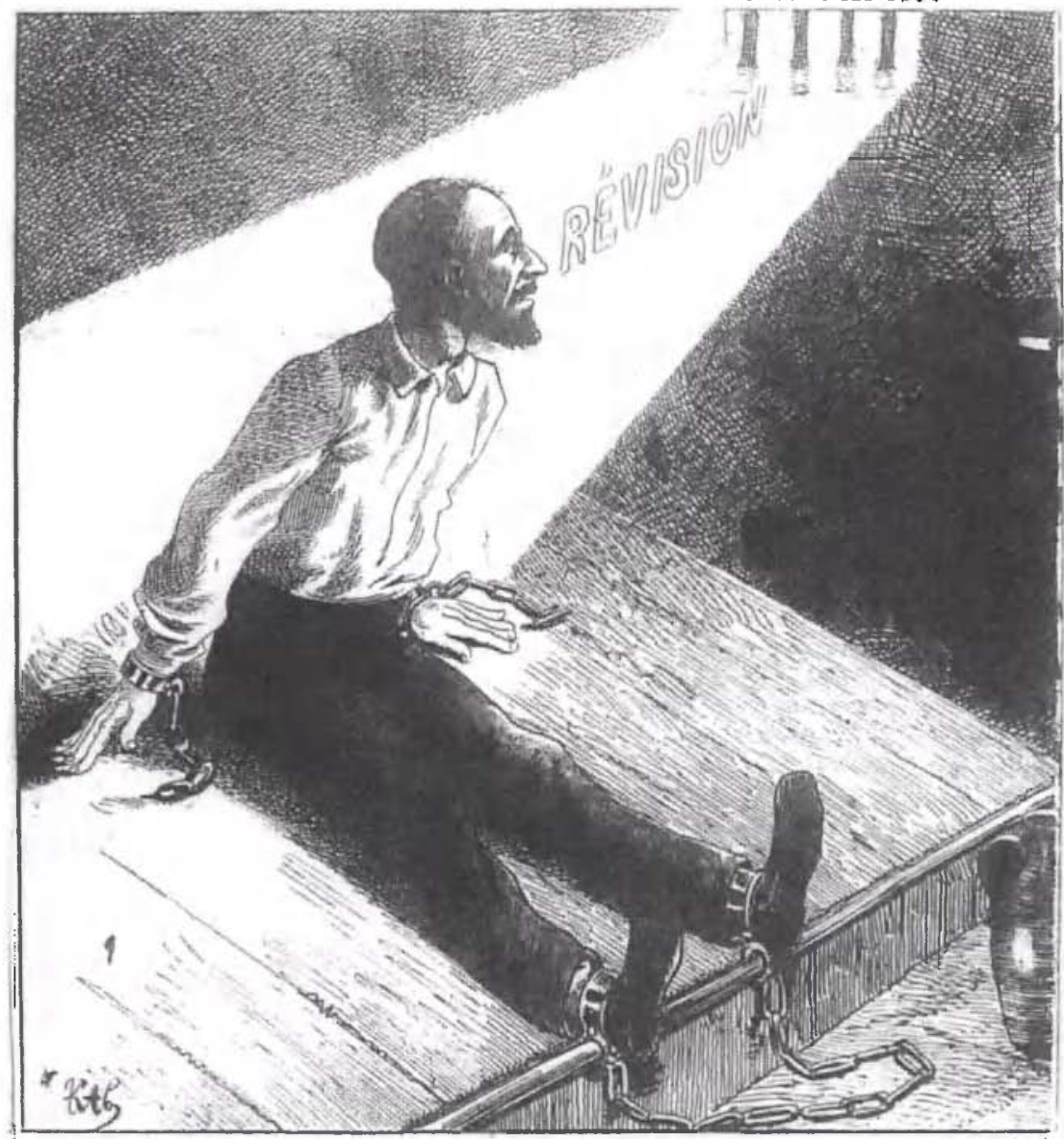

Abb. 62 Kab: De la tombe a la lumiere!..., in: La Comedie politique, 27.11.1898. Sammlung D.K. 


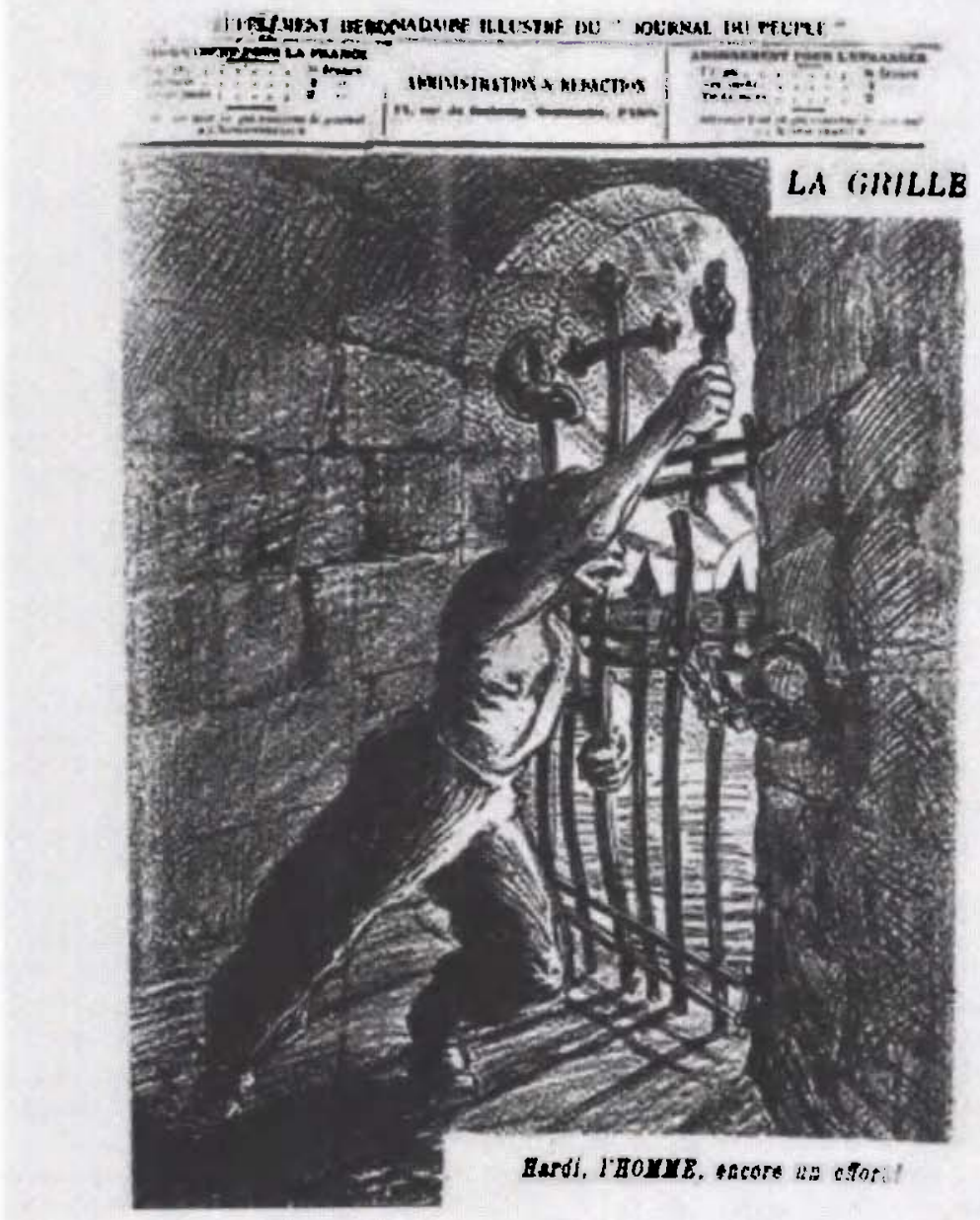

Abb. 63 Anonym: La Grille. Hardi, l'HOMME, encore un effort!, in: Le Libertaire, 5.11.-12.11.1899. BDIC, Paris. 
Übergang zu einer neutralen Bewertung der Masse als grundlegendem Phänomen der modernen großstädtischen Gesellschaft gerade in Paris schwierig, da der negative Mythos der foule in der Commune durch die anarchistischen Bombenattentate der frühen 1890er Jahre sowie die erstarkende Gewerkschaftsbewegung neue Nahrung erhalten hatte ${ }^{28}$. Unter den Massentheorien dieser Zeit ist besonders Gustave Le Bons 1895 erschienene Psychologie des foules hervorzuheben, in der die bevorstehende ère des foules als Rückfall in die Barbarei eines primitiven, vorgeschichtlichen Kommunismus beschrieben wird $^{29}$. Le Bon ergänzt dieses düstere Bild durch die Theorie des grundsätzlich labilen Charakters der Masse und des unter ihrem Einfluß zwangsläufig erfolgenden Verlusts der Individualität. Er vergleicht hierbei die Gemütsverfassung des Menschen in der Masse mit dem Zustand der Hypnose ${ }^{30}$, der das gesamte Denken und Streben in extremer Weise auf ein kollektives Ziel ausrichtet und jegliches eigenverantwortliche Handeln des Individuums zum Verschwinden bringt: "Il n'est plus lui-même, mais un automate que sa volonté est devenue impuissante à guider $\ll 31$.

Betrachtet man nun die bildliche Darstellung von Individuum und Masse im Bannkreis der Dreyfusaffäre, so fällt auf, daß das Individuum - ob allein im Bild oder aber im Angesicht einer Masse - stets ebenfalls eine solche repräsentiert. Der verurteilte Soldat auf Steinlens Blatt steht für die Masse der Opfer militärischer Willkür ebenso wie der das Gitter durchbrechende

${ }^{28}$ ForTH, Intellectuals, S. 71. Zu Anarchismus und Gewerkschaftskampf vgl. Kap. 9.2.

${ }^{29}$ Gustave Le Bon, Psychologie des foules, Paris 1947 (erste Auflage ibid. 1895), S. 11-16: L'ère des foules. Ibid., S. 13: »Aujourd'hui les revendications des foules deviennent de plus en plus nettes, et tendent à détruire de fond en comble la société actuelle, pour la ramener à ce communisme primitif que fut l'état normal de tous les groupes humains avant l'aurore de la civilisation «. Vgl. zum allgemeinen Tenor der Massenrezeptionen Barrows, Distorting mirrors, S. 191: »In formulating the composite image of the crowd, most French writers resorted to a number of motifs that mutated as quickly as the fragments of a dream. The configuration of the bête noire varied according to the imagination of the writer; the effect was phantasmagoric and unquestionably horrifiying «. Zur Bedeutung von Le Bons Werk innerhalb der Affäre vgl. ForTH, Intellectuals.

${ }^{30}$ LE Bon, Psychologie, S. 24: „Chez lui [d.h. beim einzelnen innerhalb der Masse] comme chez l'hypnotisé, tandis que certaines facultés sont détruites, d'autres peuvent être amenées à un degré d'exaltation extrême. L'influence d'une suggestion le lancera avec une irrésistible impétuosité vers l'accomplissement de certains actes«. Zur zeitgleichen Kritik an der Hypnose als Gefahr für die Selbstkontrolle vgl. CRARY, Aufmerksamkeit, S. 62: "Die Hypnose schien die exzessiven Möglichkeiten perzeptueller und kognitiver Kontrolle, ungeachtet ob sie empirisch erwiesen waren oder nicht, in solchem Maß zu verkörpern, daß sie mit den humanistischen Grundannahmen über den autonomen und voluntaristischen Charakter der menschlichen Subjektivität zwangsläufig in Konflikt geriet. Es dauerte nicht lange, und Hypnose und Suggestion wurden als Praktiken verhöhnt, die, statt als rationale Verfahren an die bewußte Mitarbeit des Patienten und seine Willenskraft zu appellieren, auf automatische (also niedere, mehr instinktive und der Animalität benachbarte) Prozesse abzielten«.

${ }^{31}$ Ibid. 
Proletarier für die Masse der in ihren Lebensverhältnissen gefangenen classes laborieuses.

Das beherrschende Motiv ist dabei in beiden Fällen das der (fehlenden) Raum- und damit Lichtbeherrschung. Das bewußte Handeln steht damit keineswegs im Zusammenhang mit der Rolle des einzelnen in der Masse, sondern mit seiner Selbstbehauptung angesichts einer übermächtigen Ansammlung konkurrierender Absichten. Welche Beziehung geht aber nun das seine Stimme erhebende Individuum als Stellvertreter für eine sich emanzipierende Masse mit der anderen, noch in Unfreiheit verharrenden, schweigenden Mehrheit ein? Le Sifflet, das wichtigste Satiremagazin der dreyfusards, zeigt am 10. März 1898 ein diesbezüglich sehr aufschlußreiches Blatt von Ibels (Abb.64): An Stelle der Sonne geht am Horizont ein lichtstrahlendes Symbol auf, vor dem eine in der Ferne zu erkennende Menschenmenge auf die Knie gesunken ist. Anders der im Vordergrund stehende Vertreter des populo, der sich über die Gestalt dieser 'Sonne` noch im unklaren ist: "Est-ce une croix ou un sabre?...« Die im Vergleich zwischen den Symbolen Kreuz und Säbel ${ }^{32}$ vollzogene faktische Gleichwertigkeit von Kirche und Militär stellt somit nicht nur die Mechanismen beider Institutionen auf dieselbe Stufe, sondern prangert zudem das quasireligiöse Selbstverständnis des Militärs an und den mit allen Mitteln gewahrten Anschein der absoluten Integrität ${ }^{33}$. Das Licht dieser Ideologie leuchtet nur für sich selbst und wird für die Gläubigen zum trügerischen Blendlicht. Als Teil des kritischen populo ist der distanzierte Betrachter, der sich außerhalb des symbolischen Einflußbereichs der Machthaber hält, in der Minderheit. Das Verhältnis zwischen Individuum und Masse ist also differenziert zu betrachten. Tatsächlich steht hier eine sich von vorgefertigten Wahrnehmungsmustern distanzierende Öffentlichkeit - nämlich das sich von traditionellen Bindungen und Sichtweisen lösende populo bzw. peup$l e$ - einer anderen, blind autoritätsgläubigen Gruppe gegenüber, die sich mit einem Licht- und Erkenntnisraum begnügt, der von Machtsymbolen abgeschlossen wird: Das am Horizont aufsteigende Gebilde wird durch den Eiffelturm im Hintergrund ergänzt, der gleichfalls als Lichtsymbol für die von oben diktierte Ordnung steht ${ }^{34}$. Licht und Raum, und damit die Orientierungspunkte schlechthin, werden somit überblendet und instrumentalisiert, was nur derjenige erkennen kann, der sich von der devoten Masse absondert. ${ }^{35}$ Deren

${ }^{32}$ Zur Bedeutung von Synekdoche und Pars pro toto für die polemisierende Sprache im Rahmen der Affäre vgl. Griffiths, Use, S.4: "Images such as >le sabre ' [...] were overused to the extent that they became almost second nature, and that it sometimes seemed to require an effort of concentration for a writer or speaker suddenly to become aware of their real implications«.

${ }^{33}$ Zum republikanischen Feinbild von le sabre et le goupillon vgl. Kap. 8.3.

${ }^{34}$ Zum Eiffelturm vgl. Kap. 7.2.

35 Zur Erweiterung des Blickwinkels als Symbol für die soziale und politische Emanzipation der Arbeiterschicht vgl. Kap.9.3., zum visuellen Komplex der Erkenntnis vgl. Kap. 8.2.2. 

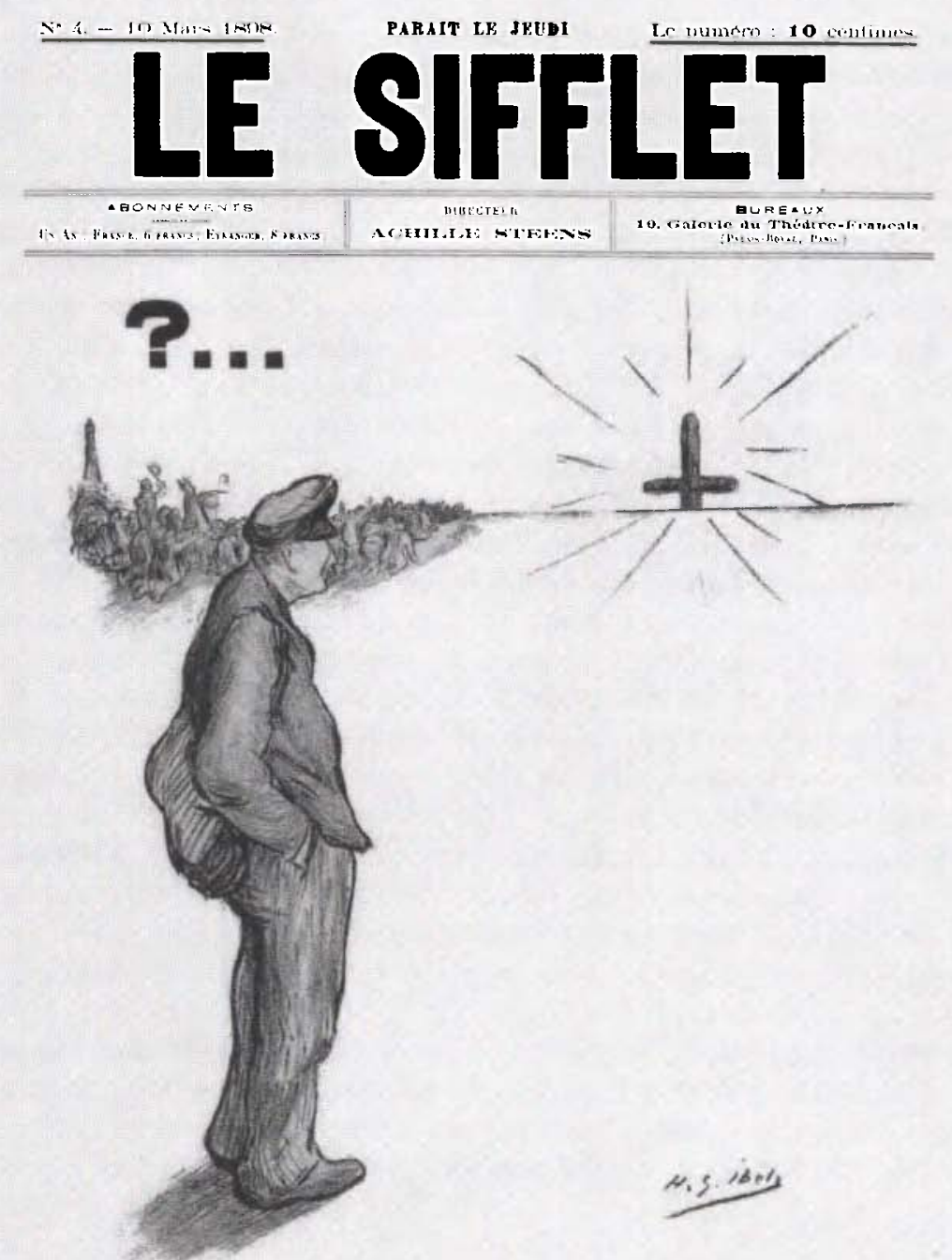

Pnpulu. - Estece une Groix on un Fabre?

Abb. 64 Henri-Gabriel lbels: ?... Populo: Est-ce une croix ou un sabre?..., in: Le Sifflet, 10.3.1898. UB Frankfurt. 
Zuwendung zu dem verheißungsvollen Licht spiegelt ein stark mit tiefliegenden Ängsten verbundenes Erlösungsbedürfnis wider, das indessen auf beiden Seiten stark ausgeprägt war:

Fears as to dark forces at work on the >other side< led to even firmer commitment to one's own. [...] Jews were seen by one side to be subverting traditional French values, and, more specifically, to be attacking the Army and the Church; Jesuits and priests, allied with the military, were seen by the other to be subverting the Republic and democratic principles $^{36}$.

Die in Ibels' Karikatur vorgedachte Fähigkeit zur Distanz und Kritikfähigkeit bringt in einem zweiten Schritt schließlich den entschiedenen Willen zur Veränderung und Erneuerung hervor, der gleichzeitig die bedrohlichste Begleiterscheinung der Massenkultur darstellte. Das Bild der sich scheinbar aus dem Nichts aufbauenden Menschenansammlung, die als künstliches, vergängliches Gebilde nirgendwohin gehört und keine Geschichte hat, stand im Gegensatz zu einer durch starre Zugehörigkeiten geprägten konservativen Gesellschaftsordnung. Diese Dynamik verband sich im antisemitischen Konstrukt der Dreyfusgegner mit dem Thema des wandernden sewigen Juden< und der Auflösung des tradierten Wertesystems innerhalb der kapitalistischen Großstadt $^{37}$. Tatsächlich scheinen die Akzeptanz oder Ablehnung der Moderne und der urbanen Massengesellschaft ein Schlüsselfaktor bei der Entscheidung für das Lager der dreyfusards bzw. der antidreyfusards gewesen zu sein ${ }^{38}$.

Für den metaphorischen Rahmen der Dreyfusaffäre erwachsen daraus zwei Folgen: Zum einen das Bewußtsein einer grundlegenden Veränderlichkeit der Verhältnisse durch und für die Masse, und zum anderen die Suche nach neuen Vorbildern, die als idealisierte Modellcharaktere aus der Masse hervorragen

${ }^{36}$ Griffiths, Use, S.9f. Dabei erlebten bei den Antisemiten traditionelle Schreckensbilder einer als okkultistisch verteufelten jüdischen Antikultur eine Renaissance. Vgl. dazu Willa Z. Silverman, Antisemitism and Okkultism in Fin-de-Siècle France: Three >Initiates«, in: Barbara T. Cooper, Mary Donaldson-Evans (Hg.), Modernity and Revolution in Late Nineteenth-Century France, Newark 1992, S. 155-163.

${ }^{37}$ Stephen WILson, Ideology and Experience. Antisemitism in France at the Time of the Dreyfus Affair, London, Toronto 1982, S. 297: "The Jew symbolized the wicked city and urban capitalism, against which were set simple and stable rural values; but, beyond opposing urbanization, antisemites seem also to have objected to the mobility of populations as such, to the uncontrolled and free movement of people across, but also within national boundaries«. Diese Gleichsetzung war übrigens auch der Grund für die antisemitisch durchsetzte Abneigung vieler Anarchisten gegenüber Alfred Dreyfus. Für das anarchistische Ideal des befreiten Individuums stellte die moderne Großstadt den negativen Gegenpol dar, was auch im fast ländlichen Milieu des Montmartre seinen Widerhall fand. Aufschlußreich ist jedoch die Besetzung des (zum Licht) Wandernden in der anarchistischen Bildpublizistik, der hierbei als positives Gegenstück zum entwurzelten, in der Dunkelheit irrenden Armen die Freiheit der Idee verkörpert. Vgl. dazu Kap. 9.1. und 9.3.

38 Christophe Prochasson, Paris 1900. Essai d'histoire culturelle, Paris 1999, S.276. Zu der zu dieser Zeit zerfallenden Impressionistenbewegung und der Haltung der Künstler zur Großstadt vgl. Philip NORD, The New Painting and the Dreyfus Affair, in: Historical Reflections/Réflexions historiques 24 (1998), S. 115-136. 
und gleichzeitig als mit ihr solidarisch empfunden werden. In jedem Fall wird das Subjekt - sei es die Masse oder der verklärte Held - zum Fürsprecher und Verteidiger des Lichts ${ }^{39}$. Wenn auf Ibels' Karikatur für Le Sifflet das abwägende Volk - populo - im Gegensatz zu der gebannten Menge als Einzelperson typisiert wird, so äußert sich darin entschiedene Kritik an der Gleichsetzung von Volk und (schweigender) Mehrheit. Aufgrund seiner Distanz sowohl in räumlicher als auch in geistiger Hinsicht erscheint der Vertreter des Volkes optisch dennoch größer und gewichtiger als die im Gebet versunkene Menge. Dieses innerlich freie Volk stellt demnach ein neues Phänomen der Masse dar, die sich scharf von der anderen, bedrohlichen Masse absetzt. Diese findet sich sowohl im Bild des unübersichtlichen Menschenauflaufs, den Félix Vallotton 1893 in seinem Blatt La Manifestation ${ }^{40}$ als konturenlose, unheilvoll schwarze Zusammenballung von Energie darstellt, die sich unkontrolliert zu entladen droht, oder in Steinlens für La Feuille ${ }^{41}$ entworfener Schreckensvision des aggressiven Mob, der ein einzelnes, anders denkendes Opfer gnadenlos niedertrampelt (Abb.65).

Die andere, oft heroische Masse zeichnet sich dagegen durch ein ihr innewohnendes Prinzip der Ordnung aus, das den auf ein bestimmtes Ziel gerichteten, gemeinsamen Willen zum Ausdruck bringt ${ }^{42}$. Exemplarisch für diese gleichzeitige Entwicklung steht das Album Hommage des artistes à Picquart ${ }^{43}$, zu dem namhafte Künstler verschiedener Nationalitäten ihren Beitrag lieferten. Hauptmann Georges Picquart (1854-1914) war zunächst von Dreyfus' Schuld zutiefst überzeugt. Als Nachfolger der Abteilung von Colonel Sandherr, der die Untersuchungen im Fall Dreyfus geleitet hatte, stieß er 1896 auf das später als petit bleu berühmt gewordene Dokument, dessen Handschrift den Verbannten entlastete und Esterhazy als den wahren Schuldigen entlarvte.

39 Insofern darf der Heldenkult besonders um Hauptmann Georges Picquart nicht nur als Gegentrend zu allen negativen Eigenschaften der Masse gesehen werden. Vgl. dazu FoRTH, Intellectuals, S. 89: $»$ The heroism of Picquart and others was partly predicated on their distance from the masses«. Als absoluter Repräsentant der das Licht fordernden Masse ist er gleichzeitig Teil davon.

40 Veröffentlicht im ersten Album von L'Estampe originale, Januar-März 1893. Abgebildet bei Shikes, Heller, The Art of Satire, S. 50. Vallottons Erfassung der bedrohlichen Massenenergie ist um so interessanter, als er selbst dem Anarchismus nahestand. Vgl. CATE, The Paris Cry, S.78. Seine Konzentration auf die äußeren Umstände verdeutlicht, da $B$ auch ihn in erster Linie die Masse als Phänomen interessierte, die - egal ob als positiv oder negativ eingestuft - als Teil der Realität akzeptiert werden mußte und somit darstellungswürdig war. Vgl. dazu Félix VAlLotron, Gravures sur bois, S.44.

${ }^{41}$ Steinlen: Arguments frappants, in: La Feuille, 21.1.1898. Vgl. dazu Ditrmar, Steinlen, S. $102 f$.

42 Auch Le Bon spricht in der Psychologie des foules die Möglichkeit an, daß die Masse zu einer moralischen Größe gelangen könne, die weit über dem Durchschnitt ihrer einzelnen Glieder liege (ibid., S.40). In der Bildpublizistik bildet sich hierbei deutlich das Bild des geordneten Demonstrationszuges heraus. Vgl. dazu Kap. 8.3.

${ }^{43}$ Hommage des artistes à Picquart. Album de douze lithographies. Préface d'Octave Mirbeau. Liste des protestaires, Paris 1899. 

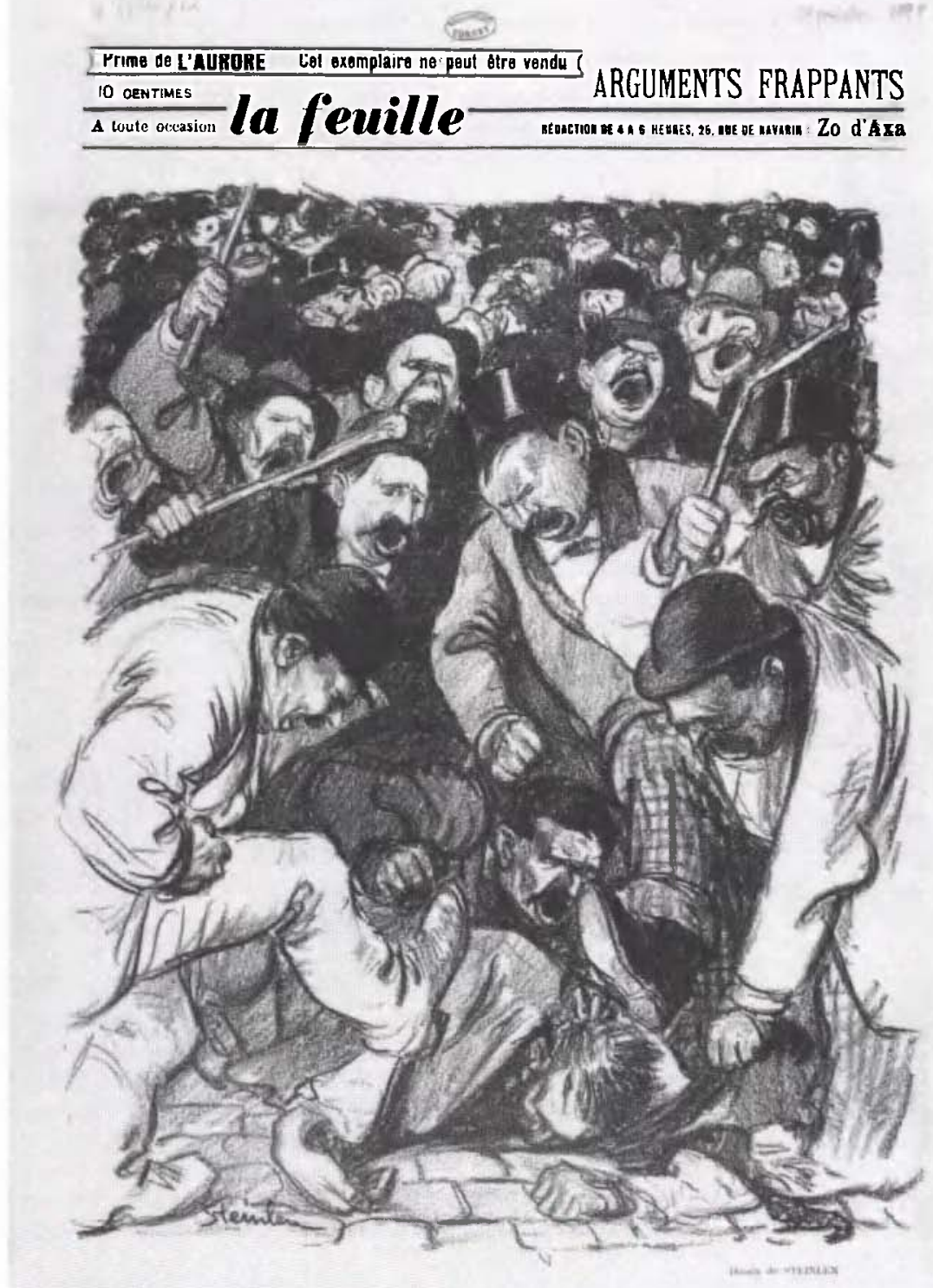

Abb. 65 Theophile Alexandre Steinlen: Arguments frappants, in: La Feuille, 21. 1.1898. Bibl. Forney, Paris. 
Das von diesem Zeitpunkt an vehemente Engagement Picquarts für die Rehabilitierung von Alfred Dreyfus brachte ihn im Januar 1899 vor das Militärgericht und bis Juni 1899 ins Gefängnis, was ihm die Aura eines Helden im Dienste der Wahrheit verlieh ${ }^{44}$. Vor diesem Hintergrund entstand im selben Jahr eine Reihe von Künstlergraphiken, die als Mappe unter dem Titel Hommage des artistes à Picquart in limitierter Aufgabe angeboten wurde.

Louis Armand Rault stellt auf einem unbetitelten Blatt einen Fackelzug zu Ehren des inhaftierten Picquart dar ${ }^{45}$. Vertreter verschiedener Schichten, Arbeiter und Bürgerliche, mitten unter ihnen der Schriftsteller Émile Zola, tragen das Licht der Wahrheit symbolisch in die Dunkelheit hinein. Diese Versammlung reflektiert im besten Sinne die Art der Masse, welche die dreyfusards zur Unterscheidung von der negativ besetzten foule als peuple charakterisierten ${ }^{46}$. Ganz anders auf Steinlens Blatt Les Moutons de Boisdeffre, das am 28. Februar 1898 in La Feuille erschien ${ }^{47}$. Die darauf abgebildete, dem Generalstabschef Boisdeffre zujubelnde Menge von Dreyfusgegnern verkörpert die blinde Raserei der Masse und bietet zugleich eine neue Sichtweise der bedrohlichen foule, unter der sich auch ein Priester findet. Der lediglich ganz am Ende der Straße aufstrahlende Lichtschein verdeutlicht die unüberbrückbare Entfernung der allein auf ihren $\mathrm{Haß}$ fixierten Menge vom Licht. Im Gegensatz dazu symbolisiert das positive peuple in Raults Fackelzug den unkorrumpierbaren Geist der lumières und schließlich das intakt gebliebene Frankreich, was auch Jaurès in den Preuves mit der entsprechenden Metapher der Leuchtfackel hervorhebt: »Oui, quelle institution qui reste debout? Il n'en est plus qu'une: c'est la France elle-même. Un moment, elle a été surprise, mais elle se ressaisit, et, même si tous les flambeaux officiels s'éteignent, son clair bon sens peut dissiper la nuit $\ll^{48}$. Die einzelnen Elemente dieses Volkes und dieses Frankreich müssen folglich in sich selbst lichterfüllt und gut sein. Der Sieg des Lichts ist somit auch der Sieg Frankreichs: »Et par la seule force de la lumière, nous vaincrons. Et notre France généreuse, faisant face une fois de

44 Christophe Prochasson, Le colonel Georges Picquart, in: Drouin (Hg.), L'affaire Dreyfus de A à Z, S.261-265. Grundlage für den Picquart-Kult war die Schrift von F. DE Pressensé, Un héros. Le lieutenant-colonel Picquart, Paris 1898. Noch nach seinem Tod im Januar 1914 setzt Hermann-Paul ihm als Helden ein Denkmal: Das Blatt $\dot{A}$ la gloire de Picquart - in memoriam! zeigt zwei Arbeiter, die gerade das Grab mit einer Platte bedeckt haben. Der Grabstein zeigt den lichtstrahlenden Spiegel der Wahrheit, als Symbol seines unvergänglichen Ruhms. Der Untertitel erhebt ihn in den Rang eines gleichsam unsterblichen Helden: »Maintenant encore, si on avait besoin de lui il se lèverait! (Gil Blas, 24.1.1914).

${ }^{45}$ Blatt 9 des Albums, abgebildet bei Kleeblatt, The Dreyfus Affair, S.220, Abb. 121.

46 Vgl. ForTh, Intellectuals, S. 71.

47 Abgebildet bei Ditrmar, Steinlen, S.102. Ibid.: Die treffende Bezeichnung moutons für die negativ konnotierte Menge beruht auf einem Wortspiel mit dem vollständigen Namen des Generalstabschefs: Raoul François Charles le Mouton de Boisdeffre. Dittmar geht allerdings nicht auf die Rolle des Lichts ein, das jedoch eine tragende Rolle spielt.

48 Jean JAURÈs, Préface, in: Les Preuves, S. VI. 
plus aux puissances de réaction et de ténèbres, aura bien mérité du genre humain $\ll^{49}$.

Nicht zuletzt die sich als moralisches Gewissen profilierenden Intellektuellen, deren Ursprung als aktive Kritiker der politischen Verhältnisse zu dieser Zeit angesetzt wird, stehen für dieses ideale Frankreich ${ }^{50}$. Erst der gemeinsame, klassenübergreifende Kampf aber garantiert nicht nur das Licht der Wahrheit, sondern auch die Sonne der Freiheit selbst, wie ein anderes Blatt des Albums verdeutlicht. Der Maler Maximilien Luce zeigt den inhaftierten Picquart in Gegenwart eines Arbeiters, der ihm zuredet, dem verlorenen militärischen Status nicht nachzutrauern und ihm eine Spitzhacke reicht: »Ne regrette pas cette épée inutile, prends cette pioche! \} ^ { 5 1 }

Mit der anderen Hand verweist der Mann auf die hinter der zu zerstörenden Mauer der Lügen aufgehende Sonne, in deren Lichtschein das Wort $\mathbf{L i}$ berté eingeschrieben steht. Die Verbindung des Proletariers mit der Sonne am Horizont ist eine unmißverständliche Übertragung der Brisanz der Affäre in die soziale Problematik hinein. Gerade das Motiv des démolisseur steht für eine Veränderung der Verhältnisse durch die Zerstörung ihrer Strukturen ${ }^{52}$.

Die Befreiung Picquarts wurde ebenso wie die von Dreyfus zur Triebfeder der Sehnsucht nach einem tiefgreifenden gesellschaftlichen Wandel, der alle Schichten erfaßte. Schon die Übertragung dieses Bewußtseins von unten nach oben trug das revolutionäre Potential in sich. Der Arbeiter war nicht mehr nur Empfänger eines Lichts, das ihm von oben in Form der instruction republikanischer Werte zuerkannt wird, sondern er kämpfte selbst aktiv dafür und damit auch für eine Ausweitung des klassischen Begriffs der lumières. Darüber hinaus verdeutlicht der Gegensatz zwischen dem (noch) untätig dasitzenden Picquart und dem zum Befreiungsschlag bereiten Arbeiter einen grundlegenden Unterschied in der Konfliktsituation mit der Republik. Während der Offizier trotz allem bereit ist, sich unterzuordnen und darauf zu warten, daß ihm Gerechtigkeit widerfährt, will sein Gegenpart diese Institutionen außer Kraft setzen. Zweifellos kommt es durch die Doppelung des Gefangenenmotivs zu einer problematischen Vermischung des Lichts der (ideellen) Wahrheit mit der Sonne der Arbeiterbewegung, die für eine sichtbare Verbesserung der äußeren Lebensverhältnisse steht. ${ }^{53}$ Die Reaktion des Inhaftierten bleibt dabei unklar. Der Offizier, dem in Wahrheit revolutionäre Überzeugungen ebenso fern standen wie Dreyfus, wird gleichwohl durch sein mutiges Handeln zum Hoffnungsträger einer Erleuchtung der Gesellschaft von innen heraus. Dieser Aspekt kommt auf einem weiteren Blatt zum Ausdruck, das Gumery für die Hom-

49 Ibid., S. XV.

50 Vgl. dazu Christophe Charle, Naissance des intellectuels, 1880-1900, Paris 1990.

51 Blatt 5 des Albums Hommage des artistes à Picquart, Paris 1899. Abgebildet bei KLEeBLATr, The Dreyfus Affair, S.218, Abb.117.

52 Dieses Motiv wird auch bei der Suche nach der im Brunnen steckenden Wahrheit bedeutsam. Vgl. Kap. 8.2.1.

53 Vgl. dazu Kap.9.3. 
mage schuf: Eine über dem Hauptmann schwebende, die Fackel der Wahrheit tragende Allegorie krönt den an den Händen gefesselten Helden mit dem Siegeskranz. Um die beiden Hauptfiguren herum gruppiert sich eine große Menge größtenteils ausgemergelter, halb nackter Menschen, die dem Licht verheiBenden Zentrum zustreben oder ihre Hände sehnsüchtig danach ausstrecken. Eine (noch) schlafende Gestalt im Vordergrund verdeutlicht die Symbolkraft der von Picquart geleisteten Wachrüttelung der Öffentlichkeit, was auch in der Widmung zum Ausdruck kommt: »À Picquart, éveilleur d'âmes « ${ }^{54}$.

Nicht zu leugnen ist jedoch auch hier die sofortige Übertragung auf die soziale Situation, die die realen Zusammenhänge weit hinter sich läßt. Der glorifizierte Picquart wird zum veritablen Gegenstand der Anbetung stilisiert. Die Erlösungsbedürftigkeit von Dreyfus, die als Spiegel der sozialen Problematik diente, findet ihre Erwiderung in der hier propagierten Erlösungsfähigkeit. So wie Picquart erst sich selbst von der Lüge befreit und dann zum $>$ Erwecker $<$ der anderen wird, ist auch allgemein nur das Individuum, das sich selbst befreit hat, in der Lage, für die Freiheit aller zu kämpfen. Im Gegensatz zu Luce stellt Gumery jedoch klar die Bedeutung der inneren, der geistigen Freiheit heraus. Picquarts gefesselte Hände machen deutlich, daß er gerade als zu Unrecht Verurteilter den Mut zur geistigen Freiheit bewiesen hat, der bis in die Seelen der anderen vordringt. Die Konsequenz dieser Erweckung bleibt hier unklar. Der nächste Schritt könnte durchaus der Aufruf der Erwachten zum Unsturz sein, wie es Luce in seiner Darstellung andeutet. Im Vordergrund steht aber die Rolle Picquarts als Hoffnungsträger, der für die Umstehenden die Garantie für Wahrheit, Licht und Gerechtigkeit zu verkörpern scheint. Das von Jaurès propagierte, intakt gebliebene Frankreich wird hier in Frage gestellt. Das Erbe von lumières und Menschenrechten scheint nicht mehr garantiert zu sein.

Dieselbe Sorge bringt Émile Zola in seiner déclaration au jury vom 21. Februar 1898 vor:

Il n'y a plus d'affaire Dreyfus, il s'agit désormais de savoir si la France est encore la France des droits de l'homme, celle qui a donné la liberté au monde et qui devait lui donner la justice. Sommes-nous encore le peuple le plus noble, le plus fraternel, le plus généreux? Allons-nous garder en Europe notre renom d'équité et d'humanité? [...] Ouvrez les yeux et comprenez que, pour être dans un tel désarroi, l'âme française doit être remuée jusque dans ses intimes profondeurs, en face d'un péril redoutable. Un peuple n'est point bouleversé de la sorte sans que sa vie morale elle-même soit en danger ${ }^{55}$.

Diese kollektive seelische Krise eines Landes, seines Volkes und seines Selbstverständnisses kann nur durch das Licht der Wahrheit überwunden werden, auf den Weg gebracht von verantwortungsbewußten Bürgern:

54 Blatt 3 des Albums Hommage des artistes à Picquart, Paris 1899. Abgebildet bei KLEEBLATT, The Dreyfus Affair, S.217, Abb.115.

55 Abgedruckt in L'Aurore, 22.2.1898. Vgl. Émile ZoLA: L'affaire Dreyfus. La Vérité en marche. Chronologie et préface par Colette Becker, Paris 1969, S. 132. 
L'heure est d'une gravité exceptionnelle, il s'agit du salut de la nation. Et, quand vous aurez compris cela, messieurs, vous sentirez qu'il n'est qu'un seul remède possible: dire la vérité, rendre la justice. Tout ce qui retardera la lumière, tout ce qui ajoutera des ténèbres aux ténèbres, ne fera que prolonger et aggraver la crise. Le rôle des bons citoyens, de ceux qui sentent l'impérieux besoin d'en finir, est d'exiger le grand jour ${ }^{56}$.

Die bon citoyens sind also durchaus Teil der großen, verunsicherten Masse. Darstellungen wie die von Gumery, in denen die Katalysatorwirkung der Affäre in all ihren Verstrickungen ersichtlich ist, machen gleichzeitig den Entwicklungsprozeß 3 der Masse und ihrer Rolle in der republikanischen $\mathrm{Ge}$ sellschaft deutlich: Der Protest gegen tiefliegende Unrechtsstrukturen - die Verurteilung von Dreyfus und Picquart ebenso wie soziales Elend - ist die Suche nach dem Licht schlechthin. Die aus dem Dunkel herausstrebende Masse verschmilzt, von den gefürchteten antisemitischen Horden deutlich abgesetzt, so mit dem peuple und den bon citoyens.

Die foule, bis dato untrennbar verbunden mit einer entfesselten, unkontrollierbaren Horde, wird so zur klassenübergreifenden Massengesellschaft, was zu einer allmählichen Neutralisierung des Phänomens der Masse führt ${ }^{57}$. Die Sehnsucht der Masse nach dem Licht schloß letztlich ebenso die Vordenker und Intellektuellen ein wie die um ihre Existenz kämpfenden Schich$\operatorname{ten}^{58}$.

Die Suche nach der einen, alle Klassen verbindenden Wahrheit verdeutlicht nichtsdestoweniger auch ein tiefliegendes Bedürfnis nach einem gemeinsamen Wertesystem, das innerhalb der in die verschiedensten Theorien, Bewegungen und Interessen zerfallenden Massenkultur immer schwerer zu finden war. Die Faszination, die von der reinen, nackten Wahrheit ausging, liegt in ihrer Entbindung von allen Interessen. Sie verkörperte zugleich die letzte allumfassende Lichtmetaphorik, während die Kluft zwischen der Symbolik natürlicher und künstlicher Lichtquellen immer größer wurde. Aus diesem Grund repräsentiert die abstrakte Lichtmetaphorik der selbst lichtstrahlenden, mit ihrem Spiegel das Licht zusätzlich reflektierenden Allegorie der Wahrheit sowohl das ideelle als auch das soziale Lichtbedürfnis; sie ist das alle Hoffnung in sich vereinende, absolute Lichtzentrum. "La lumière, toute la lumière, je n'ai eu que ce passionné désir «99 - so Émile Zolas eindringlicher Appell in seiner Verteidigungsrede.

Wie dieses reine Licht stellt der spanische Künstler Joaquín Sunyer in der Hommage des artistes à Picquart die Wahrheit dar ${ }^{60}$ : Als Lichtsäule mit nur noch zu erahnender anthropomorpher Gestalt ragt sie aus der Menge hervor,

\footnotetext{
56 Ibid.

57 ForTh, Intellectuals, S. 91.

${ }^{58}$ Prochasson, L'Affaire, S. 248: "Autant qu'une crise politique ou qu'une occasion de révolution sociale, l'affaire Dreyfus fut un événement intellectuel«.

59 Zola, La Vérité en marche, S. 128.

${ }^{60}$ La Vérité, Blatt 11 des Albums Hommage des artistes à Picquart. Abgebildet bei KleEbl.ATt, The Dreyfus Affair, S.220, Abb. 123.
} 
die ihr entgegenströmt wie der rettenden Erlösung. Wie bereits angemerkt, kann das Ideal der aus sich selbst heraus ans Licht findenden, mit dem Licht verschmelzenden Wahrheit vor der Realität nicht bestehen. Die Beziehung sowohl der Masse als auch des geforderten Individuums zu der angegriffenen, verschmähten, geschändeten oder sogar ermordeten Wahrheit steht somit nicht zufällig im Mittelpunkt der bildlichen Aufarbeitung der Affäre. Die Rolle des Gefangenen und seiner Befreiung, übertragen auf das geopferte Individuum und zurückgespielt an die sich neu definierende Masse, findet sich auch in diesem Kontext wieder. 


\title{
8.2. »La Vérité quand même!«Verständnis und Rezeption der Wahrheit im Spiegel der Affäre
}

\author{
8.2.1. "Finira-t-on par la faire sortir?" \\ Der mühsame Weg der Wahrheit zum Licht
}

Das Schicksal von Alfred Dreyfus entwickelte sich unaufhaltsam zu einem politischen und moralischen Präzedenzfall, an dem sich eine ganze Gesellschaft messen lassen mußte.

Im Widerstreit der konvergierenden Meinungen um die eine, alles erklärende Wahrheit war die aus dem Brunnen steigende Nuda Veritas mit dem Spiegel nicht nur die adäquate traditionelle Allegorie, sondern zugleich das Symbol für eine schutzbedürftige, schwache Wahrheit, die um ihre Fürsprecher bangen muß und in ständiger Gefahr schwebt. Die Lichtsymbolik selbst ist dabei ebenfalls ein zweischneidiges Schwert: Für die Trägerin des Lichts der Wahrheit ist nicht einmal sicher, ob sie selbst je ans Licht gelangen wird. Ihr Spiegel reflektiert zudem nur das Tageslicht, das man der Wahrheit vorenthalten will. Ihre Aufgabe ist es also, das ohnehin vorhandene Licht zu verstärken und es weithin sichtbar zu machen.

Die gleichsam mythische Überhöhung und überirdische Entrückung der Wahrheit, die ihre Unangreifbarkeit unterstreichen sollte, dienten in der Karikatur der III. Republik schon früh der Bekräftigung unverrückbarer Grundsätze. 1873 zeigt das antiroyalistische und antibonapartistische Satiremagazin Le Sifflet ${ }^{61}$ die Darstellung La Vérité, deren Vorbild das im Salon von 1870 ausgestellte, zu Berühmtheit gelangte Gemälde von Lefebvre war. Der Karikaturist Meyer fügt der Vérité zwei vor ihrem Licht fliehende Gestalten hinzu, was kurz nach der Etablierung von Mac-Mahons Regierung des ordre moral als eindeutige Anspielung auf die Leuchtkraft der (republikanischen) Wahrheit kaum mißverstanden werden konnte (Abb.66) ${ }^{62}$. Eine noch wesentlich dramatischere Wirkung entfaltet die Wahrheit auf einer Karikatur, die Blass 1886 für das royalistische Blatt Le Triboulet schuf: Die nackte Wahrheit kündigt vor dem lichtdurchfluteten Himmel in ihrem Spiegel die bevorstehende Monarchie an: "1886 - Philippe VII «. Währenddessen ergreifen Präsident Grévy und Jules Ferry vor den herabstürzenden Trümmern ihrer gescheiterten Regierung die Flucht ${ }^{63}$. Die unerschütterliche Wahrheit wird darin zur Verkünderin einer (göttlichen) Verheißung.

${ }^{61}$ Erschien 1872-1873. Nicht zu verwechseln mit dem gleichnamigen dreyfusard-Magazin (1898-1899).

${ }^{62}$ H. Meyer, La Vérité, d'après le tableau de Lefebvre, in: Le Sifflet, 6.7.1873. Vgl. dazu Chabanne, Salons, S. 18. Auch die 1880 entstandene Karikatur La Liberté von Émile Cohl (Abb.45) geht auf dieses Gemälde zurück. Vgl. Kap.7.1.2.

63 J. BLASs, Fiat lux, in: Le Triboulet, 10.1.1886. Die herabstürzenden Gesteinsbrocken tragen Aufschriften wie pillage, vol, laïcisation, mensonges u. a. Zum designierten Philippe VII., Comte de Paris, vgl. Kap. 7.2., Anm.113. 


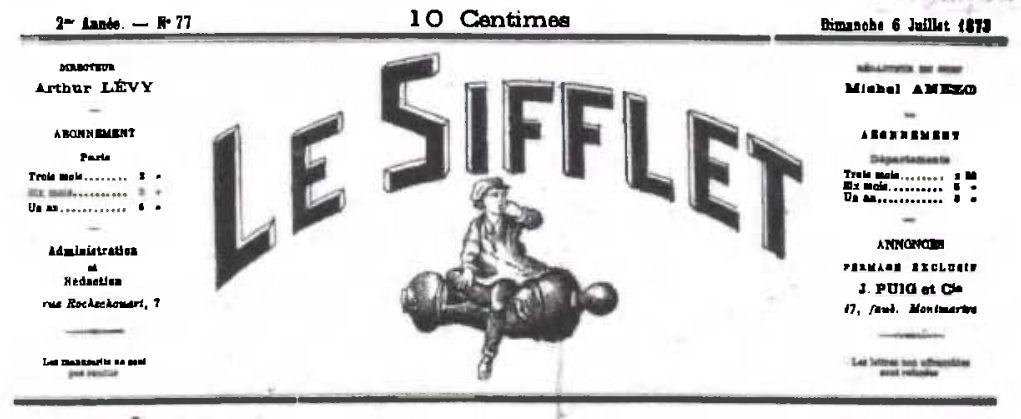

LA VHRIT'3. d'aprés le tablean de LEFEBVRE, par H. MEYER

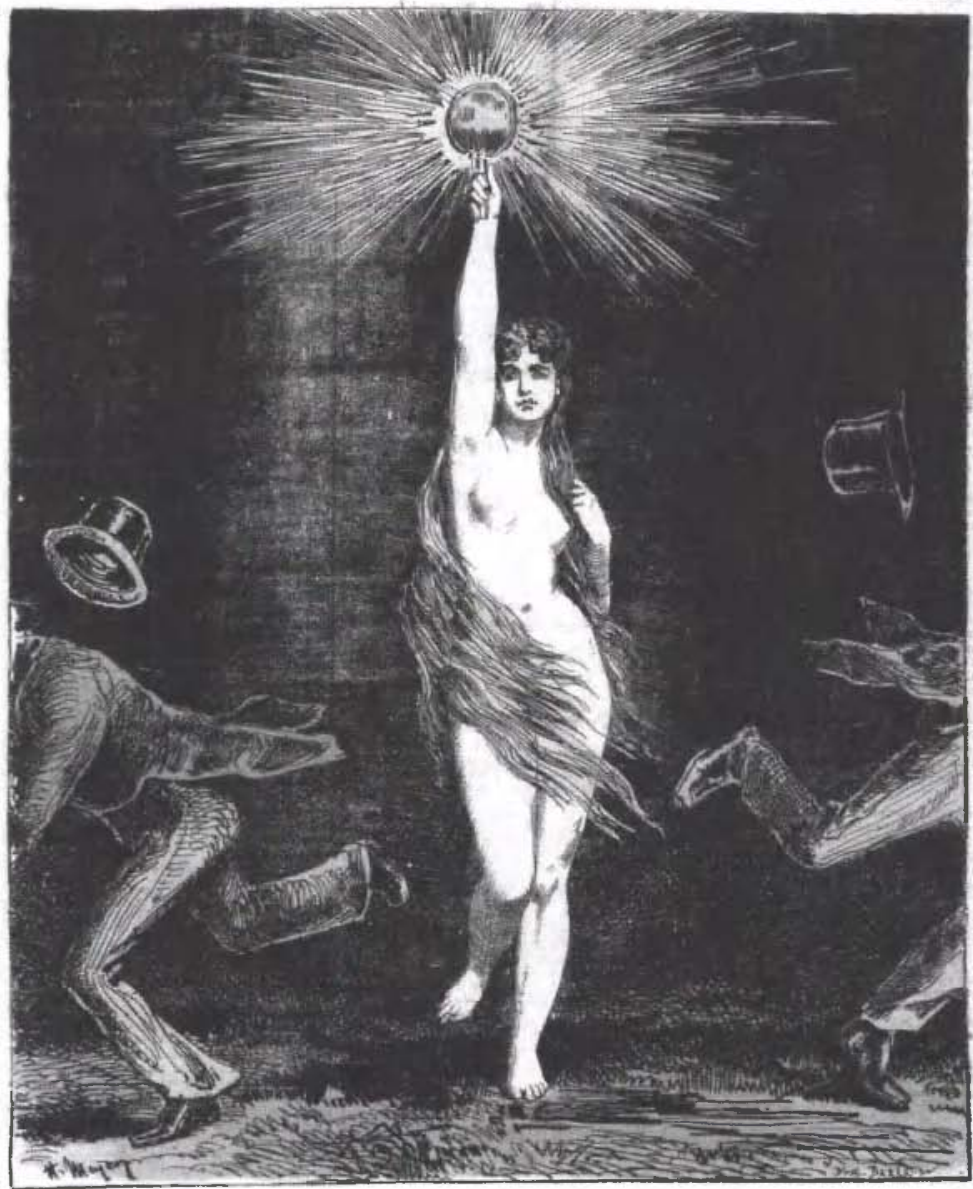

Abb. 66 Henri Meyer: La Verite, d'apres le tableau de Lefebvre, in: Le Sifflet, 6.7.1873. $B n F$. 
Parallel entwickelte sich jedoch das Motiv einer angesichts der Lüge ratlosen oder resignierenden Wahrheit, wodurch die Allegorie selbst karikiert wird. 1885 befaßte sich eine Karikatur von Stop mit dem heiklen Thema Wahrheit und Wahlkampf. Angesichts einer mit Wahlplakaten gepflasterten Mauer zieht die nackte Wahrheit es vor, kopfüber in ihren Brunnen zu springen: »La Vérité rentrant dans son puits pendant la période électorale «64. Die schwierige Vereinbarkeit der Idee einer absoluten Wahrheit in einer von unterschiedlichen Meinungen geprägten Republik wird hier mehr als deutlich. Ihr Licht scheint hinter eigennützigen Interessen und falschen Tatsachen verborgen und ist deshalb nicht mehr ohne weiteres wahrnehmbar. Dieser Konflikt spiegelt sich in den zahlreichen Wahrheitsdarstellungen der Jahre 1897 bis 1899 wider. Der Wille zur Erkenntnis drückt sich in der beharrlichen Suche auf dem Brunnengrund ebenso wie in der enormen Kraftanstrengung aus, die Wahrheit ans Licht zu befördern. Das vermutlich berühmteste Beispiel stellt hierbei Pépins Karikatur La Vérité dar, die am 19. Dezember 1897 in Le Grelot erschien ${ }^{65}$. Auguste Scheurer-Kestner, damals Vizepräsident des Senats, und der Schriftsteller Émile Zola ziehen die Wahrheit gemeinsam nach oben. Auf dem Namensschild findet sich auch die Zeitung Le Figaro, in der Scheurer-Kestner am 16. November 1897 Esterhazy als den wahren Schuldigen angeklagt hatte ${ }^{66}$. Zum Zeitpunkt der Veröffentlichung des Blattes hatte die Redaktion des Figaro sich von den Verteidigern des Hauptmanns Dreyfus jedoch bereits distanziert. Zola, der Anfang November 1897 durch Kontakte zu Bernard Lazare vom interessierten Beobachter der Affäre zum überzeugten dreyfusard geworden war, hatte in Le Figaro Anfang Dezember zwei Artikel publiziert, die den Ablauf der Affäre und ihre Mechanismen darlegten. Schon zuvor, am 25. November, formulierte Zola in einem Artikel über Scheurer-Kestner seine Maxime, die vermutlich das direkte Vorbild für Pépins Karikatur war: "La Vérité est en marche, et rien ne l'arrêtera plus « ${ }^{67}$. Diese Wahrheit aber mußte sich sogleich der harten Realität stellen: Die ablehnenden Reaktionen des konservativen Publikums von Le Figaro führten zum Bruch mit Zola, der sich daraufhin der erst kurz

${ }^{64}$ Le Charivari, 18.9.1885 (Serie Actualités).

65 Dazu allg. Fischer, Wer löscht das Licht, bes. S. 208f., Abb. S. 209. Abgebildet auch bei LETHÈve, La caricature sous la III ${ }^{\mathrm{e}}$ République, S.64. Schon am 21.8.1898 greift das Titelbild Confédérés en embuscade der in Lyon erscheinenden satirischen Wochenzeitschrift La Comédie politique ebenfalls auf das Motiv der Wahrheit zurück, die in dem Moment, da sie den Brunnen verläßt, das Opfer der Liga ihrer Feinde zu werden droht, in der sich Militär, Justiz und Klerus zusammenfinden. In der Ausgabe vom 13.11.1898 aber gewinnt die Wahrheit diesen Kampf, indem sie aus dem Brunnen steigt und ihre Feinde dabei zertritt, um sie auf denselben »Haufen«, wie der Titel präzisiert, zu werfen: "Au même tas, les 5 !... ou la revanche de la Vérité «.

66 André Roumieux, Auguste Scheurer-Kestner, in: Drouin (Hg.), L'affaire Dreyfus de A à Z, S. 280.

67 Émile Zola, M. Scheurer-Kestner, in: Le Figaro, 25.11.1897. 
zuvor gegründeten L'Aurore zuwendete ${ }^{68}$. Neben dem Brunnen steht der führende antisemitische Propagandist Edouart Drumont schon mit dem Löschhut seiner Zeitung La Libre Parole bereit, um den lichtstrahlenden Spiegel der Wahrheit den Blicken zu entziehen ${ }^{69}$. Der im Vordergrund stehende, durch ein Fernrohr blickende Vertreter der justice militaire sieht aber ohnehin nur schwarz, da Henri Rochefort, Chefredakteur des Intransigeant, die Linse abdeckt ${ }^{70}$. Damit wird auf den offenen Rassismus und Antisemitismus verwiesen, mit dem Rochefort argumentierte ${ }^{71}$. Die Rolle der freien Presse wird hier also durchaus kritisch gesehen: Sie ist nicht mehr nur die erklärte Bewahrerin und Verbreiterin der Wahrheit, sondern in ihren negativen und zweifelhaften Auswüchsen ihre erklärte Feindin, oder aber sie beugt sich der Meinungszensur der Öffentlichkeit, wie im Fall von Le Figaro ${ }^{72}$.

68 Alain Pagès, Émile Zola, in: Drouin (Hg.), L'affaire Dreyfus de A à Z, S.293f.: Zolas Veröffentlichungen in Le Figaro waren Le procès verbal (1.12.1897) und Le syndicat (5.12.1897). Vgl. dazu Boussel, L'affaire Dreyfus, S.144-146.

69 Die Argumentation von Fischer, Wer löscht das Licht, S.212, daß es sich hier nicht um einen Spiegel, sondern um eine Glühbirne handelt, entbehrt jeder Grundlage.

${ }^{70}$ Rocheforts mit Spielkartensymbolen bedecktes Narrenkostüm weist ihn dabei aufgrund seiner rasch wechselnden politischen Überzeugungen als nicht ernst zu nehmenden Aktionisten aus. Vgl. zu Rochefort auch Kap.6.3.

71 Rocheforts Antisemitismus wandte sich dabei nicht nur gegen Dreyfus, sondern in besonderem Maße auch gegen den Journalisten und Abgeordneten Joseph Reinach (1856-1921), den er der Fälschung von Entlastungsmaterial zugunsten von Dreyfus beschuldigte. Reinach verlor aufgrund seines vehementen Engagements für die Revision 1898 seinen Sitz im Parlament. Die Bildpresse der antidreyfusards wendete folgerichtig das Löschhütchenmotiv auf die andere Seite an: Am 27.11. 1898 erschien in La Silhouette Bobbs Karikatur »Leur"vérité!, auf der die Wahrheit von Clemenceau, Jaurès und anderen geschminkt wird, während ihr der als Affe dargestellte Joseph Reinach einen Löschhut überstülpen will. Vgl. dazu Jean Garrigues, Henri Rochefort, in: Drouin (Hg.), L'affaire Dreyfus de A à Z, S.268; zu Reinach vgl. Hutton, Historical Dictionary, Bd.2, S. 838f. Antisemitische Tendenzen prägen besonders die Zeitschrift Psst!... (5.2.189816.9.1898), das dreyfusfeindliche Gegenstück zu Le Sifflet. Am 16.7.1898 zeigt Forains Karikatur mit dem Titel Pour la vérité, wie ein durch dunklen Bart und Hakennase als Jude gekennzeichneter Mann einen Eimer voller Geldstücke in den Brunnen schüttet. Der sich hier manifestierende Mythos vom sjüdischen Kapitak, das sich die Wahrheit kaufen will, stellt eine der zentralen Argumentationsebenen des Antisemitismus im Rahmen der Affäre dar. Die schärfste Interpretation des Motivs der aus dem Brunnen steigenden Wahrheit stellte auf Seiten der antidreyfusards wohl die Zeichnung von Caran d'Ache dar, die Zola zeigt, der aus einer Toilette steigt, mit Dreyfus als Puppe im Arm: „Coucou, le voilà!; La Vérité sort de son puits«, in: Psst ..., Juni 1899 (No 71). Vgl. dazu Bruno de Perthuis, La Vérité sortant du puits, in: Ridiculosa 8 (2001), S.250f.

72 Zur Symbolik der Wahrheit in bezug auf die Pressezensur vgl. Kap.4.1. Fischer, Wer löscht das Licht, S.210f., hebt zwar die in diesem Blatt offenbar werdende Rolle der Presse hervor, erkennt aber nicht das eigentliche Konfliktpotential, zumal er auf die Kehrtwendung von Le Figaro gar nicht zu sprechen kommt. Auch die weitere Entwicklung des Verhältnisses von Édouard Pépin und Le Grelot ist in diesem Zusammenhang aufschlußreich: Noch bis August 1899 lieferte der Karikaturist für dieses Magazin Titelbilder, die sich ganz der Verteidigung von Alfred Dreyfus verschrieben. Darunter auch ein Blatt, auf dem die Figur der Wahrheit mit dem Löschhut bekrönt und zudem besudelt ist, be- 


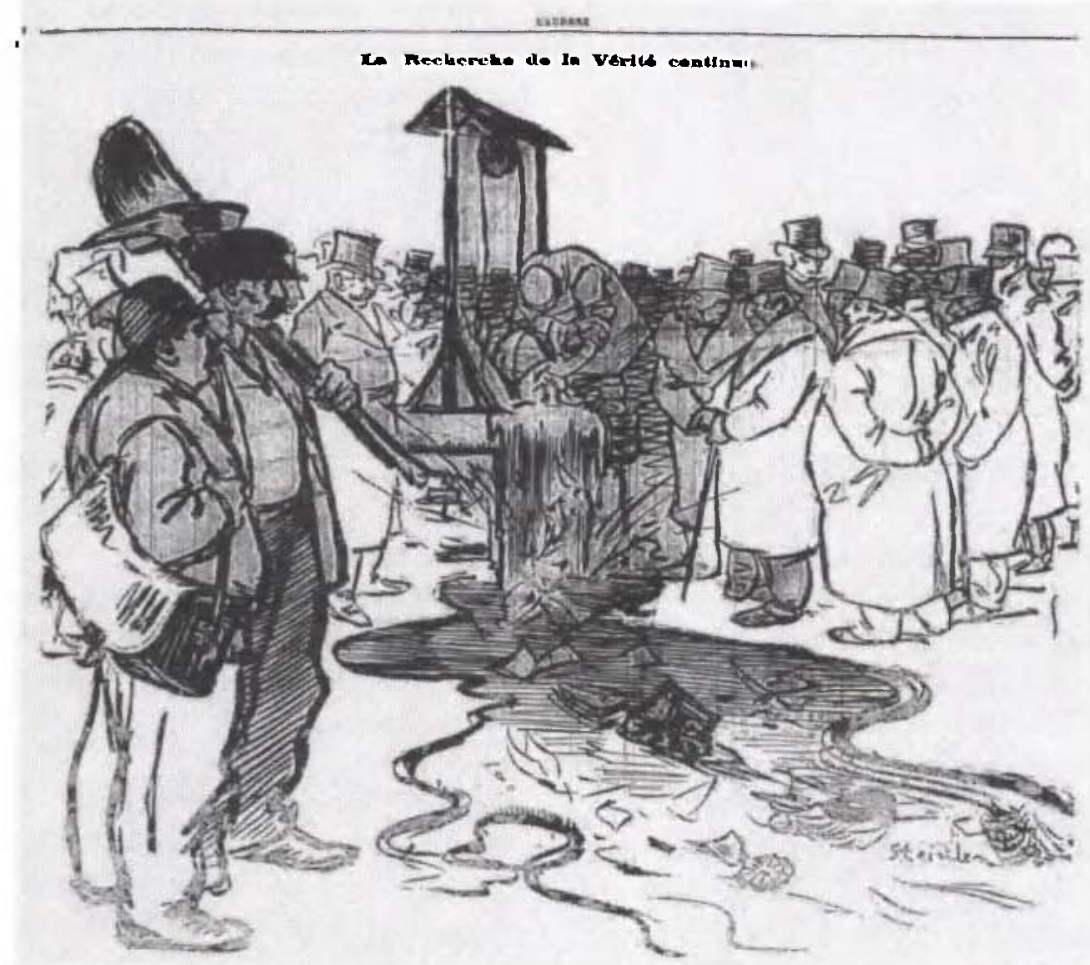

Abb. 67 Theophile Alexandre Steinlen: La recherche de la Verite continue, in: L'Aurore, 29.11.1897. Bibl. Sainte-Genevieve, Paris.

Pepins Karikatur wurde dabei von den Ereignissen überholt und gleichzeitig bestätigt, zeigt letzteres Beispiel doch die fragile Position der Wahrheit am besten, die auch der Bildtext unterstreicht: "Finira-t-on par la faire sortir? «

Die Verteidigung der Wahrheit um ihrer selbst willen, ohne sich bereits im Vorneherein für die eine oder andere Seite entschieden zu haben, stellte in jeder Hinsicht die größte Herausforderung des liberalen Denkens dar. Dies schien auch für die Eliten keine leichte Herausforderung zu sein. Die Suche nach der noch ganz und gar unsichtbaren Wahrheit ist das Thema des Bildes La recherche de la Vérite continue von Steinlen, das bereits einige Wochen vor-

gleitet vom Posaunenchor der antisemitischen und nationalistischen Presse. (Le Couronnement de la Verite, in: Le Grelot, 24.7.1898.) Doch noch in der Ausgabe vom 20.8.1899, deren Titelseite Pepins letzten Beitrag für die Zeitschrift zeigt, findet sich im Innenteil eine Karikatur von Alfred Le Petit mit dem Titel: La Verite en marche! Darauf treiben Clèméncẻau, Zola, Waldeck-Roussẻau, Jaures und andèrè diè nackte Wahrhèit mit Stèinen in ihren Brunnen zurück. Unter dem neuen Titelkarikaturisten Gravelly setzte sich in Le Grelot ein scharfer Anti-Dreyfus-Kurs durch. Pepin gab von 15. 10.1899-27.5.1900 das Satiremagazin Le Fouet heraus, in dem er weiter für die Sache der dreyfusards zeichnete. 
her, am 29. November 1897 , in $L^{\prime}$ Aurore ${ }^{73}$ veröffentlicht wurde und gewissermaßen die Vorstufe zu der von Pépin entworfenen Szenerie bildet (Abb.67). Zeitlich eine unmittelbare Reaktion auf Zolas Ausspruch, stellt das Blatt sich doch als äußerst skeptischer Kommentar dar. Ein Mann mit hochgekrempelten Ärmeln schüttet aus einem Brunnen eimerweise Wasser, das sich bereits als Fluß ergießt. Darin finden sich symbolträchtige Requisiten wie Akten, Orden oder eine Maske als Symbol von Lüge und Verstellung. Beobachtet wird die Wahrheitssuche von einer großen Menge korpulenter Männer in Mantel und Zylinder, die den Brunnen dicht gedrängt umstehen. Während diese Zeugen ihre ganze Aufmerksamkeit allein auf den Brunnen richten, betrachten zwei im Vordergrund stehende Arbeiter die zum Vorschein gekommenen Gegenstände sehr genau. Die (noch) nicht aufgetauchte Allegorie der Wahrheit selbst ist dennoch vorhanden: Sie kann aus den einzelnen Beweisstücken, die Stück für Stück zum Vorschein gekommen sind, rekonstruiert werden - vorausgesetzt, man beachtet diese Hinweise. Der offensichtliche Unwillen der unschwer als Vertreter der Politik zu erkennenden, untätigen Beobachter führt die Suche nach der Wahrheit zwangsläufig ad absurdum. Die Notwendigkeit zu handeln, erschließt sich dem unvoreingenommenen Beobachter dabei ebenso mühelos wie den beiden Proletariern.

Tatsächlich war die Berücksichtigung von stichhaltigem Beweismaterial zu diesem Zeitpunkt das Hauptanliegen von L'Aurore. In derselben Ausgabe der Zeitung schrieb Clemenceau: »L'innocence de Dreyfus n'a pas encore été démontrée. Peut-être ne le sera-t-elle jamais. Mais d'ores et déjà existent contre le commandant Esterhazy des présomptions de culpabilité suffisamment graves pour justifier une incarcération préventive ${ }^{74}$.

Eine dem Bild von Steinlen vergleichbare Ausgangssituation liegt der Darstellung Autour du puits von Georges Redon zugrunde, das am 7. September 1898 in der Tageszeitung Le Petit Bleu erschien (Abb.68). Auch hier haben sich die Vertreter der Politik in dichten Reihen um den Brunnen versammelt und spähen angestrengt hinunter. Ein auf dem Brunnen stehender Vertreter des Volkes ${ }^{75}$ teilt der in einiger Entfernung wartenden Marianne mit der phrygischen Mütze den Stand der Dinge mit: MARIANNE. - Eh bien, quoi! sort-elle? POPULO. - Elle dit qu'elle a les pieds gelés. Wiederum ist die Wahrheit zwar nicht sichtbar, aber dennoch anwesend. Die sie umgebende ,Eiszeit ‘ macht es ihr fast unmöglich ans Licht zu dringen. Das Interesse an den mißlichen Umständen geht klar vom nicht regierenden Volk auf der einen und der in

${ }^{73}$ L'Aurore. Littéraire, artistique, social. Tageszeitung, erschienen ab 17.10.1897. Zu Beginn erschien immer montags eine Karikatur. Dieser Zyklus wurde im Zuge von Zolas Brief $» J ' A c c u s e$ « (13.1.1898) und den damit verbundenen Ereignissen unterbrochen. Ab Februar 1898 tauchten sporadisch wieder Karikaturen auf, um bald darauf ein für allemal aus L'Aurore zu verschwinden.

74 L'affaire Dreyfus-Esterhazy, in: L'Aurore, 29.11.1897, S.1f.

75 Zur Definition des populo bzw. peuple als dem neuen, positiv besetzten Bild der Masse vgl. Kap.8.1. 
AUTOUR DO PUTIS, par GEORGES REDON

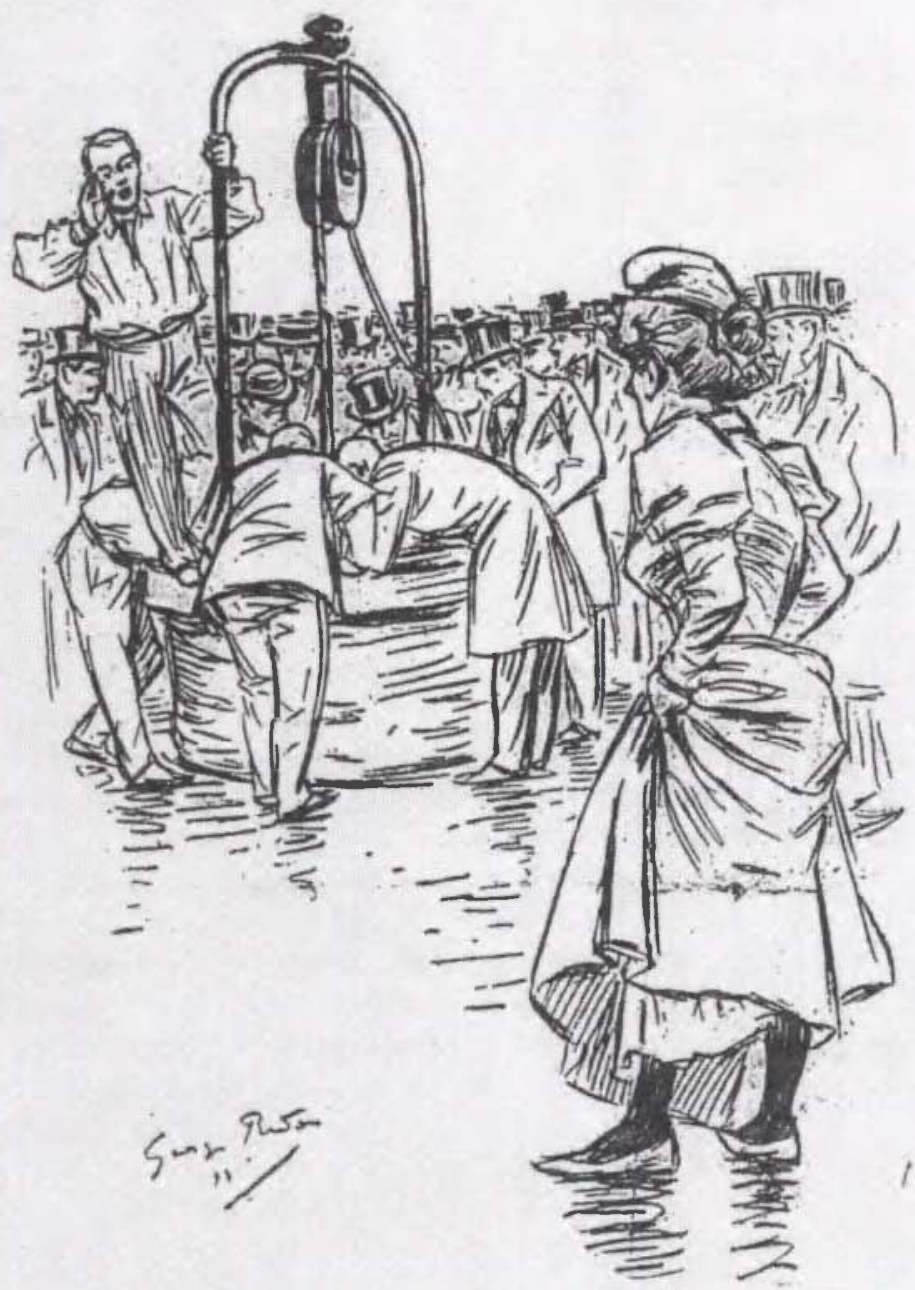

Marianise. - Fh hicn, quoi! sort-elle?

Poptito: - Elle dit qu clle a les pieds geles.

Abb. 68 Georges Redon: Autour du puits. MARIANNE. - Eh bien, quoi! sort-elle? POPULo. - Elle dit qu'elle a les pieds geles, in: Le Petit Bleu de Paris, 7.9.1898. Sammlung D. $K$. 
Marianne verkörperten idealen Republik auf der anderen Seite aus, während die Machthabenden untätig in den Brunnen starren: Sie wissen bereits, daß die Wahrheit nicht ihren Wünschen entspricht, und wollen sie deshalb nicht zu Gesicht bekommen.

Doch auch der Versuch der Wahrheit, mittels Eigeninitiative ans Licht zu gelangen, stößt auf erhebliche Widerstände: Bereits im März 1898 zeigte Le Sifflet das Blatt La Vérité quand même! ${ }^{76}$ von Raoul Barre, auf dem die Wahrheit sich unter dem mit militärischen und klerikalen Requisiten ${ }^{77}$ verrammelten Brunnen hervorzuarbeiten versucht, nervös beobachtet von Esterhazy und dem Président du Conseil Méline, der am 4. Dezember 1897 vor der Abgeordnetenkammer die Existenz der Dreyfusaffäre geleugnet hatte ${ }^{78}$ : "MÉLINE. - Malgré tout, j’ai bien peur qu'elle ne sorte, la rosse!... «79. Die Leugnung des Justizskandals beinhaltet faktisch auch die Leugnung der Schuld Esterhazys. Die ans Licht dringende Wahrheit läßt das von ihm und seinen Gönnern konstruierte Lügengebäude ebenso zusammenstürzen wie die auf den Brunnen getürmten Machtzeichen, die ihre Autorität in dem Moment verlieren, da sie zum Selbstzweck werden, zu hohlen Platzhaltern eines sinnentleerten Ehrbegriffs. Die Vertuschung der Affäre ist für die Unangreifbarkeit dieses Machtanspruchs von essentieller Bedeutung.

Am 7. Juli 1898 aber stellte der damalige Kriegsminister Cavaignac in einer Rede vor dem Parlament klar, daß Dreyfus 1894 auf einer nicht ausreichenden Beweisgrundlage verurteilt worden war, obwohl er selbst an der Schuld des Verurteilten kaum Zweifel hatte ${ }^{80}$. Diese überraschende Wendung quittierte Le Sifflet eine Woche später mit dem Blatt Après les fameuses révélations de M. Cavaignac ${ }^{81}$ von Ibels, auf dem die Wahrheit ungehindert aus dem Brunnen steigt und mit ihrem Spiegel den bereits am Boden liegenden Esterhazy blendet.

Nur kurze Zeit später wurden auch die von Cavaignac noch als echt eingeschätzten Schriftstücke als Fälschungen entlarvt: Bei genaueren Untersuchungen des Hauptbelastungsmaterials im August 1898 fielen erstmals Uneinheitlichkeiten im Schriftbild auf. Ende August konnte schließlich Oberstleutnant Henry der Fälschung der entscheidenden Beweisstücke überführt werden, der sich daraufhin das Leben nahm ${ }^{82}$. Die Anschuldigungen gegenüber Dreyfus

76 Le Sifflet, 17.3.1898. Vgl. KLeEblatt, The Dreyfus Affair, S. 178, Abb. 47.

77 Darunter Rangabzeichen, Säbel, eine Fanfare, Trommeln ebenso wie Bischofsstab und Mitra. Hierin klingt bereits die später von Clemenceau so bezeichnete Allianz von le sabre et le goupillon an. Vgl. dazu Kap.8.3.

78 Jules Méline, Président du Conseil von April 1896 bis Juni 1898. Der denkwürdige Ausspruch lautete: »Il n'y a pas d'affaire Dreyfus. Il n'y a pas en ce moment, il ne peut y avoir d'affaire Dreyfus«. Vgl. Drouin, Précis, S.66.

79 Die Angst der zu Verschwörern erklärten Protagonisten ist angesichts der Geißel, die die Wahrheit statt ihres Spiegels in der Hand hält, durchaus begründet.

80 Drouin, Précis, S. 75-80.

81 Le Sifflet, 14.7.1898.

82 Drouin, Précis, S. 75-80. 
entbehrten so mit einem Mal jeder vernünftigen Grundlage. Dennoch ließ der Triumph der Wahrheit weiter auf sich warten, brachte das Jahr 1898 noch nicht den endgültigen Sieg und Ibels nahm seine euphorische Einschätzung der Lage wieder zurück: Am 30. Dezember 1898 zeigte Le Sifflet seine Karikatur mit dem Titel Impatience. Die am Brunnengrund bis zu den Knien im Wasser stehende nackte Wahrheit versucht noch einmal, sich vor Jahresende Gehör zu verschaffen ${ }^{83}$ : "Hé, là-haut! ça serait-il pour cette année? « Seit November 1898 dauerten die Anhörungen vor der Strafkammer der Cour de cassation an, bei denen über die Zulassung einer Revision des Falls Dreyfus entschieden wurde ${ }^{84}$. Die unterstellte mangelnde Objektivität der Kammer führte nach verschiedenen Vorfällen ${ }^{85}$ am 1. März 1899 schließlich zur loi de déssaisissement, die der Strafkammer das Privileg entzog, allein über die Revision zu entscheiden, und dieses Recht statt dessen allen drei Kammern übertrug ${ }^{86}$. Diese endlosen Verzögerungen fanden ihren Widerhall in Paul Balluriaus am 28. Januar 1899 in Le Petit Bleu veröffentlichten Blatt Vérité! (Abb.69). Zwei Arbeiter haben sich vor dem Brunnen aufgebaut, offenbar fest entschlossen, nicht unverrichteterdinge abzuziehen. Einer der beiden ruft auf den Grund des Schachts: »Sors, n. d. D...! Et, qui que tu doives escarbouiller ${ }^{87}$ de tes morceaux..., éclate! « Die Anspielung auf die Einzelteile, in welche die Wahrheit möglicherweise zerborsten ist, spielt deutlich auf die komplizierte Rekonstruktionsarbeit der Untersuchungskommission an und variiert die Thematik der zersprengten Hinweise auf die Wahrheit, die auch

83 Zur Symbolik des Jahreswechsels und des Jahres 1899 in Verbindung mit der Tradition von Veritas und Chronos vgl. Kap. 8.2.2.

84 Die Ergebnisse der endlosen enquêtes vor der Kammer kommentiert Balluriau in einer Karikatur für Le Petit Bleu de Paris am 9.2.1899: Neben Marianne, die in einer Schale ein Feuer entzündet hat und eine Fackel schwenkt, steht ein Arbeiter, den offenbar die Neugier hergetrieben hat: - »Je croyais voir luire enfin le flambeau de la Vérité!... - Non, c'est du sucre qu'on brûle, ici, après chaque enquête! « Die Allegorie der Republik mit der phrygischen Mütze und entblößtem Oberkörper wird hier gleichsam selbst zur Karikatur der nackten Wahrheit.

${ }^{85}$ Nach Verzögerungen seitens der Regierung bezüglich der Übergabe des berühmten dossier secret (vgl. dazu Kap. 8.2.2.) sorgten im Januar 1899 die in $L^{\prime} \dot{E}_{c}$ cho de Paris veröffentlichten Enthüllungen von Quesnay de Beaurepaire, dem am 8. Januar zurückgetretenen Präsidenten der Zivilkammer an der Cour de cassation, für Verwirrung. Quesnay de Beaurepaire wollte angeblich Zeuge von geheimen Absprachen zwischen den Gerichtsräten und den Familien Dreyfus und Picquart geworden sein. Hermann-Paul thematisiert dies in der Karikatur: La Lutte contre la Vérité, in: Le Cri de Paris, 15.1.1899: Quesnay de Beaurepaire steht vor dem Brunnen der Wahrheit und ist dabei, einen Richterhut hinunterzuwerfen, der Richtermantel hängt wie ein verhüllender Vorhang über dem Rand: „On fait ce qu'on peut«. Das wichtigste Bildorgan der dreyfusards, Le Sifflet, stellte ihn nach dem Ende seiner 'Medienkarriere ‘ am 2.6.1899 als erloschenen Kerzenstummel dar, der langsam auf den Kerzenhalter des Écho de Paris heruntertropft. Vgl. zu Quesnay de Beaurepaire Bredin, L'Affaire, S. 467-469; Drouin, Précis, S.92f.

86 Chastenet, Histoire de la Troisième République, Bd. 2, S. $211 \mathrm{f}$.

87 Bei dem Ausdruck escarbouiller handelt es sich um eine Dialektform von écrabouiller (zerquetschen). 


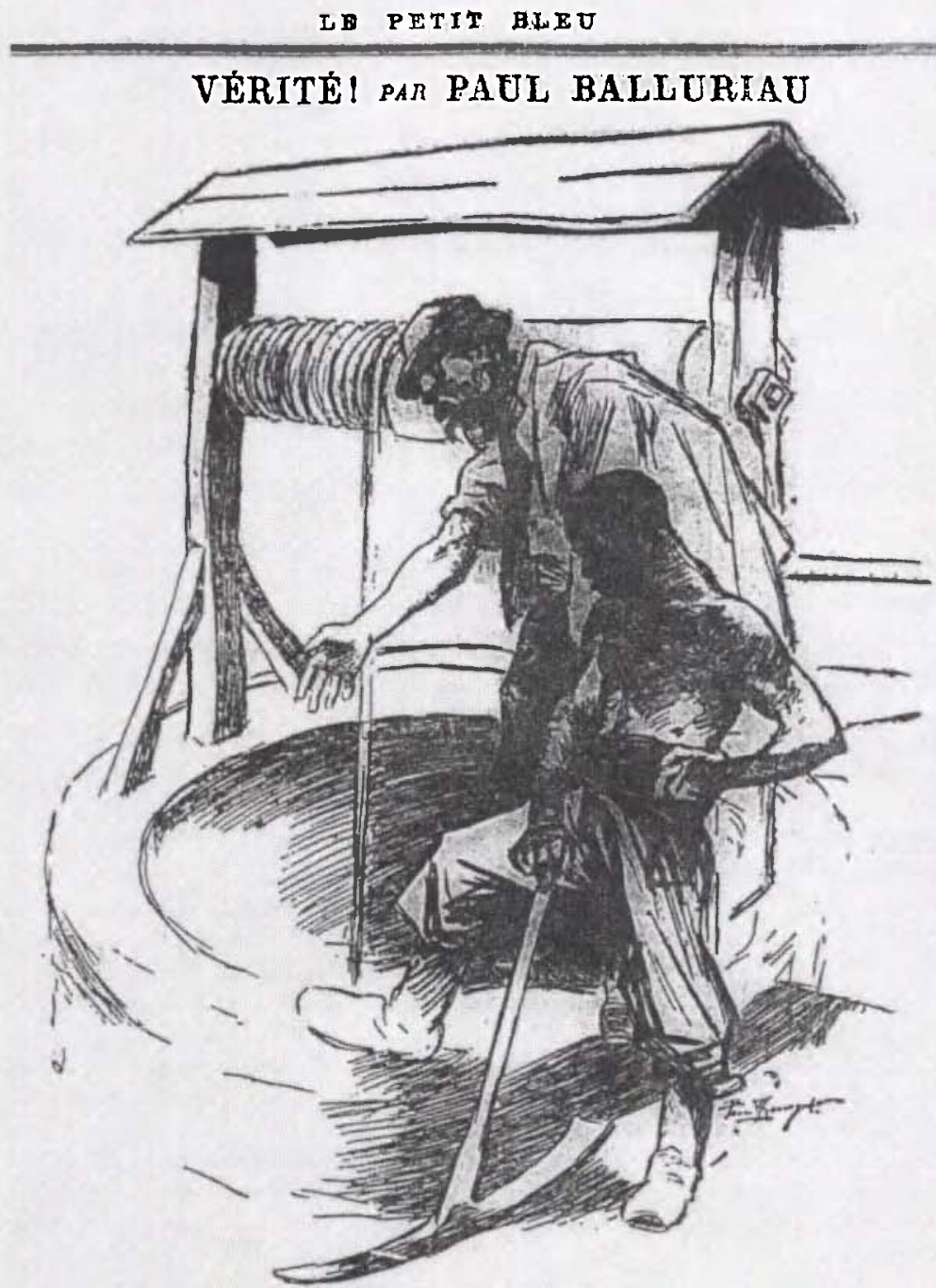

- Sors, n. d. D...I Et, qui que tu doives escarbouiller do tes morceaux..., eclate!!

Abb. 69 Paul Balluriau: Verite! - Sors, $n$. d. D...! Et, qui que tu doives escarbouiller de tes morceaux..., eclate!!, in: Le Petit Bleu de Paris, 28. 1.1899. Sammlung D.K. 
bei Steinlens bereits erwähntem Blatt im Vordergrund steht. Die breite Masse des Volkes aber will diesen Prozeß nun nicht nur zu Ende geführt, sondern auch beschleunigt sehen. Die Handlungsbereitschaft der Proletarier wird dabei, wie so oft, durch die pioche, die Spitzhacke, symbolisiert ${ }^{88}$ Die Entscheidung, selbst aktiv zu werden, um der Wahrheit zu ihrem Recht zu verhelfen, ist hier aber offenbar noch nicht gefallen. Vergleicht man die Ausgangssituation mit der von Ibels Blatt Impatience, so wird klar, daß der paradigmatische Wechsel in bezug auf die Verantwortung des einzelnen für die Wahrheit noch in vollem Gange ist. Erst in Balluriaus Blatt Du courage!, das am 9. August, zwei Tage nach dem Beginn des neuen Prozesses vor dem Kriegsgericht in Rennes veröffentlicht wurde, haben die zwei Proletarier gemeinsam das Brunnenseil ergriffen und ziehen die sich daran festklammernde Wahrheit mit vereinten Kräften nach oben, während ihr hellstrahlender Spiegel bereits sein Licht verbreitet (Abb. 70). Der Kommentar zu dieser mühsamen ,Geburtshil$\mathrm{fe}<$ lautet: $\gg$ C'est dur, mais, en France, on y arrive «. Die symbolische Botschaft ist in ihrer Tragweite nicht zu überschätzen: Das Volk zieht die Wahrheit aus eigenem Antrieb zu sich herauf und verwirklicht so seinen unmittelbaren Souveränitätsanspruch ${ }^{89}$. Der so angedeutete Machtwechsel kann unter Umständen das einzige Mittel sein, um die Wahrheit vor ihren Angreifern zu retten. Zu spät kommt jede Hilfe dagegen auf einem Bild, das der dreyfusard Félix Vallotton für Le Cri de Paris ${ }^{90}$ schuf. Leblos hängt die Vérité in ihrem Brunnenseil; sie wurde erdolcht, um ihr Licht so zum Erlöschen zu bringen: "Voilà donc pourquoi elle ne sortait pas! «

Darin klingt, während des bis Anfang September dauernden Revisionsprozesses, in dem Dreyfus wiederum schuldig gesprochen wurde, eine tiefe Resignation an. Der Hoffnung, daß die Wahrheit trotz aller Anfechtungen immer intakt bleibt, setzt Vallotton das Bild einer durch fortgesetzte Lügen, Intrigen und Angriffe gescheiterten Wahrheit entgegen.

Wenn auch, wie auf Ibels Blatt Ressaisissement ${ }^{91}$ vom 7. April 1899, die Wahrheit aus ihrem Brunnen steigt und ihre Feinde in die Flucht schlägt, so wird doch klar, daß die nicht zu leugnende Wahrheit diesem Umstand zum Trotz lange nicht von allen anerkannt wird. Die Annahme, daß die Wahrheit allein dadurch auf breitester Basis akzeptiert wird, daß sie sichtbar ist, erweist sich als illusorisch ${ }^{92}$.

${ }^{88}$ Die Spitzhacke wird vor allem als unabdingbares Requisit des démolisseurs bedeutsam. Vgl. dazu Kap. 9.2.2.

89 Vgl. Blumenberg, Paradigmen, S.29: "Im umgekehrten Verhältnis zur Macht, die der Wahrheit zugemessen wird, wird das $\mathrm{MaB}$ der eigenen Anstrengung um der Wahrheit willen stehen «.

90 Titelbild vom 14.5.1899.

91 Ans Licht geholfen wird der Wahrheit dabei vom Maskottchen von Le Sifflet, der als Sänger mit Gitarre auftritt.

92 Eine andere interessante Verknüpfung von triumphierender Wahrheit und Lichtsymbolik weist ein Blatt auf, das CouturIER am 16.12.1898 in Le Sifflet zeigt: Zwei Männer 


\section{DU COURAGE| PAA BALLURIAU}

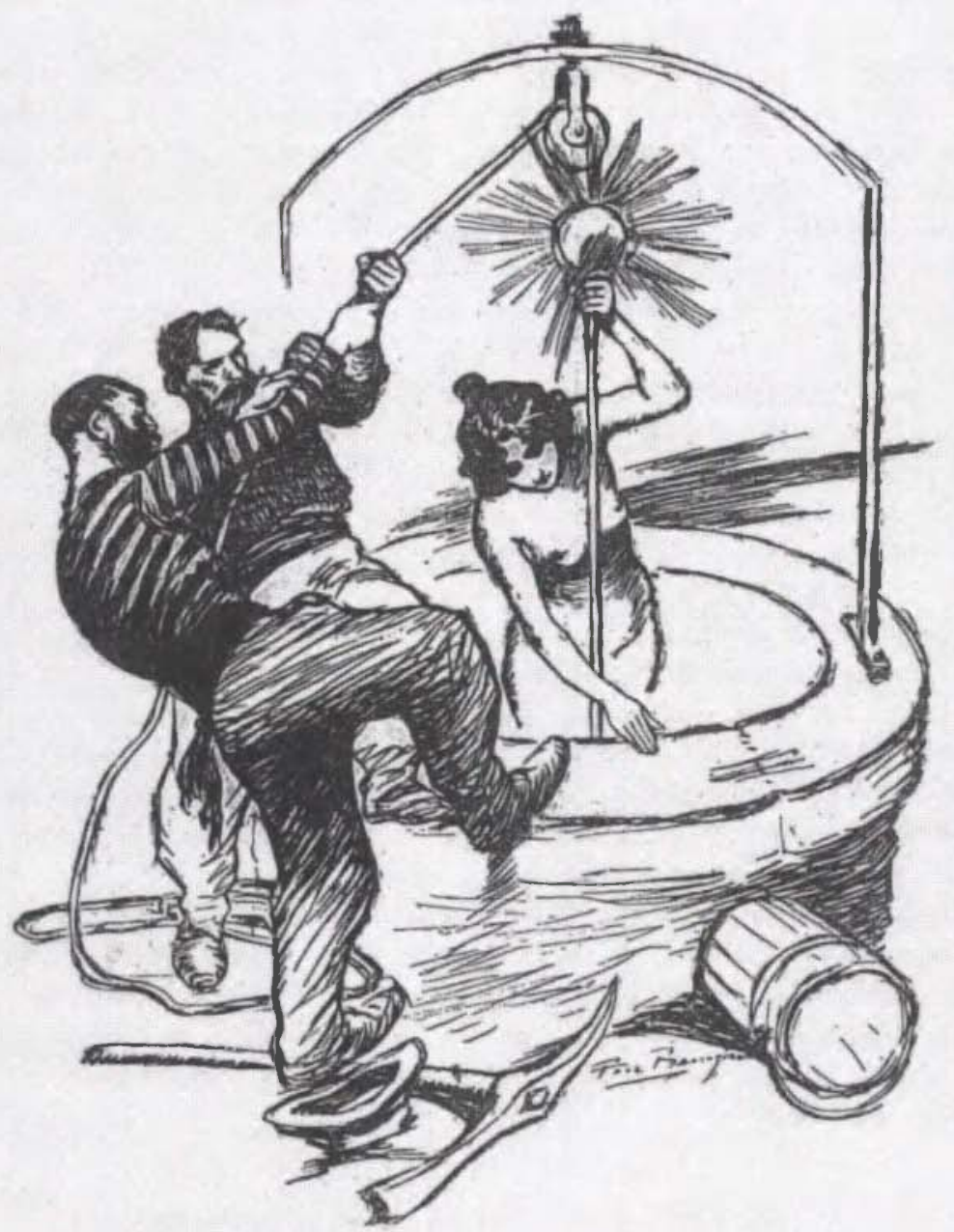

- Cest dur, mais, en France, on y arribe.

Abb. 70 Paul Balluriau: Du courage! - C'est dur, mais, en France, on y arrive, in: Le Petit Bleu de Paris, 9.8.1899. Sammlung D.K. 
Die Ablehnung der sich doch geradezu aufdrängenden Wahrheit kennzeichnet die gesamte weitere Entwicklung der Dreyfusaffäre nach der letztendlich erfolgten Begnadigung. Erst im Juli 1906 wurde Alfred Dreyfus vollständig rehabilitiert und zum Mitglied der Ehrenlegion ernannt ${ }^{93}$. Als er im September 1908 der Überführung der Asche Zolas ins Pantheon beiwohnte ${ }^{94}$, wurde er von zwei Schüssen des Journalisten Grégori am Arm getroffen und leicht verletzt. Der Attentäter wollte nach eigenen Angaben gegen den dreyfusisme protestieren und der Armee die Ehre zurückgeben, die ihr durch Dreyfus und Zola genommen worden sei, und wurde schließlich freigesprochen $^{95}$.

Das traditionell royalistische Magazin Le Triboulet, das sich damals bereits an die ultranationale und antisemitische Action française ${ }^{96}$ angenähert hatte, feierte dies am 20. September 1908 mit der Darstellung Après l'acquittement (Abb.71). Während im Hintergrund die Justiz in einem Brunnen vergeblich nach der Wahrheit sucht, steigt diese gerade, den Spiegel hoch erhoben, aus einem zweiten Brunnen im Bildvordergrund, woran eine Gruppe Maskierter sie hindern will. Dieser Versuch aber wird, wie der Bildtext präzisiert, zwangsläufig scheitern: "Les Juifs et leurs valets auront beau faire, la Vérité surgit et, seule, elle `éclairera maintenant!...«

Die Komposition des Brunnens mit der Wahrheit auf diesem Blatt ist unverkennbar dem Gemälde La Vérité sortant du puits des glühenden DreyfusAnhängers Édouard Debat-Ponsan nachempfunden, das dieser im Jahr 1898 geschaffen hatte und das später als Geschenk einer Gruppe von Bewunderern in den Besitz von Émile Zola gelangte (Abb. 72) ${ }^{97}$. Die abstrakte Metaphorik des Gemäldes aber prädestiniert es geradezu für den hier erfolgten Rollentausch zwischen lichtstrahlender Wahrheit und Dunkelmann. Damit profitierte nun auch die Gegenseite von der extremen symbolischen Aufladung des Motivs der Wahrheit, die aus dem Brunnen steigt. Die so dargestellte zeitliche Verzögerung des Sichtbarwerdens der swahren Wahrheit erscheint als die Wiederaufnahme einer unterbrochenen Entwicklung: Die dreyfusards haben ,ihre< Wahrheit im falschen Brunnen gesucht - und offenbar gefunden. Das

beobachten unter dem sich am Morgen aufhellenden Himmel das Schiff, das Dreyfus zurück nach Frankreich bringt: »C'est le steamer de la Guyane, dans trois heures il sera en France, dans quatre il aura coulé l'État-Major, sans tirer un coup de canon «. In Wirklichkeit kehrte Dreyfus erst am 30.6.1899 nach Frankreich zurück. BrEDIN, L'Affaire, S. 492. In der Situation der sich in Widersprüchen und Intrigen verstrickenden Untersuchungen der chambre criminelle Ende 1898 aber wird dieses Ereignis zur regelrechten Rückkehr des Lichts stilisiert bzw. mit der Überwindung der Nacht gleichgesetzt.

93 BREDIN, L'Affaire, S.611-616.

94 Zur Pantheonisation Zolas vgl. Jean-François CondeTte, La translation des cendres d'Émile Zola au Panthéon. La difficile et posthume revanche de l'intellectuel dreyfusard, juillet 1906-juin 1908, in: Revue historique 304 (2000), S. 655-684.

95 BREDIN, L'Affaire, S.618.

96 BonNefous, Histoire politique, S. 114-116.

97 Kleeblatt (Hg.), Dreyfus Affair, S. 258, Kat. 189. 


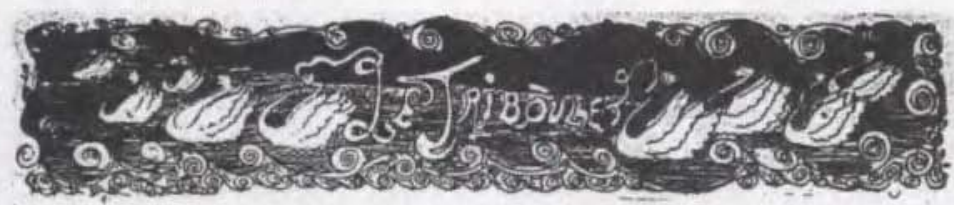

\section{APRES L'ACQUITTEMENT}

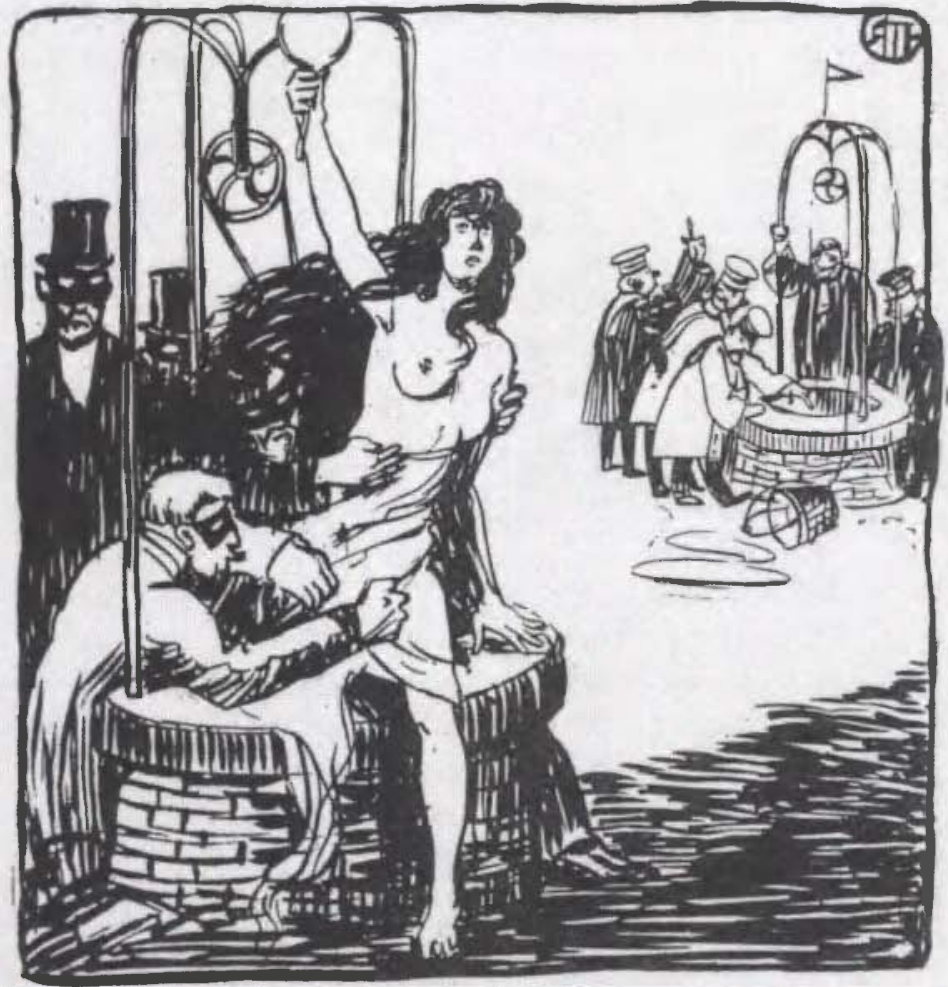

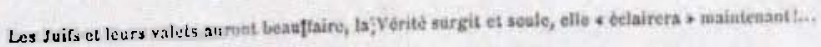

Abb. 71 Name unkenntlich: Apres l'acquittement. Les Juifs et leurs valets auront beau faire, la Verite surgit et seule, elle seclairera maintenant!..., in: Le Triboulet, 20.9.1908. Sammlung D.K. 
Abb. 72 Edouard DebatPonsan: La Verite sortant du puits. Öl auf Leinwand, 1898. Musee de l'hôtel de ville d'Amboise.

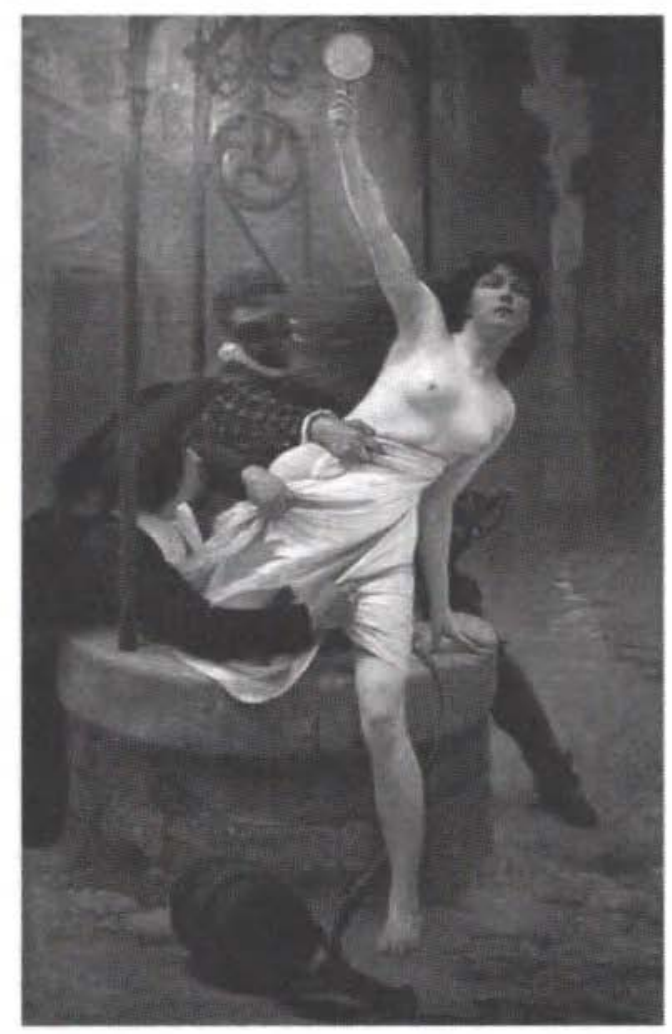

wahre Licht dringt aber erst jetzt ans Tageslicht - und damit wird der Moment der Wahrheitsfindung an den Anfang zurückversetzt. Jeder glaubt, den $\mathrm{Zu}$ gang zur allein gültigen Wahrheit zu besitzen, was, jenseits aller Fakten, auf das Gebiet des Willens zur Erkenntnis bzw. der Verweigerung führt.

\subsection{2. "Le Bandeau nationalistex: Der Symbolkomplex »Sehen - Erkenntnis" und die Metaphorisierung der Wahrheitssuche}

Der schwierige Weg der Wahrheit ans Licht zeichnet einen Konflikt nach, in dem die Forderung nach Erhellung und »Aufklärung« sich stets mit der Ablehnung der Erkenntnis und Verschleierung der Wahrheit konfrontiert sieht. Darin spiegelt sich nicht nur ein zentrales Thema der Licht- und Finsternisproblematik im allgemeinen, sondern es stellt sich zugleich die Frage, wie der metaphorische Erkenntniskomplex der lumieres sich in diesem Zusammenhang am Ende des 19. Jahrhunderts darstellte und welche Faktoren zu der Entstehung dieser Situation beitrugen. Die vom Licht abhängige Sehkraft und die daraus erwachsende Erkenntnisfähigkeit erschienen schon in der Bildsprache der Französischen Revolution als Symbol für die Wirkung der lu- 
mières auf das Individuum: Das Thema »Sehen « ist auf den Gegensatz des "Nichtsehens" angewiesen, um als Bildcode lesbar zu werden. Die (innere) Blindheit wurde meist durch die doppeldeutige Symbolik der Augenbinde dargestellt ${ }^{98}$ : (Noch) nicht sehen können bzw. nicht sehen wollen - Blindheit gegenüber der Wahrheit ist die Unfähigkeit oder der Unwille, die von Descartes formulierte faculté der Erkenntnis zu nutzen ${ }^{99}$. Das Sehen allein ist also ein automatisierter Ablauf, dem erst die Erkenntnis den Sinn verleiht. Das Entfernen der Augenbinde zeigt den Moment, in dem dieses Bewußtsein im Menschen erwacht und aktiviert wird ${ }^{100}$.

Erst durch die eigene Anschauung kann das Geglaubte faktisch auf seinen Wahrheitsgehalt hin beurteilt werden. Der zum ersten Mal aktiv Sehende und Erkennende symbolisiert die (erstmals) unvoreingenommene, unvorbelastete Sicht auf die Dinge, die nicht mehr in überkommenen Denksystemen verankert ist, ausgelöst durch die »dé-institutionalisation et [...] dé-historisation de la perception visuelle « in der Aufklärung ${ }^{101}$. Im Kontext des mythischen ersten, das heißt bewußt wahrgenommenen Blicks wird die für die Entwicklung der Erkenntnisfähigkeit benötigte Zeitspanne allein durch die Geste symbolisiert, mit der die Augenbinde entfernt wird. Der erste Blick steht dabei für den kulturellen Fortschritt, den das zum erkennenden Sehen gereifte Individuum stellvertretend für die ganze Gesellschaft vollzieht.

Die Rolle der Zeit selbst ist dabei bereits stark reduziert. Die Zeit führt nicht mehr automatisch zur Erkenntnis und damit zur Wahrheit, wie in dem mythologischen Paar von Chronos und Veritas bildlich dargestellt. In der ikonographischen Tradition sind für die Sichtbarmachung der Wahrheit durch die Zeit zwei Motivstränge verbreitet: Zum einen die Enthüllung, also Entkleidung der Wahrheit, zum anderen ihre Befreiung aus dem tiefen Brunnen ${ }^{102}$. Kern der mythologischen Szenen ist stets die aktive Rolle der Zeit gegenüber der passiven Wahrheit. Der Moment des Hervorsteigens aus dem Brunnen weist ebenso wie der Akt der Entschleierung auf die Spannung zwischen Präsenz und Wahrnehmbarkeit der Wahrheit hin, der dazwischen ablaufende Prozeß der Erkenntnis wird durch die Initiative von Chronos versinnbildlicht.

In Cochins Frontispiz zur Encyclopédie wurde dieses Motiv entscheidend abgewandelt: Nicht mehr die Zeit lüftet die Schleier der Wahrheit, sondern

98 Reichardt, Lumières, bes. S. 118 und 133, sowie grundlegend: Peter BeXte, Blendung: Figuren der Blindheit in Kunst und Wahrnehmungstheorie, Kassel 1996. Vgl. zu dieser Darstellungsweise auch Daumiers Blatt Le Jeu de l'éteignoir von 1872 (Kap.6, Anm. 88).

99 Vgl. dazu Kap.2.1.

$100 \mathrm{Zu}$ diesem Motivkomplex vgl. BexTe, Blendung, bes. S. 159-174.

101 Carl Havelange, L'institution du regard au XVIII e siècle, in: Mortier ( $\mathrm{Hg}$.), Visualisation, S.21. Als derart symbolischer Einschnitt findet sich das Anlegen der Augenbinde im Aufnahmeritus der Freimaurer. Vgl. dazu Reichard, Lumières, S.107, S. 108, Abb.11.

102 Guy de Tervarent, Veritas and Justitia triumphant, in: Journal of the Warburg and Courtauld Institutes 7 (1944), S. 95. 
die Personifikationen von Philosophie und Vernunft ${ }^{103}$. Gewechselt hat also das Erkenntnisprinzip, das nun dem positiven Fortschrittsmodell folgt. Das so neu begründete Verhältnis der lumières zur enthüllten Wahrheit bildet ihr unmittelbares Identifikationsmodell: »Die Metapher der >nackten< Wahrheit gehört zum Selbstbewußtsein der aufklärerischen Vernunft und ihrem Herrschaftsanspruch ${ }^{104}$. Die Zeit ist in diesem Zusammenhang also nur noch insofern von Bedeutung, wie sie sich in dieses Modell einordnet und sich mit dem Begriff des kulturellen Fortschritts vereint. Die durch die Maximen der Aufklärung geweckte, intensivierte und somit beschleunigte Erkenntnisfähigkeit überträgt sich schließlich auf die Zeit selbst, was besonders auf Chronos' Rolle als Erfüller und Vollender der Zeit innerhalb der Bildpublizistik der Französischen Revolution verweist ${ }^{105}$. Die so vollzogene Unterscheidung zwischen (negativer) Vergangenheit und (positiver) Zukunft bestimmt auch das bildsymbolische Zeit-Erkenntnis-Schema am Ende des 19. Jahrhunderts. Die Absetzung des hoffnungsvollen sneuen Jahr beinhaltet dabei genau jenen in sich bereits revolutionären Mythos des Neubeginns, der auch dem überhöhten ersten Blick innewohnt. Im Rahmen der Dreyfusaffäre gilt diese Erwartung eines individuellen und kulturellen Entwicklungssprungs dem Jahr 1899. Ein Blatt von Couturier für Le Sifflet mit dem Titel Mal an! Bon an! zeigt am 6. Januar 1899 das neue Jahr als junge Frau mit phrygischer Mütze ${ }^{106}$, die in den puits de la Vérité hineinruft: "La fête va commencer, tu peux sortir! « Das gescheiterte Jahr 1898 in der Gestalt eines abgerissenen Bettlers verschwindet unterdessen, von einem Rabenschwarm verfolgt, in der Dunkelheit. Die an die Stelle von Chronos getretene Allegorie verkörpert in mehr als einer Hinsicht diesen mythischen Neubeginn - für die Zeit ebenso wie für die Republik. Insofern kann dieses Blatt als mehrfach codierte Antwort auf Ibels' eine Woche zuvor erschienene Karikatur Impatience ${ }^{107}$ gelten, da Couturier die Voraussetzungen darstellt, die für den Aufstieg der Wahrheit ans Licht gegeben sein müssen.

103 Alexander Perrig, Das Frontispiz der Encyclopédie oder die hohe Kunst der Verblümung, in: Idea 9 (1990), S.77: "Für Cochin (und die Enzyklopädisten) dürfte die traditionelle Bildformel -Wahrheit von Zeit enthüllt‘ nicht viel mehr als der Ausdruck von Gedankenlosigkeit gewesen sein. Denn wenn Wahrheit an den Tag kommt, dann durch das gemeinsame Engagement von Vernunft und Verstand«. Zum Schleier als Symbol des Vergessens vgl. analog Francesca RigotTI, Schleier und Fluß - Metaphern des Vergessens, in: Michael B. BuchHOLz (Hg.), Metaphernanalyse, Göttingen 1993, S. 229-252.

104 Blumenberg, Paradigmen, S. 71.

105 Vgl. dazu Kap.3.1.1.

106 Die phrygische Mütze verweist auf die Ineinssetzung von Personifikation der Republik und Jahresallegorie. Auch auf der Karikatur Sous le même bonnet vert!... von Kab für La Comédie politique (11.6.1899) wird die Bedeutung des Jahres 1899 hervorgehoben: Vor dem Hintergrund einer strahlend aufgehenden Sonne stülpt die Allegorie des Gesetzes den wahren Verrätern eine riesige phrygische Mütze wie einen Löschhut über, auf der 1899 zu lesen steht: La seule sanction nécessaire qui puisse être efficace, so der Untertitel.

$107 \mathrm{Vgl}$. dazu Kap. 8.2.1. 
Daß die Zeit dagegen keine Rolle spielt, wenn es gar keine Wahrheit gibt, die aus dem Brunnen steigen könnte, thematisiert der zu diesem Zeitpunkt noch dreyfuskritische Charles Léandre ${ }^{108}$ mit einem Blatt, das am 27 . September 1898 in der Zeitung Le Figaro abgedruckt wurde ${ }^{109}$ : Chronos steht in Gesellschaft des revisionistischen Präsidenten der Abgeordnetenkammer, Henri Brisson ${ }^{110}$, der einen Arm fast väterlich um die Schulter der Zeitallegorie gelegt hat, am Brunnen. Obwohl beide offenbar schon so lange vergebens warten, daß unterdessen die Nacht hereingebrochen ist, und statt des erwarteten Lichts der Wahrheit nur noch zwei Laternen die Szenerie erhellen, weist Chronos unverdrossen in den Brunnen: »Patience, mon Président, il en sortira peut-être quelque chose «. Dennoch handelt es sich hierbei um die bloße Karikatur eines geläufigen Motivs, die den traditionellen Deutungsmustern verhaftet bleibt. Wenn dagegen auf der überwiegenden Zahl der dreyfusfreundlichen Bilder der Vertreter einer bestimmten Geisteshaltung oder einer bestimmten gesellschaftlichen Gruppe die Wahrheit aus dem Brunnen holt und damit die Zeit ersetzt, so zeugt dies von einem emanzipierten Zeit- und Erkenntnisbegriff, der sich mit der Forderung nach intellektuellem und sozialem Fortschritt trifft. Der so symbolisierte Neubeginn ist die geistige Befreiung einer aktiv geleisteten Erkenntnis und eines darauf gegründeten Urteils.

Auf der anderen Seite aber steht eine ebenso entschiedene Ablehnung dieser Erkenntnis, die besonders bei denen ausgeprägt zu sein scheint, die den direkten Zugang zu den faktischen Beweisen haben. Hierin liegt der entscheidende Unterschied dieser Lichtfeindschaft zu der, die traditionell den Republikgegnern und der Kirche zur Last gelegt wurde. Nun aber ging es nicht mehr um weltanschauliche Prinzipien und Wahrheiten, wie um den Glauben an einen Gott oder um eine Staatsform, sondern um einen konkreten Fall, der auf einer rational zu rekonstruierenden Beweislage beruhte. Offensichtlich schienen aber gerade Justiz und Militär, zwei der Hauptsäulen der Republik, die sich daraus aufzwingende Wahrheit abzulehnen. Aufgrund der sich verselbständigenden, katalysatorischen Wirkung der Affäre wurde diese Ablehnung aber automatisch auf die gesamtgesellschaftliche Ebene umgelegt ${ }^{111}$. Die Unfähigkeit, die Wahrheit zu erkennen und der Unwillen wurden dabei eins und gleichzeitig politisiert: Lichtscheuheit, Gleichgültigkeit gegenüber dem Licht und seine brutale Unterdrückung tragen vereint dazu bei, den Triumph der Wahrheit aufzuhalten.

In dieser Dreiheit spiegelt sich die Bedrohung, der die Republik - und mit ihr die Wahrheit in der Tradition der lumières - fortwährend ausgesetzt war: Wenn das Sehen des Lichts zur Erkenntnis führt, muß das Sehen eben ver-

108 Léandre änderte seine Meinung im Laufe des Jahres 1899 und wurde zum Fürsprecher von Dreyfus und seinen Verteidigern. Vgl. dazu Bachollet, »Le Rire«, S.14.

109 Einsehbar in der retrodigitalisierten Ausgabe von Le Figaro auf http://gallica.bnf.fr.

110 Zu Henri Brisson (1835-1912) vgl. HuTton, Historical Dictionary, Bd. 1, S. $134 \mathrm{f}$.

111 Zu diesem Konflikt vgl. Kap.8.3. 
hindert werden, bzw. muß das Licht zum Feindbild erklärt werden ${ }^{112}$. Die Flucht vor Licht und Wahrheit, die etwa in Ibels' bereits erwähnter Karikatur Ressaisissement ${ }^{113}$ thematisiert wurde, reduzierte Hermann-Paul in einer Illustration seines Albums 200 dessins $^{114}$ auf ihre wesentlichsten Bestandteile. Sichtbar ist von der Wahrheit allein der ins Bild ragende Spiegel, der bei denen, die sein Licht fürchten, blankes Entsetzen auslöst. Der Untertitel »Les chiens aboient, la caravane passe « betont wie zum Trotz den nicht aufzuhaltenden Fortschrittsprozeß der Wahrheit. Der Maler Louis Welden Hawkins drückt dies durch das emblematische Bild der »verderbenbringenden Begierde« aus. Im Oktober 1898 veröffentlicht die kurzlebige Tageszeitung La Volontét15 seine Zeichnung De la lumière ${ }^{116}$ : Um den hellen Lichtschein einer Kerze flattern Falter, die teilweise schon auf den Kerzenhalter niedergefallen sind, wo auch ein Löschhütchen liegt: Die von ihren Gegnern unterschätzte Wahrheit strahlt letztendlich zu mächtig, um unterdrückt werden zu können ${ }^{117}$. Hermann-Paul zeigt dies in einem Blatt ohne Titel, das er zu dem Album Hommage des artistes à Picquart beisteuerte ${ }^{18}$. Die Wahrheit hat sich schon fast aus ihrem Brunnen befreit. Ihr Spiegel ist bereits sichtbar, worauf der in der Nähe stehende Präsident Félix Faure - an ihn hatte Zola seinen offenen Brief »J'Accuse « gerichtet - einen Repräsentanten des Militärs mit Macht nach unten drückt und ihm die Augen zuhält, um ihn so vor diesem Licht zu schützen. Auf die Spitze getrieben sieht sich diese Symbolik in einer Karikatur von Kab mit dem Namen Sous l'éteignoir!..., die am 16. Ja-

112 Den ersten historischen Bruch in der positiven Rezeption des Erkenntnislichtes setzt Hans Blumenberg mit der Ablehnung des Fernrohrs und den dadurch sich aufdrängenden Korrekturen des Weltbildes an: »Nach der ältesten Metapher, die es für sie gibt, ist die Wahrheit Licht; aber jetzt erwies sich, daß sie eben nur Licht ist und der Mensch auf die natürlichste Weise sich gegenüber dem Licht so verhalten kann, wie er sich gegenüber dem Laut nach dem mythischen Vorbild des Odysseus, der sich gegen die Sirenen die Ohren verstopft, zu verhalten vermag, indem er die Augen schließt und nicht sehen will«. Vgl. Hans Blumenberg, Sidereus Nuncius. Nachricht von neuen Sternen, Frankfurt a. M. 1980, S.9f.

113 Vgl. Kap. 8.2.1.

114 Hermann-Paul, Proverbe arabe, in: Ders., 200 dessins. 1897-1899, Paris, 1899, S.66f.

115 La Volonté. Journal quotidien, politique et littéraire (1898-1899).

116 In der Chronique des arts et des lettres auf derselben Seite steht zu diesem Bild nur soviel: "Notre numéro d'aujourd'hui contient un dessin du peintre Hawkins ayant trait à la grande question. Ce dessin [...] doit pouvoir se passer des louanges autant que de tout commentaire, car les unes seraient banales ou n'importe quel autre semblerait oiseux. L. W. Hawkins, naturalisé Français et habitant Paris depuis vingt-six ans, ne pouvait pas plus que nous se désintéresser des choses du jour, et il a mis à en exprimer la philosophie son tempérament d'artiste libre et sans préoccupation du squ'en-pensera-t-on`? «

117 Das Bild der gleichbleibend starken Kerzenflamme, die das Opfermotiv des Sichverzehrens ausblendet, steht in seiner Statik dabei keineswegs im Widerspruch zum vorwärts schreitenden Fortschrittsmodell. Die Unbesiegbarkeit des Lichts ist bei beiden Motivsträngen das bestimmende Argument.

118 Hermann-Paul, (Ohne Titel). Blatt 4 des Albums Hommage des artistes à Picquart, Paris 1899. Abgebildet bei Kleeblatt, The Dreyfus Affair, S.217, Abb. 116. 
nuar 1898 den Titel der in Lyon erscheinenden Zeitschrift La Comédie politique zierte (Abb. 73): Der Entwurf für den Gerichtssaal ${ }^{119}$ des zu erwartenden Prozesses präsentiert sich als das Innere eines riesigen Löschhuts, der das Geschehen hermetisch gegen die von außen angestrengt lauschende Öffentlichkeit abschirmen soll. Alles steht ganz im Zeichen des éteignoir: Alle Richter, Zeugen und Geschworenen tragen übergestülpte Löschhüte auf dem Kopf, darunter auch die ominöse dame voilée, eine Erfindung Esterhazys, die ihn angeblich vor einer Verschwörung gegen ihn gewarnt und ihm Papiere $z u$ seiner Entlastung übergeben hatte ${ }^{120}$. Ein schwarzer Schleier verstärkt in ihrem Falle noch die Finsternis des Löschhütchens. Ein solches bedeckt auch ihre zum Schwur erhobene Hand. Vor dem Richtertisch stehen weitere Löschhütchen mit den Aufschriften rapports d'experts, pièces à conviction oder bordereaux, die Liste, mit der die Affäre ihren Anfang nahm ${ }^{121}$. Das Licht selbst ist unter dem sprichwörtlichen Scheffel verschwunden. Daß die Resultate eines solchen Prozesses nur ebensolche Finsternis hervorbringen können, steht außer Frage.

Die immer massiveren Vorkehrungen gegen das Licht - und damit die Wahrheit - zeigen aber, daß die Gegner dieses Lichts seine blendende Leuchtkraft - und damit die Offensichtlichkeit der Sachlage - durchaus realistisch einschätzen. Was geschieht, wenn infolgedessen alle Versuche, das Licht nicht sehen zu müssen, fehlschlagen? Muß das sichtbare Licht, müssen die sichtbaren Zusammenhänge nicht wahrgenommen werden, wenn sie sich förmlich aufdrängen? Ein nicht betiteltes Blatt von Théo von Rysselberghe für die Hommage des artistes à Picquart zeigt ein Porträt der lichtstrahlenden Wahrheit, der eine große Hand den Mund zuhält ${ }^{122}$. Anders als Vallottons ermordete Vérité hat sie offenbar aus dem Brunnen herausgefunden, ihr Licht wirksam verbreiten kann sie dennoch nicht. Wahrgenommen wird das Licht nur als zu eliminierende Bedrohung. Wie beharrlich man sich der Erkenntnis entziehen kann, zeigt auch das am 4. November 1898 in Le Sifflet veröffentlichte Blatt Le Dossier secret von Ibels, dessen Untertitel schlicht lautet: La Lumière!

$119 \mathrm{Vgl}$. den Bildkommentar: "Projet de dispositions architecturales pour les salles des conseils de guerre de l'avenir et projet de tenue de gala pour les juges, avocats, témoins et pièces de conviction de ces conseils«.

120 Am 31.10.1897 erwähnte Esterhazy die dame voilée erstmals in einem Brief an Präsident Félix Faure. Später behauptete er, die besagte Dame hätte Picquart die Fotografie eines Dokuments gestohlen, das für mehrere hochgestellte Persönlichkeiten äußerst kompromittierend seine könne. Tatsächlich meldeten sich nach Bekanntwerden dieses Gerüchts mehrere Frauen, die vorgaben, selbst die dame voilée gewesen zu sein. Vgl. dazu Johnson, The Dreyfus Affair, S.72-78. Der dreyfusard und Karikaturist Édouard Pépin stilisierte die dame voilée zur tief schwarz verschleierten Gegenfigur der nackten Wahrheit, also zur Lüge, die auf Seiten der Dreyfusgegner steht: En marche pour la vérité (Le Grelot, 6.2.1898) und Nouvelle Religion (Le Grelot, 27.2.1898).

121 Vgl. zum Inhalt des bordereau BREDIN, L'Affaire, S. 81.

122 Théo van Rysselberghe, Ohne Titel. Blatt 10 des Albums Hommage des artistes à Picquart, Paris 1899. Abgebildet bei KLeEblatT, The Dreyfus Affair, S.220, Abb. 122. 
Jourcal satirique hobdomadairo, illustre, politique, judiciaire of financie:r

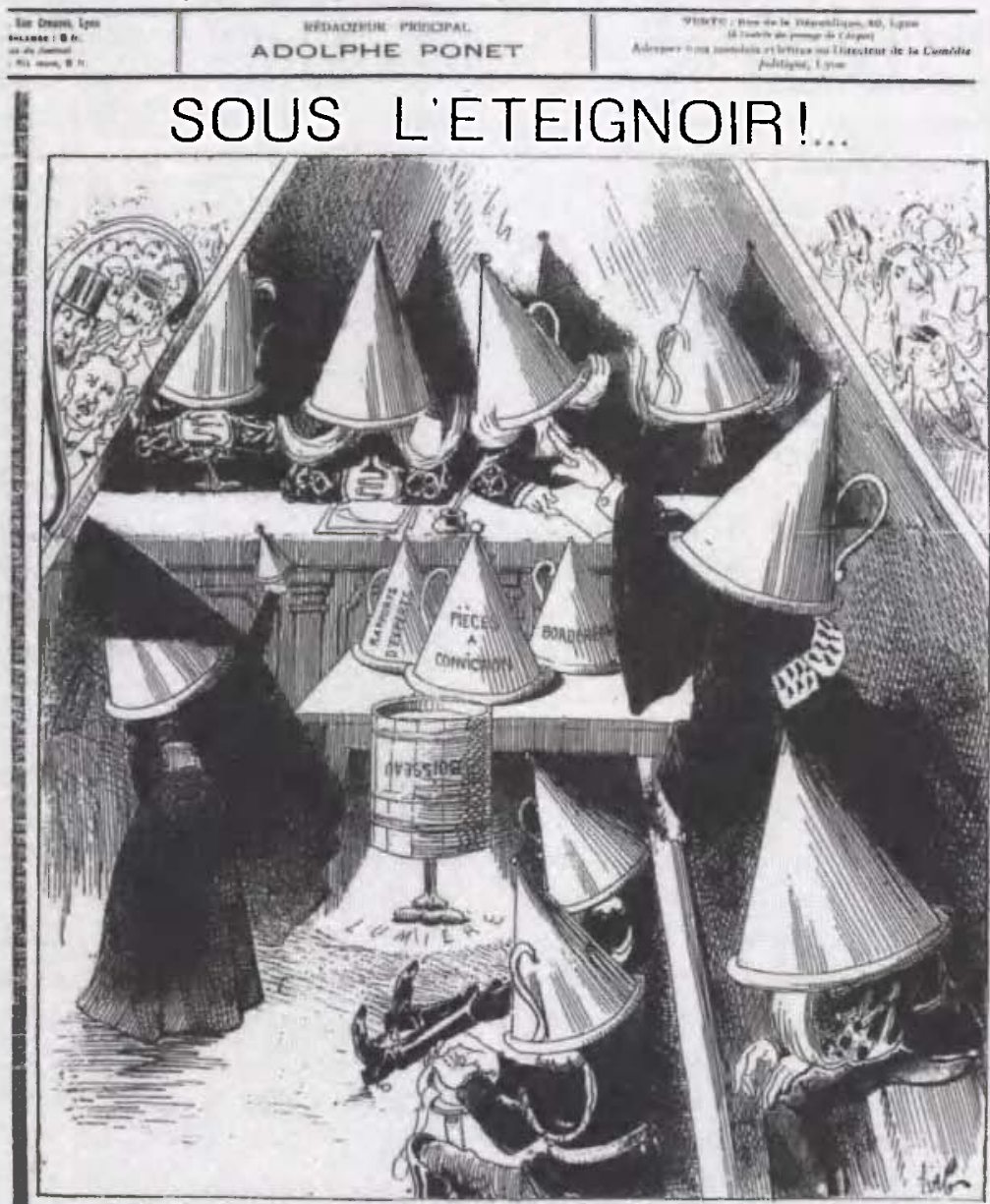

Projot do dispositions arohitooturalos pour les sallos dos Consoils do guorre do l'avonir ot projet do tonue do gale pour los jugos, avooats, aoouste, tómoins ot pleaes do conviotion do oos Conealle.

Abb. 73 Kab: Sous l'eteignoir!..., in: La Comedie politique, 16.1.1898. Sammlung D.K. 
(Abb.74). Ein am Boden kniendes Ratsmitglied der Strafkammer wühlt in den Papieren des geheimen dossier, umstanden von drei teilnahmslosen Vertretern des Militärs, die den hellen Lichtschein, den die Akten abstrahlen, gar nicht wahrzunehmen scheinen. Der Künstler nimmt so die Untersuchung des dossier secret vor der Strafkammer vorweg, die erst ab dem 30. Dezember begann und die zu dem Schluß führte, daß die angeblich erdrückende Beweislast schlichtweg nicht existierte ${ }^{123}$. Hermann-Paul zeigt in seiner Karikatur Rien $n^{\prime} y$ fait $^{124}$ die vergitterte Tür von Picquarts Gefängniszelle, die wie von einem Scheinwerfer in ein übermächtiges Licht getaucht wird, das die beiden davor stehenden Personen - ein Militär und ein durch hochgestellten Mantelkragen und tief ins Gesicht gedrückten Zylinder unkenntlicher Mann - vorgeblich ignorieren und sich so unwillkürlich davor schützen.

Die Vorkehrungen gegen die Wahrheit gipfeln schließlich darin, sich selbst die Sehkraft zu entziehen: In der Karikatur Le Bandeau nationaliste ${ }^{125}$ entwirft Hermann-Paul das Modell eines nationalistischen Dreyfusgegners, der sich vor der Abreise zum Prozeß in Rennes die Augen verbindet: Allons voir la Vérité. Die Großschreibung Vérité spielt bewußt auf die Personalisierung durch die Allegorie an: Der sich so Vorbereitende will die Wahrheit nicht sehen, selbst wenn sie so offenkundig wäre wie eine leibhaftig vor ihm stehende Person. Daß der Nationalist gut daran tut, sich gegen diese unübersehbare Wahrheit so gut zu wappnen, bestätigt Zola am 12. September in L'Aurore: »Si un doute était resté chez quelque peuple lointain, l'éclat aveuglant du procès de Rennes aurait achevé d'y porter la lumière ${ }^{126}$.

Hermann-Pauls Darstellung ist nicht nur eine einfache Umkehr des mythischen ersten Blicks der lumières. Vielmehr weiß der so Handelnde, daß er zwangsläufig erkennen müßte - was er unbedingt verhindern will -, ohne zu bedenken, daß er lediglich einem Selbstbetrug aufsitzt.

Diese Haltung zieht weite Kreise: Ibels thematisiert die offizielle Dementierung der enormen Auswirkungen der Affäre auf das ganze Land mit dem im April 1899 für die Zeitung Le Siècle geschaffenen Blatt La Peur des coups $^{127}$. Im Hintergrund bedrängen drei Vertreter von Klerus, Militär und Bourgeoisie die Republik, die zwar eine phrygische Mütze trägt, ansonsten aber gekleidet ist wie ein Hausmädchen mit Schürze. Die Machtlosigkeit der Republik wird also mit der unsicheren sozialen Stellung einer bonne verglichen, die häufig den sexuellen Übergriffen ihrer Arbeitgeber ausgesetzt war. Gleichzeitig erinnert das so entstehende Bild der wehrlosen Frau an die ge-

123 Ibid., S. 467: »Peu à peu, la certitude gagnait la plupart des conseillers que le dossier secret était aussi vide que le dossier judiciaire«.

124 Hermann-Paul, Guignols. Soixante dessins, Paris 1899, S. 60

125 Le Figaro, 27.7.1899. Einsehbar in der retrodigitalisierten Ausgabe von Le Figaro auf http://gallica.bnf.fr. Wieder in: HeRmann-Paul, 200 dessins, S. 78.

126 Émile ZoLA, La Vérité en marche, S. 162.

127 Les Légendes du Siècle. Album de dessins par H.-G. IBELs, Abb. 26 (zuvor erschienen in Le Siècle, April 1899). 


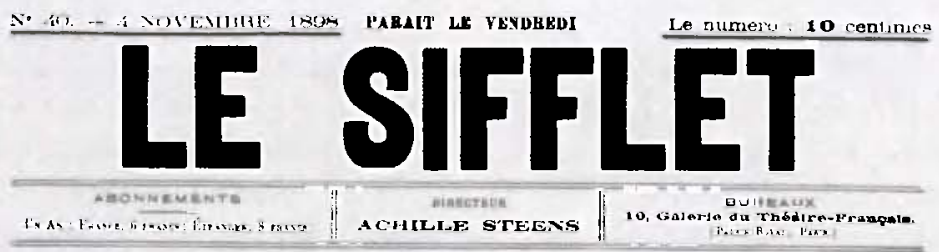

\section{Le Dossier secret}

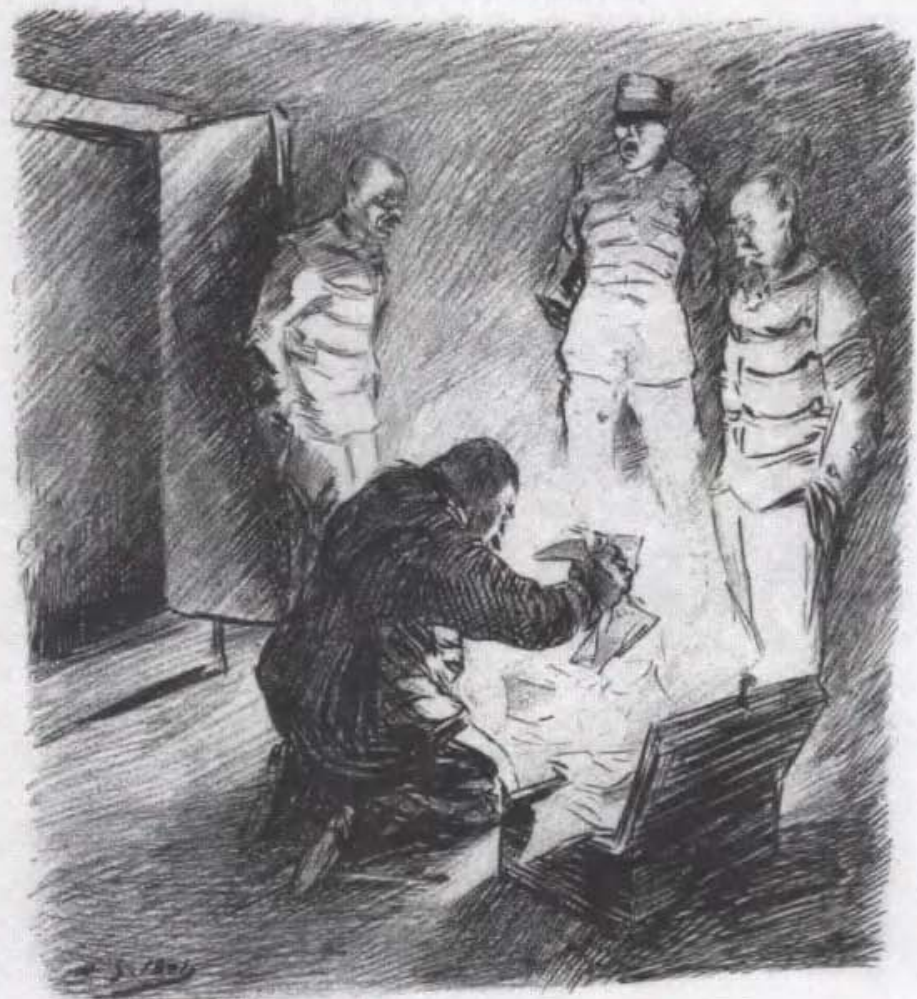

La Lumière!

Abb. 74 Henri-Gabriel Ibels: Le Dossier secret. La Lumiere!, in: Le Sifflet, 4.11.1898. UB Frankfurt. 
fährliche Situation der nackten Wahrheit. Die drei Angreifer tragen schwarze Masken, die ihre Augen verbergen und sie vor dem Licht der Wahrheit schützen sollen. Der im Vordergrund, von der Szenerie abgewendet stehende Président du Conseil Dupuy ist wegen seinem fehlenden rechten Auge, dessen Lid geschlossen wurde, ein sehr willkommenes Symbol der Lichtfeindschaft: »Dupuy: Fermons l'œil... et le bon!«

In Louis Chevaliers Karikatur Une mauvaise farce ${ }^{128}$ ist immerhin der riesige Löschhut umgefallen (Abb.75). Darunter kommen Schriftstücke zutage, die den wahren Sachverhalt enthüllen und die der Vertreter der Justiz nun zur Kenntnis nehmen muß, was ihm aber keineswegs gelegen kommt: „Sapristi! qui a fait ça? « Nur die personifizierte Justitia selbst ist wirklich willens, die Wahrheit anzuerkennen: Am 7.September 1899, zwei Tage vor dem erneuten Schuldspruch, zeigt Le Figaro eine Karikatur von Hermann-Paul, auf der die Allegorie der Gerechtigkeit mit dem Richterhut die preuves mittels einer Öllampe ins Licht rückt: „C'est étonnant, quand j'y vois clair, je ne trouve plus rien! ${ }^{129}$ Daraus spricht nicht nur die Überzeugung, daß das für die Rehabilitierung sprechende Recht bessere Vertreter verdient hätte, sondern es klingt einmal mehr das grundlegende Wahrnehmungsproblem an. Das >klar sehen macht auch Henriot für die dreyfusfreundliche Zeitung L'Événement ${ }^{130}$ während der Untersuchung vor der Strafkammer der Cour de cassation im Januar 1899 zum Gegenstand eines Bildkommentars ${ }^{131}$. Eine vor einer dünnen Mondsichel stehende Kerze wurde von einem übergehängten Talar und daraufgesetzten Richterhut zum Erlöschen gebracht: "Il y a des soirs de clair de lune où quand on éteint la bougie on y voit quelquefois plus clair«. Zum einen ist die Funktion der Richtertracht unverkennbar dem Löschhütchen nachempfunden. Darüber hinaus sind Kerze und fahles Mondlicht im Zeitalter der Elektrizität ausgesprochen schwache Lichtquellen. Beides verdeutlicht das tiefe Mißtrauen gegenüber der Justiz und ihrem Interesse an der Wahrheit. Die Aufforderung aber, das Licht zu löschen, verweist auf eine andere Ebene: die der sich von äußeren Faktoren frei machenden Erkenntnis. Die Stille und Dunkelheit der Nacht ist ein klassischer Topos der Besinnung auf das Wesentliche und der Kontemplation ${ }^{132}$. Erst das Meditieren über den Fakten und die objektive Abwägung führen zu der Erkenntnis, die im (mit Absicht schwach gehaltenen) Licht nur scheinbar ihren Ausdruck findet.

Diese Alibifunktion des Lichts wird in der dreyfusard-Bildpublizistik häufig im Symbol der Lampe dargestellt. Repräsentanten von Justiz und Militär

128 Le Sifflet, 7.4.1899.

129 Einsehbar in der retrodigitalisierten Ausgabe von Le Figaro auf http:/gallica.bnf.fr.

130 Erschienen von 1872 bis 1966.

131 Henrior, Croquis d'actualité, in: L'Événement, 16.1.1899.

$132 \mathrm{Zu}$ diesem Komplex vgl. Walter SerTTER, Die Geschichte der Nacht, Berlin u. a. 2000, S. 91. Zur Bildgeschichte vgl. Justus MüLler-Hofstede, Vita Mortalium Vigilia. Die Nachtwache der Eremiten und Gelehrten, in: Leselust. Niederländische Malerei von Rembrandt bis Vermeer, Frankfurt 1993, S.34-53. 
Une mauvaise farce

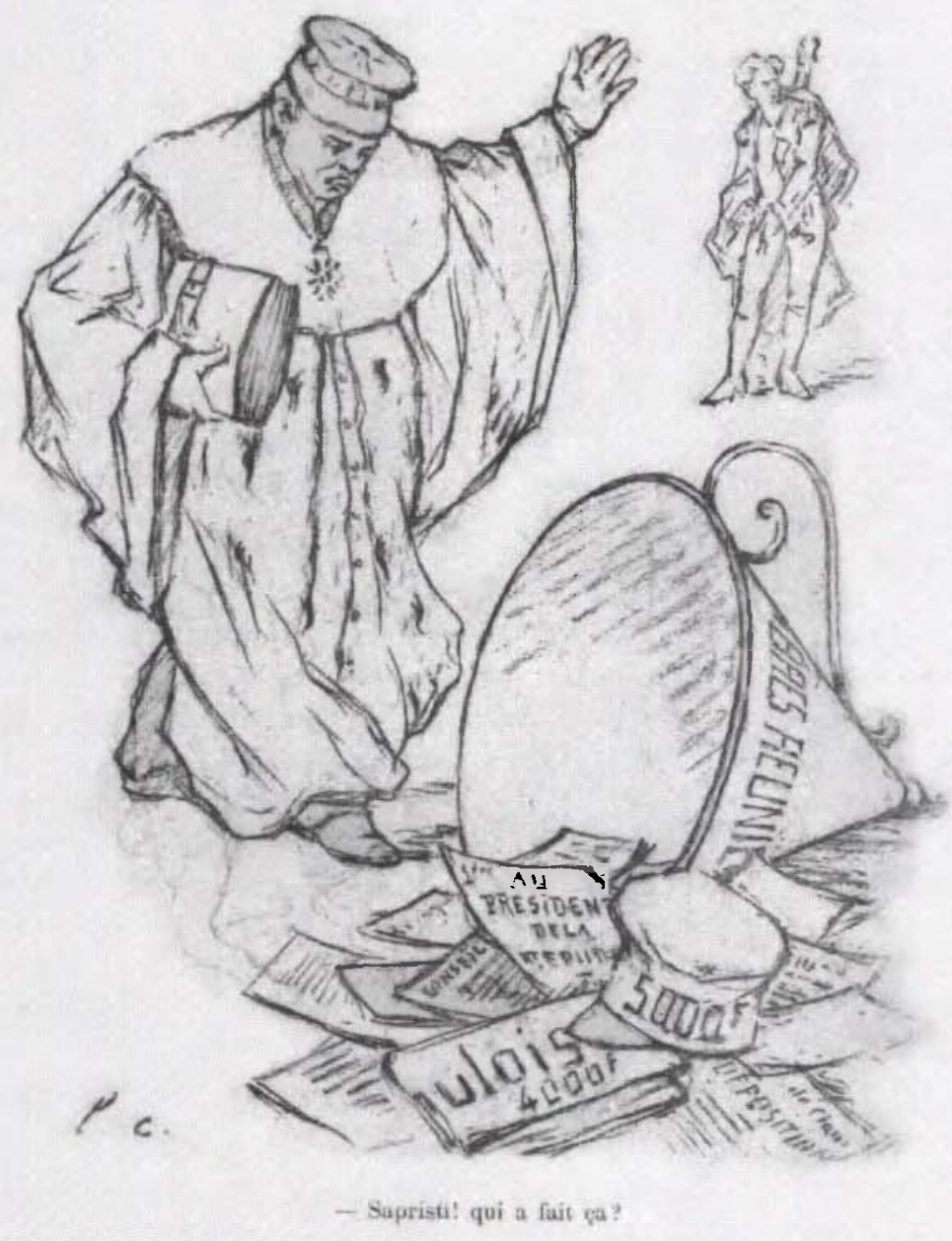

Abb. 75 Louis Chevalier: Une mauvaise farce. - Sapristi! qui a fait ça?, in: Le Sifflet, 7.4.1899. UB Frankfurt. 
machen durch dieses Requisit überdeutlich, daß von ihnen allein das Licht ausgeht, daß sie ergo im Besitz der Wahrheit sind, weil sie von Rechts wegen entscheiden, wessen Aussagen als wahr zu gelten haben, oder weil sie die Macht haben, die Wahrheit durch Verschleierung des Beweismaterials und falsche Aussagen zu manipulieren. Die Lampe ist, anders als das im Spiegel der Wahrheit sich reflektierende und verstärkende Licht, ein manipulierbares Instrument: Der Vorsitzende des conseil de guerre in Rennes hält die Petroleumlampen mit den Aufschriften Justice bzw. Vérité als Lumière éblouissante wie Monstranzen in beiden Händen, während seinen Kopf eine Straßenlaterne ziert ${ }^{133}$. Alles, was dieses Licht erhellt, sind aber längst widerlegte Beweise und Vorurteile, wie Merciers bordereau oder Rocheforts Theorie vom syndicat.

Die Petroleumlampe kann ausgeblasen werden, um die Tarnung perfekt zu machen, wenn die Offiziere sich vor der vorübergehenden, in ihrem eigenen Licht erstrahlenden Lex im Gebüsch verstecken: »Pourvu qu'elle ne nous voie pas! ${ }^{134}$

Noch wenn die Mitglieder des État major als Schiffsbrüchige inmitten der gefälschten Dokumente auf einem Floß - Le Nouveau Radeau de la Méduse ${ }^{135}$ - auf Rettung hoffen, dient die Lampe als Mittel, um sich selbst - und nicht etwa die Wahrheit - ins rechte Licht zu setzen. Mit der Offenlegung der Wahrheit hat die Lampe schließlich ausgedient. Couturier stellt das Ende der Täuschungsmanöver als Schlußakt einer Theatervorstellung dar, mit einem sich verbeugenden Esterhazy. Die Petroleumlampe liegt, neben dem ihr gleichgestellten Symbol der Aktenmappe mit gefälschten Dokumenten, zerbrochen am Boden ${ }^{136}$. Die aufrührerische Symbolik, die der Petroleumlampe im Gefolge der Commune anhing ${ }^{137}$, scheint hier vergessen. Doch auch die brennende elektrische Lampe wird zum Symbol des rein materiellen Aufklärungsverständnisses, wenn Un ex-magistrat bien éclairé seiner Urteilsfindung am Schreibtisch mit Geld auf die Sprünge helfen läßt ${ }^{138}$. Die Lampe weist somit unterschwellig auf den Einfluß der Beleuchtungskultur auf die Seh- und Wahrnehmungsgewohnheiten hin. Die Möglichkeit, das schnell und leicht regulierbare Licht der Lampe, egal ob durch Elektrizität oder Petroleum erzeugt, zur zweckdienlichen Beleuchtung einzusetzen, beeinflußt entscheidend ihre Rolle als Bildsymbol: Die künstliche Beleuchtung ist hier nicht mehr

133 Édouard PÉpIn, Lumière éblouissante, in: Le Grelot, 30.7.1899. Der Bildtext lautet: "Allons, Messieurs, déballez tout, sortez vos preuves, et qu'on en finisse!..."

134 Ibels, Dura Lex, Sed Lex, in: Le Siècle, 29.5.1899 (vgl. Les Légendes du Siècle, Abb. 3).

135 IBELS, in: Le Sifflet, 21.4.1899. Ibels wiederholt dieses Motiv in der Karikatur La Mare aux faux in Les Légendes du Siècle, Abb.4: Noch während die überführten Fälscher im Moor versinken, wird das Lampenlicht trotzig emporgehalten.

136 Couturier, Et maintenant... rideau!, in: Le Sifflet, 5. 5.1899.

137 Vgl. dazu Kap. 5.4.

138 Couturier, Un ex-magistrat bien éclairé, in: Le Sifflet, 13.3.1899. 
Hilfsmittel zur Erkenntnis und Unterstützung des Tageslichts wie bei der oben erwähnten personifizierten Justitia mit der Öllampe, sondern vielmehr zutiefst korrumpierbar. Neben dem im Rahmen der Dreyfusaffäre neu aufgelegten Kampf der Sehenden und Erkennenden mit der >dunklen $<$ Gegenseite bildet sich im Hinblick auf den Einfluß der modernen Massen-, Medien- und damit auch Sehkultur eine weitere Problematik heraus - nämlich die Gefahr der absoluten Relativierung von Erkenntnis und somit der Relativierung und Einschränkung der Existenz einer Wahrheit überhaupt. Das Versagen der unvoreingenommenen Urteilskraft verweist im besonderen Maße für den stark technisierten, industrialisierten Blick, der sich jeder ethischen Verantwortung zur Erkenntnis entzieht. Im Gegenzug ist die Suche nach der reinen Wahrheit und der absoluten Erkenntnis eng verbunden mit der Sehnsucht nach einer Wiedereinsetzung des Sehens in den Erkenntniskontext der lumières. Im Spannungsfeld dieser beiden Komponenten tritt eine Problematik in den Vordergrund, die das Sehen als autonome Instanz in Frage stellt. Ein Blick auf die Geschichte des Sehens im 19. Jahrhundert soll diesen Konflikt veranschaulichen: Während noch in den Sehtheorien des 17. und 18. Jahrhunderts der Tastsinn ein unabdingbares Zwischenglied für die Veranschaulichung der Erkenntnis bildete ${ }^{139}$, änderte sich dies im 19. Jahrhundert von Grund auf. Eine strikte »Trennung der Sinne « ${ }^{140}$ verabsolutierte und isolierte nun das Sehen:

139 Bexte, Blendung, bes. S.138-155; Crary, Techniken, S.30. Vgl. René Descartes, La Dioptrique, in: Ders., CEuvres philosophiques, Bd. 1 (1618-1637), Paris 1988, VI, S.134: "Pour la situation, c'est-à-dire le côté vers lequel est posée chaque partie de l'objet au respect de notre corps, nous ne l'apercevons pas autrement par l'entremise de nos yeux que par celle de nos mains«. Das Beispiel des auf seinen Tastsinn angewiesenen Blinden, dessen sich Descartes in diesem Zusammenhang bedient, verdeutlicht den virulenten Unterschied zwischen Sehen und Erkennen. Auch Diderot bezieht sich in seiner Abhandlung über die Blinden und ihre Art der Weltaneignung direkt auf Descartes: Vgl. Denis Dideror, Lettre sur les aveugles à l'usage de ceux qui voient, Genf, Paris 1970, S.6: "Ouvrez la Dioptrique de Descartes, et vous y verrez les phénomènes de la vue rapportés à ceux du toucher, et des planches d'optique pleines de figures d'hommes occupés à voir avec des bâtons. Descartes et tous ceux qui sont venus depuis n'ont pu nous donner d'idées plus nettes de la vision «. Zur Präsenz des Blinden in philosophischen Sehtheorien vgl. Bexte, Blendung, S.47: »Wo immer vom Sehen die Rede ist, da ist ein Blinder nicht fern «. Auch der Artikel Vue in der Encyclopédie verweist noch explizit auf die integrale Bedeutung des Tastsinns für die Erkenntnis. Vgl. Encyclopédie ou Dictionnaire raisonné des sciences, des arts et des métiers, par une société de gens de lettres. Mis en ordre et publié par M. Dideror; \& quant à la partie mathématique, par M. D'AlemberT. Nouvelle édition, 39 Bde., Genf 1777-1780, Bd. 17, Paris 1765, S.567: "Avec le seul sens le la vue, nous nous tromperions également sur les distances; $\&$ sans le toucher, tous les objets nous paroîtroient être dans nos yeux, parce que les images de ces objets y sont en effet; ce n'est qu'après avoir mesuré la distance en étendant la main, ou en transportant son corps d'un lieu à l'autre, que l'homme acquiert l'idée de la distance \& de la grandeur des objets «. Allgemein zu dieser Problematik vgl. Nathalie Binczek, Kontakt: Der Tastsinn in Texten der Aufklärung, Tübingen 2006, sowie Thomas KleinsPEHN, Der flüchtige Blick. Sehen und Identität in der Kultur der Neuzeit, Reinbek 1989.

140 Crary, Techniken, S. 30. 
Daß das Sehen nicht mehr analog zum Tasten begriffen wurde, bedeutete auch die Loslösung des Auges aus dem Netzwerk der Referentialität, die in der Greifbarkeit und ihrer subjektiven Beziehung zum wahrgenommenen Raum verkörpert war. Diese Autonomisierung des Sehens, die sich auf vielen verschiedenen Gebieten vollzog, war eine historische Bedingung für die Umstrukturierung des Betrachters, der für den Konsum von sSpektakeln` ausgerüstet sein sollte. Die empirische Isolierung des Sehens ermöglicht nicht nur dessen Qualifizierung und Homogenisierung, sondern brachte es auch mit sich, daß die neuen Objekte des Sehens (seien es nun Waren, Fotografien oder der Akt der Wahrnehmung selbst) eine mysteriöse und abstrakte Identität annahmen, die keine Beziehung zur Position des Betrachters auf einem einheitlichen Erkenntnisfeld mehr hatte ${ }^{141}$.

Das Ideal des mythischen ersten Blicks der Erkenntnis verschwand hinter der Realität dieses rein passiven und konsumierenden Sehens. Walter Benjamin beschreibt in seinem Passagenwerk ${ }^{142}$ den Flaneur in Paris, »der Hauptstadt des 19. Jahrhunderts ${ }^{143}$, als den Prototyp des modernen Sehenden. Sein zielloser Weg führt durch die mit visuellen Reizen überflutete Welt der Geschäftsstraßen und vor allem der Passagen, seit der Julimonarchie die Wiegen der verführerisch präsentierten Warenwelt einer allein auf Konsum und Genuß ausgerichteten Kunden- und Käuferkultur und Vorläufer der grands magasins. Die einander ständig überlagernden optischen Eindrücke und die Kurzlebigkeit von Wirklichkeitskonstellationen schließen ein kontemplatives Sehen von vorneherein aus. Deutlich setzt Benjamin den Flaneur vom »philosophischen Spaziergänger« $\mathrm{ab}^{144}$. Er unternimmt seine Streifzüge nicht mehr zu dem Zweck, um aus dem dabei Erlebten Mutmaßungen über das Leben anzustellen, sondern wird zum passiven Konsumenten der Wirklichkeit, die für ihn vor allem eine Welt der Bilder zu sein scheint. Die abwartende Haltung dieser ichbezogenen Wirklichkeitskonstruktion - die nach Benjamin »eigentümliche Unschlüssigkeit des Flanierenden ${ }^{145}$ - beobachtet nicht Menschen, sondern den Markt ${ }^{146}$. Das Sehen wird damit entpersonalisiert und infolgedessen entpolitisiert. ${ }^{147}$

141 Ibid.

142 Walter Benjamin, Das Passagenwerk, in: DeRs., Gesammelte Schriften, hg. v. Rolf TiedeMANN, Hermann SCHWEPPENHÄUSER, 10 Bde., Frankfurt a. M. 1972-1985, Bd. 5.1 und 5.2 (1982). 143 Benjamins berühmter Essay enthält zugleich das Programm des geplanten Passagenwerks.

144 Benjamin, Das Passagenwerk, Bd.5.1, S. 526: [M 1, 6] „Entfernung des Flaneurs vom >philosophischen Spaziergänger<, nimmt »die Züge eines unstet in einer sozialen Wildnis schweifenden Werwolfs « an. Eng damit zusammen hängt das Problem der Aufmerksamkeit im späten 19. Jahrhundert. Vgl. dazu Crary, Aufmerksamkeit, S. 28: »Im letzten Viertel des 19. Jahrhunderts machte sich das spezifisch moderne Problem der Aufmerksamkeit vielerorts bemerkbar. Innerhalb der in den Geistes- und Humanwissenschaften stattfindenden Diskurse und Verfahren wurde die Aufmerksamkeit in weitem Umfang zum Bestandteil eines dichten Netzwerks von Texten und Techniken, um die herum die Wahrheit der Wahrnehmung organisiert und strukturiert wurde. Es waren die neuen Imperative der Aufmerksamkeit, durch die der wahrnehmende Körper - sei es als Gelehrter, als Arbeiter oder als Konsument - entwickelt, produktiv und berechenbar gemacht wurde«.

145 Benjamin, Das Passagenwerk, Bd.5.1, S. 535-536 [M 4a 1].

146 Ibid., S. 537f. [M 5, 6]: »Der Flaneur ist der Beobachter des Marktes. Sein Wissen steht der Geheimwissenschaft von der Konjunktur nahe. Er ist der in das Reich des Konsumenten ausgeschickte Kundschafter des Kapitalismus«. 
Für das moderne Sehen als auf den Kosmos der Großstadt ausgerichtete Wahrnehmungsstrategie ergeben sich aus dem Schema des Flaneurs folgende Ableitungen: Der konsumierende Betrachter läßt sich passiv im optischen Raum treiben, ohne sich über das Gesehene ein Urteil zu bilden. Diese aus der Unterhaltungskultur übernommene Vorgehensweise überträgt er auf sein Verhältnis zur Wirklichkeit und wandelt diese ebenfalls in einen fiktiven visuellen Erlebnisraum um. Daraus erwachsen Probleme für die Rezeption der medial rekonstruierten Wirklichkeit:

Der oft kaum wahrnehmbare Schritt vom fiktiven zum dokumentarischen Bildmedium und die von dieser Unbestimmbarkeit geprägte Rezeption ${ }^{148}$ hinterließen dabei zwangsläufig ihre Spuren, ebenso wie die Pluralität der

147 Mithin wird die unpolitische Passivität des Flaneurs zur »Abbreviatur für die politische Haltung der mittleren Klassen unter dem zweiten Kaiserreich«. Ibid., S. 529 [M 2, 5]. 148 Besonders das Medium der Fotografie, das ein Wirklichkeitsausschnitt zu sein vorgab, erwies sich in diesem Sinne als problematisch, da die Prozesse der fotomedialen Inszenierung noch nicht verinnerlicht waren. Vgl. dazu Bodo von DewITz, Roland Scorrı $(\mathrm{Hg}$.), Alles Wahrheit! Alles Lüge! Photographie und Wirklichkeit im 19. Jahrhundert. Die Sammlung Robert Lebeck, Ausstellungskatalog, Köln 1996, darin besonders: Roland Scortı, »Denn sie sind nicht wahr, obwohl sie den Schein der Wahrheit tragen«, S. 15: »In gewisser Weise wurde die Photographie zum (fast zu spät erfundenen Werkzeug) des siècle des lumières: Da sie (anscheinend) ausschließlich das Vorhandene, das Sichtbare abbildete, eignete sie sich hervorragend, um das Wahre vom Falschen, das Rationale vom Irrationalen zu trennen«. Vgl. Hubertus v. Amelunxen, Die Domestizierung des Lichts. Ein Essay, in: Fotogeschichte 9 (1989), S. 19-25. Amelunxen spricht in seinen Überlegungen zum Verhältnis von Fotographie und individueller Macht zu Recht von einer »Domestizierung des Lichts«. Zur Rolle der Fotografie in der Dreyfusaffäre vgl. ENGlish, Political uses, S. 177-213, der die Affäre als grundlegend sieht für »truly modern propaganda techniques. [...] And from this perspective the years of the Dreyfus Affair mark a significant milestone in the development of photography in French politics that will serve as a model for all in the new century «. Ibid., S. 177f. Auch das um 1900 bereits im Verschwinden begriffene Medium des Panoramas, das während des 19. Jahrhunderts die Emanzipation des Betrachters entscheidend beeinflußt hatte, spielt hierbei eine Rolle. Man könnte sagen, daß Panorama und Flaneur sich, für das Medium auf fatale Weise, gegenseitig hervorgebracht haben. Das nicht auf einen Blick zu erfassende Bild forderte einerseits die Entwicklung des vorbeispazierenden Betrachters geradezu heraus. In dem Moment, da die Aufmerksamkeit aber nicht mehr der Gesamtaussage des Panoramagemäldes, und damit nicht mehr der schrittweisen Entdeckung eines bestimmten Themas galt, sondern nur noch den Einzeleindrücken, mußten Betrachter und Panorama sich zwangsläufig voneinander entfremden. Im Zusammenhang mit dem Erkenntnisproblem im Rahmen der Dreyfusaffäre ist es sehr aufschlußreich, daß auf der Weltausstellung von 1900 eines der wenigen Panoramen in traditioneller $>$ Reinform $`$, ohne illusionistische Zufügungen, das Panorama des Prozesses von Rennes war, das die Möglichkeit bot, dieses auf diese Weise gleichsam historisierte Ereignis - respektive seine idealisierte Reproduktion - abzuschreiten, ohne sich involviert oder zur Stellungnahme verpflichtet zu fühlen. (Zum Dreyfuspanorama vgl. kurz Anne-Claude AmbroISE-Rendu, L'Exposition universelle de 1900. Gloires et ambiguiités d'une célébration fin de siècle, in: Gervereau, Prochasson [Hg.], L'affaire Dreyfus, S.229. Zu den hybriden Formen des Panoramas auf der Weltausstellung von 1900 vgl. Kap.7.1.2., zur Weiterentwicklung des panoramatischen Sehgedankens vgl. Kap. 9.3.) 
Meinungen und Auslegungen innerhalb der modernen Massenkultur. Die berühmte Graphik L'Âge du papier ${ }^{149}$ von Félix Vallotton thematisiert die Situation des einzelnen als Teil eines sich herausbildenden Meinungsspektrums, das neben den realen Ereignissen ein völlig autonomes Lager bildet. Die wie ein willkürlicher Ausschnitt angelegte Komposition zeigt die Besucher eines Cafés bei der Lektüre verschiedener Zeitungen, darunter L'Aurore mit Zolas Artikel »J'Accuse«. Der Titel L'Âge du papier verweist dabei explizit auf den epochenprägenden Charakter der Presse - nicht nur als Institution, sondern auch als fragiles Gebilde ständig im Wechsel begriffener Meinungen, die sich in der Praxis miteinander vermischen und so weiter fortschreiben.

Diese Techniken und Erfahrungen unterstützen einen Proze $\beta$, den Foucault als »une volonté de vérité au XIX ${ }^{\mathrm{e}}$ siècle« bezeichnet ${ }^{150}$. Vor diesem Hintergrund aber stellt sich die Forderung nach der Wahrheit auch als die kollektive Suche nach der prämedialen Gestalt der Dinge dar, nach dem Kern - der nackten Wahrheit. Nicht zufällig war die Allegorie der Nuda Veritas um die Wende zum 20. Jahrhundert allgemein in der bildenden Kunst sehr verbreitet: »L'iconographie générale de la Vérité a connu à cette époque une vogue nouvelle, qu'explique une réflexion passionnée, voire angoissée, sur la quintessence du monde ${ }^{151}$. Gerade ihre vielfältigen Variationen im Umkreis der Dreyfusaffäre weisen jedoch ein Detail auf, das dem Bedürfnis nach einer Erkenntnis entspringt, die sich mit dem visuellen Anschein der Wahrheit nicht mehr zufrieden gibt: Wer nämlich der Wahrheit eigenhändig dabei hilft, den Brunnen zu verlassen, der verfügt mit der Wiedereinsetzung des Tastsinns über eine Gewißheit, die dem rein visuellen Erfassen der äußeren Umrisse, dem bloßen Blick, weit überlegen ist.

${ }^{149}$ Le Cri de Paris, 23.1.1898. Abgebildet bei Kleeblatt, The Dreyfus Affair, S.89, Abb.46, Kat.218. Allg. dazu Alain Deligne, L'Affaire dans la rue: commentaire d'une estampe de Vallotton, in: Ridiculosa 1 (1994), S. 44-51.

150 Michel Foucault, L'ordre du discours, Paris 1971, S.18. Diese volonté de vérité setzt Foucault ab von der volonté de savoir des âge classique. Dieser Paradigmenwechsel geht Hand in Hand mit der raschen Entwicklung der modernen Informationsgesellschaft: "Cette volonté de vérité [...] s'appuie sur un support institutionnel: elle est à la fois renforcée et reconduite par toute une épaisseur de pratiques comme la pédagogie, bien sûr, comme le système de livres, de l'édition, des bibliothèques [...]. Mais elle est reconduite aussi plus profondément sans doute par la manière dont le savoir est mis en œuvre dans une société, dont il est valorisé, distribué, réparti et en quelque sorte attribué«. Ibid., S.19f.

151 Markéta Theinhardi, Pierre Brullé, Kupka et la presse illustrée: >Des idées sérieuses sous une forme piquanter, in: Vers des temps nouveaux, S.64. Als Beispiel wäre etwa Gustav Klimts Nuda Veritas (1899) zu nennen. (Wien, Österreichische Nationalbibliothek.) Auch die vielfach variierten Allegorien der Elektrizität schöpfen ganz unverkennbar aus der Bildtradition der nackten Wahrheit. Als Trägerin eines gleichsam mythischen, aus sich selbst heraus leuchtenden Lichtes erscheint sie auch als Garantin einer aus sich selbst heraus gerechtfertigten Wahrheit, die ins Absolute strebt. Allg. zu diesem Bildtypus Kaenel, Affiche; Jan Garnert, Seize the Day. Ethnological Perspectives on Light and Darkness, in: Ethnologia Scandinavica, 1994, S.38-59; OsIETZKI, Weiblichkeitsallegorien. 
Damit vollzieht sich ein paradigmatischer Rückgriff auf das Erkenntnismodell der lumières. Die durch die Berührung symbolisierte Eigeninitiative steht dabei auch für weitreichende Konsequenzen, die ein emanzipiertes Individuum aus dem Erkenntnisprozeß abzuleiten vermag. Die reine, nackte Wahrheit ist immer eine Projektionsfläche der Meinungen und ein Exerzierfeld der persönlichen Erkenntnisfähigkeit. Ihre Nacktheit wird dabei zum Ärgernis für die, deren industrialisierter, passiver Blick plötzlich auf einen Widerstand stößt.

Dies thematisiert das Blatt La Vérité au conseil de guerre ${ }^{152}$, das Maximilien Luce 1898 für das Album des Temps nouveaux schuf. Die nackte Wahrheit, hinter der das Licht durch die offene Tür in den dunklen Saal strömt, löst beim Vorsitzenden nichts anderes als eine abwehrende Schutzreaktion aus, indem er seine Zuständigkeit schlichtweg leugnet: »Nom de Dieu!! Allez vous habiller, c'est pas ici le conseil de révision?? «

František Kupka greift dies erneut auf in einer am 25. November 1905 in der anarchistischen Zeitschrift Les Temps nouveaux veröffentlichten Zeichnung ${ }^{153}$. Inmitten eines belebten Platzes hat sich die nackte Wahrheit wie selbstverständlich unter die Flaneure gemischt, die allerdings längst vor der Gestalt zurückgewichen sind. Die Reaktionen spannen sich vom Entsetzen eines Priesters und dem Versuch einer Nonne, einem Kind im Kommunionkleid die Augen zuzuhalten, bis zum Neid der Frauen und der gespannten Erregung der Männer. Ein von hinten heranstürmender Gendarm schließlich streckt seine klauenartige Hand bereits nach der zarten Gestalt aus und wirkt durch seine schwarze Erscheinung als direkter Gegenpol zur lichten Wahrheit. Ablehnung der Wahrheit oder der Wunsch, sie zu erobern und zu instrumentalisieren, schließlich der Versuch, sie zu unterdrücken: All dies setzt sich deutlich ab von der Allianz, die sich im Akt des Heraufholens aus dem Brunnen herausbildet. Die Verbreitung ihres Lichtes geschieht allein durch ihre Anwesenheit, denn den Spiegel trägt sie nachlässig in den hinten gefalteten Händen. Ihr Schicksal bleibt aber im ungewissen: Von neuem sieht sie sich dem verhängnisvollen Kreislauf von Unfähigkeit und Unwillen zur Erkenntnis und Nachstellung ausgeliefert. Der mythische erste Blick findet nicht statt, das langsame Sich-Herantasten an die Wahrheit ist nicht möglich. Die bürgerliche Gesellschaft hat an diesen Erfahrungen kein Interesse. Doch vor allem die Republik sollte sich von dem Vorwurf, die Wahrheit zu unterdrücken und zu instrumentalisieren, nur noch schwer befreien können.

152 Blatt No.12 des Album des Temps nouveaux. Vgl. Kap.9.3. Vgl. Aline Dardel, Les Temps nouveaux 1895-1914. Un hebdomadaire anarchiste et la propagande par l'image, Paris 1987, S.53, Kat. 70. Vgl. auch Kleeblatt, The Dreyfus Affair, S.93, Abb.54, Kat. 53. 153 Zu diesem Blatt vgl. Theinhardt, Brullé, Kupka, S. 64f. (mit Abbildung). 


\section{3. »Les éteignoirs de la pensée« Der Verrat des bürgerlichen Lagers am Licht der Freiheit}

Die in hohem Maße katalysatorische Wirkung der Dreyfusaffäre hatte verschiedene politische und gesellschaftliche Prozesse zur Folge, die schon zuvor längst im Entstehen begriffen waren, durch die extrem aufgeheizte Stimmung besonders der Jahre 1898 und 1899 aber entscheidend beschleunigt wurden. Rechte und linke Gruppen wurden in ihren jeweiligen Vorbehalten bestärkt. Das Schema antidreyfusard - dreyfusard, so wenig es auch auf die komplizierte politische Konstellation der Republik übertragbar sein mochte, schien doch die zwei Hauptströmungen innerhalb der Gesellschaft widerzuspiegeln:

Basically the Affair added nothing new to French politics - it merely revealed with disturbing clarity the division that still existed between those on one hand who accepted Republican hopes for a humanity emancipated from sirrationak beliefs and prejudices, and those on the other hand who felt that Republican policies ran counter to all that was great and good in the French tradition ${ }^{154}$.

Der tiefgreifende Vertrauensverlust in die Republik umfaßte ihre tragenden Säulen, seien es Erziehungswesen ${ }^{155}$, Militär oder Justiz. Diese fanden sich in der dem Sozialismus nahestehenden Bildpublizistik in der Rolle wieder, die in der republikanischen Tradition den Vertretern der Kirche vorbehalten gewesen war. Die Instanzen der Republik schienen sich in einer immensen Verschwörung der Macht gegen die Masse des Volkes zusammengefunden zu haben. Schon die 1893-1895 erschienene Zeitschrift Le Chambard socialiste reflektierte besonders in den sozialkritischen Bildbeiträgen von Théophile Alexandre Steinlen gesellschaftliche Unterdrückungsmechanismen, doch erst in den Jahren nach der Dreyfusaffäre entwickelte sich eine weitverbreitete sozialkritische Bildsprache, die ihre Anklage zielgerichtet gegen die Instanzen der Republik richtete. Die Herausbildung und Modifikation einiger Schlüsselmotive vollzog sich dabei im direkten zeitlichen und thematischen Umkreis der Affäre, deren obskure Ursachen ihre Schatten auf Gegenwart und Zukunft gleichermaßen zu werfen schienen. Die Republik selbst wurde zunehmend zur Feindin der Freiheit, was sich in der allmählichen Verselbständigung der $\mathrm{Li}$ berté als Allegorie bemerkbar macht. Dabei schien dieses Empfinden gleich stark ausgeprägt bei Künstlern, die zum Lager der dreyfusards gehörten, wie auch bei einigen antidreyfusards - darunter etwa Willette und Forain - und solchen wie Grandjouan, die eine Klassenbindung jeglichem Engagement vorgezogen hatten. Viele Künstler des sozialistischen Lagers betrachteten den Fall

154 LARKIN, Church and State, S. 63.

155 Zur Kritik an der Schule nach der Dreyfusaffäre vgl. Michel Winock, La Belle Époque. La France de 1900 à 1914, Paris 2003, S.306: »L'affaire Dreyfus et la poussée du socialisme ont diffusé une critique de l'État et de la fonction idéologique de l'école prêchant aux pauvres la résignation autour des valeurs telles que l'épargne, l'obéissance, la soumission «. 
nach wie vor als rein bürgerliches Problem. Auch das geläufige Klischee vom jüdischen Kapitalisten blieb dabei weitgehend konstant ${ }^{156}$.

Auf dem Terrain sozialer Mißstände trafen sich engagierte Künstler wieder, deren libertär-anarchistische und syndikalistische Überzeugungen ein starkes Band darstellten. Die bedrängte Republik wurde, auch jenseits der Affäre, zum extrem aufgeladenen Symbol für eine dem peuple versagte politische Mitwirkung.

Ibels zeigte in den Légendes für die Zeitung Le Siècle am 26. Juni 1899 das Bild La Semeuse ${ }^{157}$. Beim Aussäen wird die allegorische Frauengestalt mit der phrygischen Mütze massiv von einem riesigen Schwarm schwarzer Vögel behindert und angegriffen: »Ils finiraient par me manger moi-même«. Der Ausgang des Kampfes wird im unklaren gelassen, über die Gefahr, in der sie schwebt, ist sich die Säerin jedoch durchaus im klaren. Ibels' Darstellung leitet sich von dem offiziellen Bild der Semeuse her, das der Künstler Roty im Jahr 1895 für die Silbermünzen geschaffen hatte und das seit der Weltausstellung von 1900 auch die am meisten verkauften Briefmarken zu 10 Centimes zierte, offiziell wie folgt beschrieben: »la République en marche, semeuse d'idées et soleil levant « ${ }^{158}$. Dieses Bild wurde in der Presse stark kritisiert: Als besonders unlogisch wurde empfunden, daß die Republik ihr Saatgut gegen den Wind ausstreut ${ }^{159}$. Tatsächlich wird der Semeuse dies nun zum Verhängnis: Denn in Ibels' Interpretation ist die ideale, unangreifbare Figur in der rauhen politischen Wirklichkeit angekommen. Allein auf weiter Flur, hat die semeuse d'idées offenbar keine effiziente Möglichkeit, um ihr Werk vor den gierigen Vögeln zu schützen.

In der anarchistischen Zeitschrift Le Libertaire wird dieses Motiv in entscheidender Weise abgewandelt. Das Blatt Les Corbeaux ${ }^{160}$ (Abb.76) von A. G. Wuyts indessen nennt schon im Titel die Gefahr beim Namen - nämlich den traditionell als Raben dargestellten Klerus ${ }^{161}$. Hier aber ist die Frau mit

156 Dazu ausführlich Wilson, Ideology, S. 319-378: „Social antisemitism: A Kind of Socialism«. Die Auswirkungen der Affäre auf stereotype antisemitische Gestaltungsweisen bei Künstlern, die für Dreyfus eintraten, waren unterschiedlich. Steinlen, der zu Beginn der 1890er Jahre in Le Chambard socialiste dem Kapitalisten, Grundherren und Fabrikbesitzer durchweg negativiert jüdische Züge verlieh, distanzierte sich davon nach der Affäre. Auch Hermann-Paul, der besonders als Verteidiger von Picquart hervortrat, bediente sich bis 1896 in seinen Illustrationen durchaus negativierender jüdischer Stereotypen. Vgl. dazu Cate, The Paris Cry, S. $72 \mathrm{f}$.

157 Vgl. Les Légendes du Siècle, 1900, Abb. 7.

158 Agulhon, Marianne au pouvoir, S. 27-29.

159 Ibid., S. 30. Ibid. zum Erfolg des Bildes: "Le fait est que chicanes et sarcasmes n'ont pas tenu devant les qualités simples qui ont dû faire le succès: un parti iconographique original, une silhouette gracieuse et souple, une lisibilité parfaite enfin: soleil, semailles, chacun comprend - contraste facile avec tant de vignettes concurrentes où il fallait déchiffrer des attributs entassés«.

160 Veröffentlicht in der Ausgabe 3.9.-9.9.1899.

$161 \mathrm{Vgl}$. dazu Kap.6.3. 


\section{LES CORBEAUX}

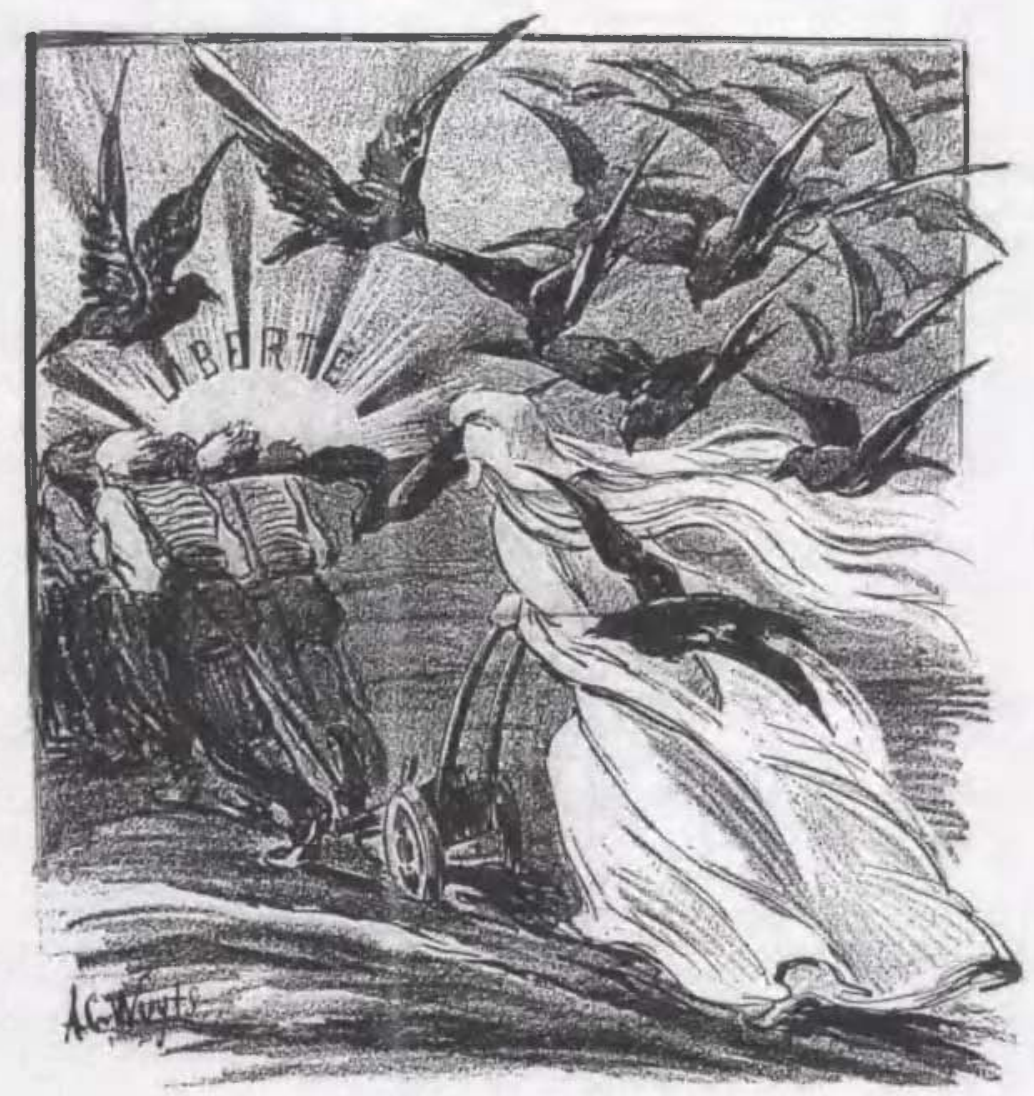

Eule mnxohe tout de nabme.

Abb. 76 A. G. Wuyts: Les Corbeaux. Elle marche tout de meme, in: Le Libertaire, 3.9.-9. 9. 1899. BDIC, Paris. 
der phrygischen Mütze nicht allein: Der Pflug, mit dem sie das Feld bestellt, wird von einer Gruppe von Arbeitern gezogen, während am Horizont die weithin strahlende Sonne der Liberté aufgeht und den unaufhaltsamen Fortschrittsprozeß erhellt: »Elle marche tout de même «. Fast scheint es, als hätte die Semeuse aus der Lage, in die Ibels sie versetzt hat, ihre Lehren gezogen. Die in der offiziellen Version fast schwerelose Gestalt wird zu einer bodenständigen Landarbeiterin, die ihre Saat in soliden Furchen ausbringen und so vor den Raben schützen wird. Ihr Weg zum Licht, der sie einer (anarchistischen) Freiheitssonne entgegenführt, ist nicht der propagierte Weg der Republik in Richtung eines technisierten Fortschritts. Vielmehr führt diese Szenerie zurück zu den Wurzeln. Das bäuerliche Milieu der Semeuse zeigt sich in seiner Ursprünglichkeit als ein gnadenloser, unromantischer Zustand, in dem es um die Früchte der Arbeit zu kämpfen gilt - zugleich aber als Neuanfang jenseits alter Strukturen. Diese Verpflanzung der Freiheitsidee in ein primitives Umfeld steht in direktem Zusammenhang mit den milieux libres, den ländlichen Kolonien, die nach der Periode der anarchistischen Attentate als Gegenentwürfe zur verhaßten bürgerlichen Gesellschaft ihre Blütezeit erlebten. Eine radikale Abkehr von zivilisatorischen Errungenschaften sollte auch alle moralischen Übel überwinden helfen, die allein der modernen, profitgierigen Gesellschaft angelastet wurden ${ }^{162}$.

Das Motiv der Raben als Räuber des Saatguts ist auch Thema einer Lithographie von Jules Hénault mit dem Titel $A h$, les sales corbeaux! ${ }^{163}$. Das Blatt zeigt ein bäuerliches Paar, das aus der Entfernung einen am Horizont auftauchenden Zug von Priestern beobachtet, dem ein Rabenschwarm folgt. Fast scheint es, als würden die Raben sich in die schwarz gekleideten Geistlichen verwandeln, sobald sie den Boden berühren. Die Bedrohung für die Ernte ist präsent, ohne direkt thematisiert werden zu müssen. Das Bild der Semeuse wird durch eine vordergründig völlig realistische Szene ersetzt ${ }^{164}$. So soll verdeutlicht werden, daß es das Volk ist, die Schicht der hart arbeitenden Menschen, denen geschadet wird. Der vorher vieldeutige Angriff wird dadurch in den sozialen Bereich versetzt. Zweifellos erwies sich die Dreyfusaffäre auch für die séparation des Jahres 1907 als Katalysator, waren daran doch maßgeb-

$162 \mathrm{Zu}$ den milieux libres vgl. Jean Marron, Le mouvement anarchiste en France, Bd.1: Des origines à 1914, Paris 1975, S. 382-408. Zu den Verbindungen zwischen Naturismus und Lichtsymbolik vgl. Kap. 9.3.

${ }^{163}$ Dieses Blatt ist Teil einer Kollektion von Künstlerlithographien (30 Illustrationen sowie ein Frontispiz), die Jean Grave, Herausgeber der künstlerisch anspruchsvollen anarchistischen Zeitschrift Les Temps nouveaux, seit 1896 in Auftrag gab und zum Kauf anbot. Vollendet war die Serie erst 1903. Die vollständige Sammlung bildete das Album des Temps nouveaux. Vgl. Dardel, Les Temps nouveaux, S. 18-21, sowie: Dies., Les Temps nouveaux 1895-1914. Eine anarchistische Wochenzeitschrift, in: Paris. Belle Époque, Ausstellungskatalog, hg. v. d. Kulturstiftung Ruhr, Essen 1994, S. 91-94, Kat. 353-358. Bei Hénaults Beitrag handelt es sich um Blatt No. 15 des Album des Temps nouveaux, erhältlich seit dem 24.6.1899.

164 Zum vordergründigen Realismus in den Beiträgen für das Album vgl. Kap.4.2. 
lich Politiker beteiligt, die auch zur Aufklärung der Affäre beigetragen hatten. Für die linke Agitation aber war die Kirche in das System Republik integriert und nur eine weitere Schattierung des Unterdrückungsmechanismus der herrschenden Klassen. Es gilt also genau zu unterscheiden, ob eine bestimmte Allianz als Gefahr für die Republik verstanden wurde oder als Teil davon. Clemenceau etwa prägte 1898 das Begriffspaar le sabre et le goupillon, um verschwörerische Bande zwischen den beiden Institutionen Militär und Kirche auf der gemeinsamen Basis des Antisemitismus anzuprangern, die eine Gefahr für die republikanische Freiheit darstellten ${ }^{165}$ : Der mittelalterliche Geist der Kirche, besiegt durch »l'esprit humain révolté«, habe seit dem Machtverlust im Zuge der Revolutionen sein ganzes Vertrauen in die Armee gelegt, um wieder an die Macht zu gelangen ${ }^{166}$. Im September 1899 griff die anonyme Illustration Le Fétiche $e^{167}$ in Le Libertaire das Thema auf: Ein auf einen Pfahl gespießter Totenkopf trägt militärische Abzeichen wie Schulterklappen und eine Offiziersmütze. Der Säbel und der Weihwasserwedel, unterhalb des Schädels ineinander gekreuzt, komplettieren das gespenstische Gebilde. Der >Fetisch $\measuredangle$ ist von einem hellen Lichtschein umgeben, der die Vereinigung der beiden Symbole und der dadurch symbolisierten Prinzipien die Aura des Überzeitlichen und Autonomen verleiht: Eine andere Sonne ist an dem mit schwarzen Vögeln bedeckten Himmel nicht zu entdecken. Die unter dem Totem auf Steinen lesbaren Jahreszahlen 1789, 1830, 1848 und 1871 erinnern an die vergeblichen Versuche, sich von diesem Joch zu befreien: "Quatre révolutions pour aboutir à ça!«

In der anarchistischen Sicht der Dinge also wurden Militär und Kirche durch die als gescheitert empfundenen Revolutionen nur gestärkt. Das Ergebnis ist die Republik im Zeichen ihrer vereinten Machtsymbole. Neben Krieg und Zerstörung verkörpert dieses System die brutal verteidigte Ignoranz. Eine unbetitelte Karikatur von A. G. Wuyts in Le Libertaire variiert zwei Monate später das Prometheus-Motiv: Gefesselt an den Felsen der Ignorance und bewacht von einem Adler, der in seinen Klauen den Säbel hält, erwartet ein bärtiger Mann seine Bestrafung durch schwarze Raben ${ }^{168}$. Der Anarchist als gescheiterter Lichtbringer ${ }^{169}$ wird zum Opfer dieser unheilvollen Allianz - und mit ihm auch das Volk, das er über die Mechanismen dieser Verbindung aufklären wollte. Das Prinzip der Freiheit ist mit diesem korrum-

165 Georges Clemenceau, Toujours le sabre et le goupillon. À M. le colonel Z. (= La Dépêche de Toulouse, 25.1.1898). Vgl. RÉmond, L'Anticléricalisme, S. 205.

166 „Chassée des admirations par la révolution laïque, expulsée du prétoire même qu'elle a, pendant des siècles, ensanglanté de ses horreurs, n'ayant, d'ailleurs, jamais compté pour son triomphe que sur la puissance de l'épée, elle a mis, depuis la Révolution, toute sa confiance en l'armée« (ibid.).

167 Veröffentlicht in der Ausgabe 17.9.-23.9.1899.

168 Ausgabe vom 31.12.1899-6.1.1900.

169 Zum Prometheusmotiv vgl. auch Kap.3.1.2. und 5.1. Zum Bild des Anarchisten als dem unsteten Wanderer, der so seine Botschaft verbreiten will, vgl. Kap. 9.3. 
pierten System absolut unvereinbar, der Bruch mit der so wahrgenommenen Republik unabwendbar.

Auf der anderen Seite aber steht immer noch die République sociale als Garantin der Rechte der Arbeiterschaft. Der ideelle Konflikt mit der offiziellen Republik trat etwa bei der Enthüllung von Jules Dalous ${ }^{170}$ Monument Le Triomphe de la République am 19. November 1899 offen zutage.

Die Einweihungsfeier auf der Place de la Nation geriet unversehens zu einer Gegendemonstration der Gewerkschaften, deren Mitglieder - anwesend waren zwischen 300000 und 500000 Menschen - stundenlang an dem Denkmal vorbeidefilierten und somit ihrer Republik huldigten ${ }^{171}$. Das Werk des ehemaligen Kommunarden und dreyfusards Jules Dalou (1838-1902) gilt gleichermaßen als »contributing to a cult of the Republic and a cult of workers ${ }^{172}$. Die barock anmutende Vielfigurigkeit des Werkes dient dazu, die Abhängigkeit der Republik von den Leistungen und Idealen des Volkes zu verdeutlichen: Die auf der Kugel der Fortuna schreitende Republikfigur mit der phrygischen Mütze wird auf einem Triumphwagen gezogen, vor den zwei Löwen gespannt sind. Auf diesen sitzt der Genius der Freiheit mit der Leuchtfackel, flankiert wird die Gruppe von den Allegorien Travail und Justice, während die Personifizierung der Paix das Schlußlicht des Zuges bildet $^{173}$. Am Tag nach der Enthüllung, dem 20 . November, veröffentlichte Le Siècle im Rahmen von Ibels' Légendes das Blatt Allégorie, auf dem die Figuren der monumentalen Gruppe sich gegen aggressive Angreifer zur Wehr setzen müssen. Der Vertreter des Julikönigtums (mit Birnenkrone und rifflard) traut sich zwar nicht an den Löwen vorbei, doch Ratapoil versucht, den Genius der Freiheit von hinten zu erstechen, während ein Vertreter des Militärs ihm die Fackel entreißen will. Auf der anderen Seite muß die Allegorie der Justice sich gegen einen Kleriker verteidigen, während der finstere Antisemit Édouard Drumont sich drohend der neben ihr stehenden Kinderfigur nähert. Allein die Republik selbst bleibt auf ihrer erhöhten Position vollkommen unberührt, was den auch im Bildtext angedeuteten Ausgang des Angriffs vorwegnimmt: »Le Triomphe de la République! (D’après Dalou et pour l'histoire.)«Der Vergleich der ein gesellschaftliches und soziales Fortschrittsmodell darstellenden Skulpturengruppe mit der Vérité en marche liegt nicht fern. Dabei zeigt sich, daß den traditionellen Republikfeinden - Monarchisten und Klerus - mit dem Militär und den Antisemiten nun neue Kräfte zur Seite gestellt werden, die eine vereinte Gegenwehr der republikanischen Seite erfordern. Ibels' Karikatur entstand wahrscheinlich Tage vor der Enthüllung,

170 Zu Dalou vgl. Hutron, Historical Dictionary, Bd. 1, S. 259-261.

171 Ibid.: Anläßlich der Einweihung verlieh Präsident Loubet Dalou das Kommandantenkreuz der Ehrenlegion, das dieser kurzerhand in seine Tasche steckte womit er seine Meinung über offizielle Ehrungen der Republik unmissverständlich zum Ausdruck brachte.

172 Ibid., S. 259.

173 Agulhon, Marianne au pouvoir, S. 77. 
so daß die Begleitumstände des Festaktes wohl kaum noch in die Ideengebung miteingeflossen sind ${ }^{174}$. Die Vision des Angriffs bezieht sich somit allein auf das Klima der Dreyfusaffäre, das als ein geschlossener Angriff auf die Republik dargestellt wird ${ }^{175}$. Eine Versöhnung zwischen radikaler Republik und Sozialisten hat dagegen nicht stattgefunden.

Die ideelle Republik, der die Gewerkschaften die Ehre erweisen, ist die Liberté, eine Kämpferin für die Rechte des Proletariats, die von ihrem Sockel heruntersteigt und den Demonstrationszug der Arbeiter zum Licht anführt ${ }^{176}$. In noch weitaus monumentalerer Gestalt, mit phrygischer Mütze und Lorbeerkranz und im hellen Lichtschein, stürmt sie in Steinlens Karikatur L'Avenir $^{177}$ das Parlament, um mit einem Besen für Ordnung zu sorgen: »LA GRANDE: Le bal est fini, les lampions éteints. Allons ouste! mes petites ordures, je viens faire les chambres«. Offensichtlich kann diese Gestalt sich mit diesen Repräsentanten nicht mehr identifizieren: Der Wille zur Freiheit hat sich in ihr bereits emanzipiert.

Das genau gegenteilige Bild einer schwachen, ganz von diesen Repräsentanten abhängigen Republik ohne Willen zur Freiheit zeigt dagegen Adolphe Willette nur ein Jahr später in L'Assiette au beurre ${ }^{178}$ : Die erleuchtende Funktion der Republik ist völlig verkümmert, als verschüchterte, unterdrückte Frau, die wie zum Hohn die rote Mütze mit der Kokarde trägt, leuchtet sie den unaufhaltsamen Vormarsch der typisierten, fürstlich honorierten Beamten - der eigentlichen Herren - mit einem Kerzenlicht aus: La République éclairant le monde des fonctionnaires. Die Abspaltung der Freiheit vom Bild der Republik ist direkt in Steinlens Karikatur Comme en quatre-vingt-treize ersichtlich, die am 15. Februar 1902 in L'Assiette au beurre erschien (Abb. 77) ${ }^{179}$. Die mit dem

174 Ibid., S. 77: Das genaue Aussehen des Werkes war seit langem bekannt, da schon anläßlich des Centenaire 1889 das Gipsmodell (im Maßstab 1:1) am späteren Standort der Bronzeausführung enthüllt worden war.

${ }^{175}$ Bei der erneuten Veröffentlichung des Blattes in Ibels' Album Les Légendes du Siècle sind die zum Denkmal gehörenden Figuren zur besseren Unterscheidbarkeit von den Angreifern dunkel eingefärbt.

176 Vgl. dazu Kap. 9.3.

177 L'Assiette au beurre No. 15, 11.7.1901 (= 44 Juillet). Vgl. LANGEMEYER, Bildwelten II, S. 120, Abb.193. Das Blatt wird zu Recht in Verbindung gebracht mit Honoré Daumiers berühmter Karikatur Le Dernier Conseil des ex-ministres (Le Charivari, 9.3.1848), das die Ankunft der lichtstrahlenden Freiheitsallegorie mit der roten Mütze im Kabinett zeigt (ibid., Abb.194).

178 No. 90, 20.12.1902 (= Le Singe).

179 L'Assiette au beurre No.46 (= La Vie facile). Ein ähnliches Motiv zeigt ein undatiertes Pastellbild von Steinlen mit dem Titel Poignardons Marianne, das sich im Musée du Petit Palais in Genf befindet: Im Schutz einer Mauer drückt ein Geistlicher einem bulligen Mann, den er offenbar als Mörder gedungen hat, ein Messer in die Hand, genau in dem Moment, als die von einem hellen Lichtschein umgebene Marianne vorbeikommt (vgl. Cate, Gill, Théophile Alexandre Steinlen, S.152, Kat.209; S.69, Abb.55). Auch für Le Chambard socialiste (24.3.1894) griff Steinlen die Thematik auf, wobei Marianne in der Gestalt eines jungen Mädchens auftritt, die in den Armen eines Arbeiters vor den in einer 


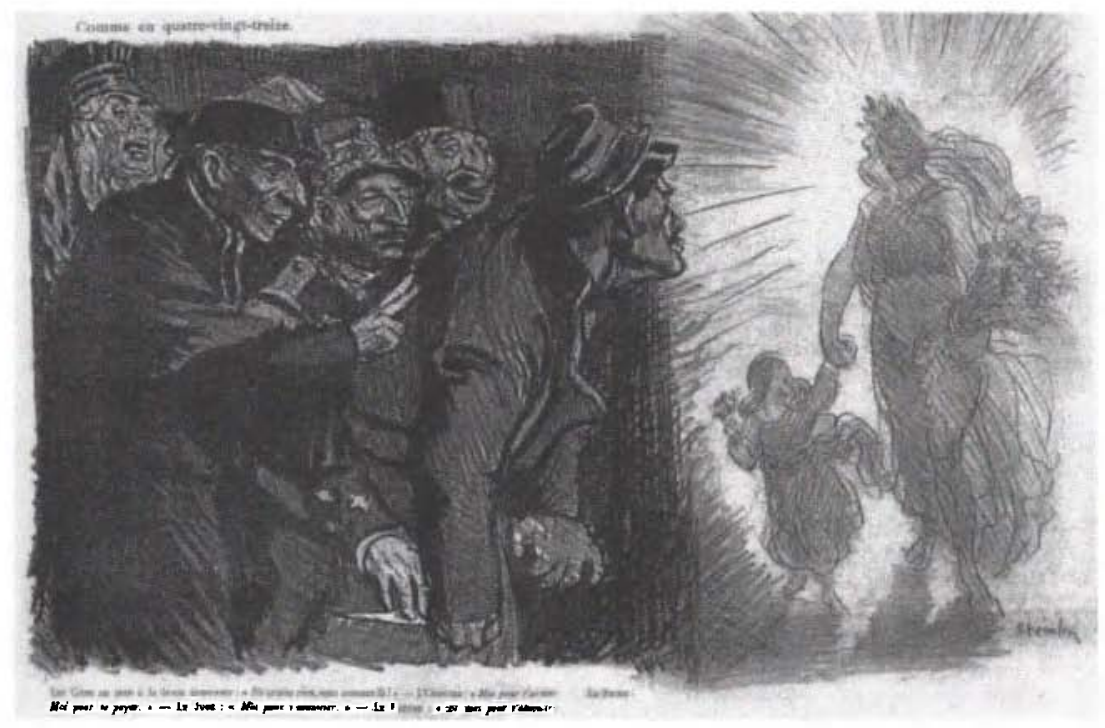

Abb. 77 Theophile Alexandre Steinlen: Comme en quatre-vingt-treize. LES GENS DE BIEN à la brute ignorante: "Ne crains rien, nous sommes là! - L'OFFICIER: "Moi pour t'armer." - LE RICHE: "Moi pour te payer. - LE JUGE: »Moi pour t'acquitter." - LE PRETRE: "Et moi pour t'absoudre.", in: L'Assiette au beurre, 15.2.1902. Sammlung D.K.

Lorbeerkranz bekrönte Freiheit führt mütterlich die kindliche Republik ${ }^{180}$, die vertrauensvoll zu ihr aufblickt. Der gleißend helle Lichtschein, der beide umgibt, steht im krassen Gegensatz zu der undurchdringlichen Finsternis, in deren Schutz hinter einer Mauer die gens de bien lauern:

LES GENS DE BIEN à la brute ignorante: Ne crains rien, nous sommes là! - L'OFFICIER: Moi pour t'armer. - Le RICHE: Moi pour te payer. - Le JUGE: Moi pour t'aquitter. - Le PRETRE: Et moi pour t'absoudre.

Zum gemeinsamen Anschlag versammelt haben sich also die Vertreter der vier Gruppen, die jede für sich bereits eine Bedrohung darstellen: Militaris-

finsteren Ecke lauernden Angreifern - drei Priestern und einem gedungenen Mörder sicher ist. Auf vergleichbare Weise kommentierte übrigens Lemot unter dem Pseudonym Uzes am 17.11.1883 in Le Chat noir die Politik von Jules Ferry: Dieser hat sich mit seinen Spießgesellen - La bande de Neuilly - im Schatten eines Hauses versteckt, um die vorbeikommende France zu überfallen. Diese erleuchtet mit ihrem Strahlen die Nacht und trägt eine Leuchtfackel in der hocherhobenen Hand.

180 Der Titel spielt auf den Ursprung der Republik in der Französischen Revolution an. Gemeint ist also dẽr Uršprung der Republik, fèrn der politischen Gegenwart. Die lauernde Gefahr stellt diesen idealen Zustand aber sofort in Frage. Deshalb gilt das Blatt zu Recht ăls pessimistischer Kommentar auf Daumiers triumphierende Liberte in der Karikatur Le Dernier Conseil des ex-ministres, deren Ankunft die korrupte Juliregierung hinwegfegt (Le Charivari, 9.3.1848). Vgl. dazu u. a. LANGEMEYER, Bilderwelten II, S.22f. 
mus, Kapitalismus, Justiz und Klerikalismus. Jeder der Repräsentanten ist entschlossen, die noch unerfahrene Republik auf seine Weise zu korrumpieren. Dazu aber - und das ist der Sinn des gemeinschaftlichen Hinterhaltes muß sie der Obhut der Freiheit entrissen werden. Auf einer zweiten Ebene aber symbolisiert das Kind, dessen Zukunft auf dem Spiel steht, auch das Volk, das auf seinem Weg von der versprochenen Freiheit in das Räderwerk der Machthabenden zu geraten droht. Jules Grandjouan zeigt dies ebenfalls für L'Assiette au beurre ${ }^{181}$ am traditionellen Beispiel des Scheidewegs (Abb.78). Eine sich gabelnde Straße führt rechts zur Kaserne, links zur Kirche. Ein Junge, der unter diesen zwei Möglichkeiten wählen soll, ist den , Überzeugungsversuchen einer verhärmten Nonne auf der einen Seite und der zur alten Vettel verkommenen Republik auf der anderen Seite ausgesetzt. Jede der beiden versucht, den Kleinen am Ohr gewaltsam zu sich zu ziehen:»Choisis... tu es libre...«

Die entartete, ihren Idealen untreu gewordene Republik unterscheidet sich in nichts mehr von der gierigen Kirche. Jede der beiden will das Kind, und mit ihm das Volk, zum Erhalt der eigenen Macht instrumentalisieren. Die Sonne der Freiheit aber, die am Horizont aufgeht, weist einen dritten Weg, an den beiden Institutionen vorbei, deren strenge Hierarchie durch die ansteigenden Straßen symbolisiert wird. Auf beiden Seiten säumen dazu rauchende Fabrikschlote den Weg und drohen den Himmel zu verdunkeln ${ }^{182}$ : Verlust der Freiheit und Ausbeutung sind auf dem Weg zur Kirche wie zur Kaserne vorprogrammiert. Brutale Repressionen von Seiten der staatlichen Institutionen versuchen darüber hinaus, jedes Element der Freiheit zu tilgen. Grandjouan widmet eine allein von ihm gestaltete Nummer der Assiette au beurre ${ }^{183}$ den éteignoirs de la pensée, der Justiz im Kampf gegen die pensée libre. Diese, dargestellt als nackte Frau in der Tradition der Wahrheit, versinnbildlicht keine bestimmte, sondern jedwede Denk- und Meinungsfreiheit. Auf dem Titelblatt der Ausgabe versuchen die wie zu einem schwarzen Ungetüm verschmolzenen Richter, die lichtstrahlende, blendendweiße Gestalt unter ihre Roben zu zerren und so den Blicken zu entziehen (Abb.79). Die Illustration La Pensée libre im Innenteil zeigt die Verurteilung der nackten, noch allen ungehindert zur Verfügung stehenden Denkfreiheit: "D'abord elle est indécente! Elle débauche la jeunesse. Étranglez-la! «184

181 L'Assiette au beurre No.155, 10.3.1904 (= La Liberté de l'enseignement). Zu diesem Blatt vgl. auch LANGEMEYER, Bilderwelten II, S.25 und S. 176, Kat.136 vgl. dort den Verweis auf ein 1898 von Thomas Theodor Heine für die Münchner Zeitschrift Simplicissimus geschaffenes Blatt mit dem Titel Die Lösung der sozialen Frage: Dort steht ein Proletarier am Scheideweg zwischen Fabrik und Gefängnis.

182 Zu diesem Motiv vgl. Kap. 9.3.

${ }_{183}$ L'Assiette au beurre No.244, 2.12.1905 (= Les Éteignoirs de la pensée).

184 Abgebildet in: Jules Grandjouan: créateur de l'affiche politique illustrée en France, S.121. Vgl. auch Gervereau, Prochasson (Hg.), L'affaire Dreyfus, S. 82, Abb.15. 


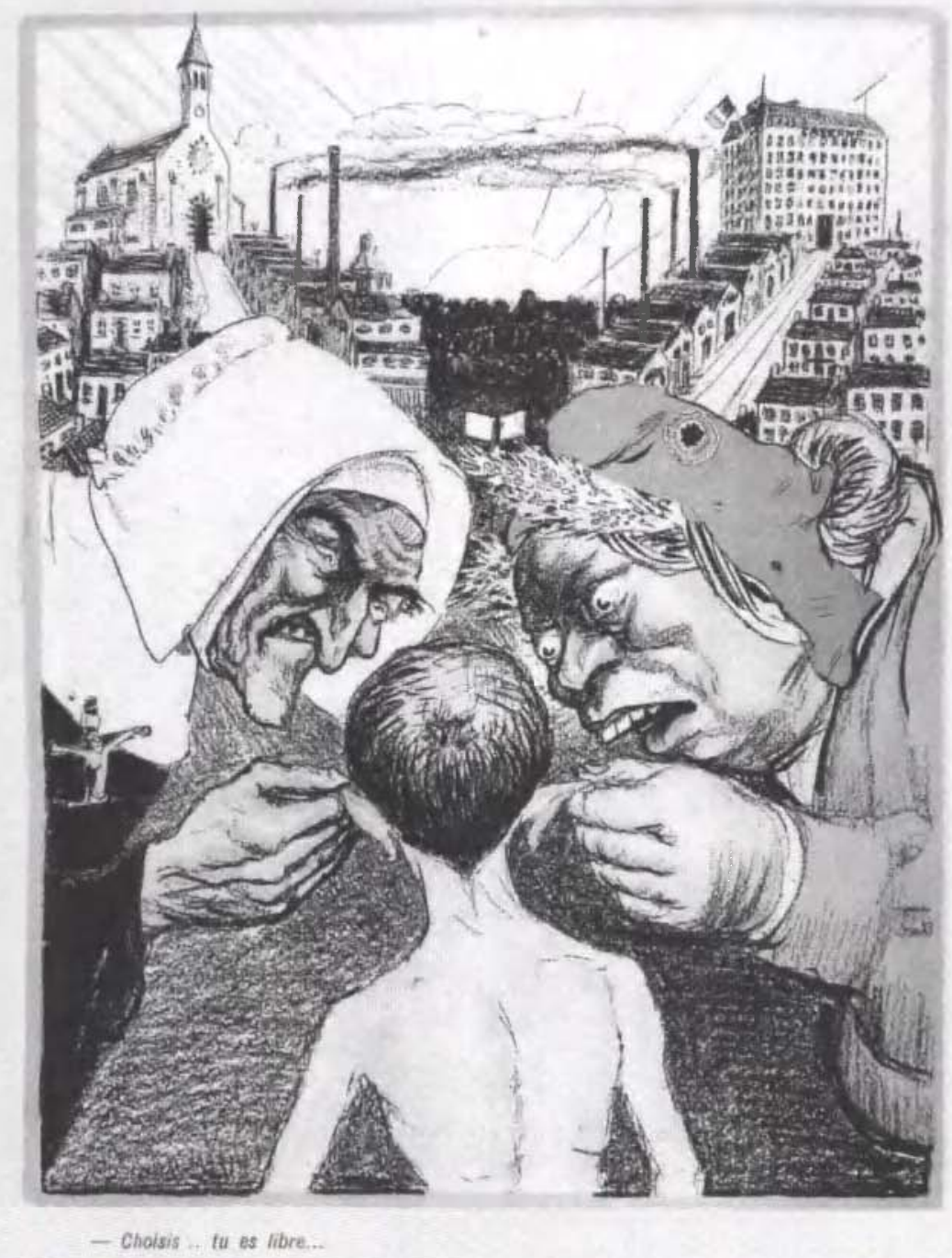

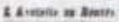

Abb. 78 Jules Grandjouan: - Choisis... tu es libre..., in: L'Assiette au beurre, 10. 3. 1904. Bibl. Forney, Paris. 


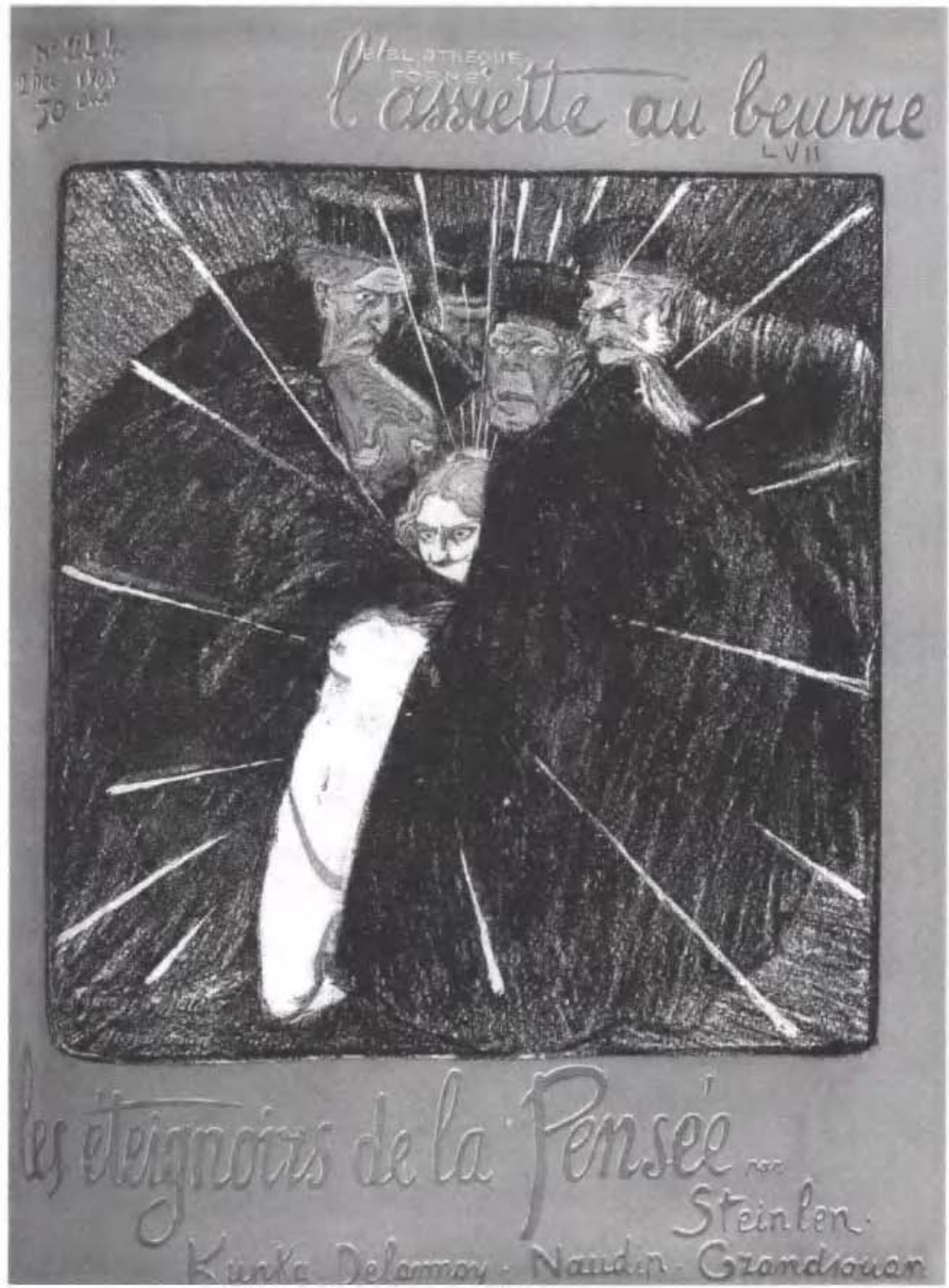

Abb. 79 Theophile Alexandre Steinlen: Les Eteignoirs de la Pensée, in: L'Assiette au beurre, 2. 12.1905. Bibl. Forney, Paris. 
Wie zuvor die Wahrheit in der Dreyfusaffäre soll nun jede Wahrheitsäußerung im Keim erstickt werden. Die katalysatorische Wirkung der Affäre bewahrheitet sich auch hier. Auch Willette, überzeugter Antisemit, widmet sich dem Thema der juristischen Repression, die er allerdings als Vertuschung und Verschleppung charakterisiert. Sein Bild des Rechtswesens zeichnet er in Le Triomphe de monsieur Qui-de-Droit ${ }^{185}$. Dieser ist ein Esel im Schlafrock, der im Lehnstuhl vor sich hindöst, das Gesicht hinter Schal und Brille versteckt. Die Repräsentanten des Staates - teils mit eindeutig typisierten jüdischen Zügen - tragen ihn in einem Triumphzug auf einem Podest, umgeben von den Insignien seiner Macht; Schreibfedern, Tintenfaß und Siegeln. Tropfende, kaum mehr brennende Kerzen stehen dabei ebenso für den Verlust des Lichts der Erkenntnis wie die Legion von Löschhütchen, wovon eines sich drohend auf eine Petroleumlampe senkt ${ }^{186}$.

Viele Karikaturen aber bringen zum Ausdruck, daß der Fall Dreyfus das wahre Gesicht der Justiz enthüllt hat, die nun versucht, ihr Ansehen mit drastischen Maßnahmen zu retten - unvereinbar mit der häufig dargestellten Sehnsucht nach wahrer Gerechtigkeit. 1901 entwirft Jouve für L'Assiette au beurre ${ }^{187}$ das düstere Bild einer gnadenlos richtenden Justiz. Vor einem hoch aufragenden Schafott ist der mit Leichen dicht bedeckte Boden zu erkennen, erleuchtet von einer Laterne, die der sich auf die Guillotine stützende Richter in der hocherhobenen Hand hält. Der Lichtschein, den die Lampe abstrahlt, zeichnet sich vor dem dunklen Hintergrund als Kreuz ab, wodurch angedeutet wird, daß eigentlich die Kirche - schon aufgrund ihrer eigenen inquisitorischen Vergangenheit - hinter dieser harten Rechtsprechung steht. Die unterstellte unheilvolle Allianz von Kirche und Justiz, die ebenso wie das Schrekkensbild le sabre et le goupillon in der Dreyfusaffäre ihren Ursprung hat ${ }^{188}$, bleibt oft auch gegenüber gegenteiligen politischen Ereignissen immun: Im Jahr 1910 sorgte ein Skandal im Rahmen der Liquidationen religiöser Gemeinschaften für Aufregung: Einer der mit den Liquidationen beauftragten Juristen wurde der Unterschlagung von 4 Millionen Francs aus der Liquidationsmasse überführt. Brisant war der Fall nicht nur deshalb, weil die Integrität des laizistischen Staates gefährdet schien, sondern auch, weil das geschätzte Vermögen der Orden von 1 Milliarde Francs der Schaffung von Rentenfonds für Arbeiter und Bauern zugute kommen sollte, die schon seit 1901 diskutiert

185 No. 90, 20.12.1902 (= Le Singe).

186 Zur Symbolik der Lampe und ihrer Löschbarkeit in der Dreyfusaffäre vgl. Kap. 8.2.2. Vgl. zum Paar Petroleumlampe - Löschhütchen auch Kap.6.2.1.

187 L'Euvre: Est-il nécessaire que la justice des hommes aboutisse au charnier?, in: L'Assiette au beurre No.34, 23.11.1901 (= Vengeances sociales).

188 Die naheliegendste Verbindung stellte dabei im Brennpunkt der Affäre zweifellos zunächst die Verbindung zwischen Justiz und Militär dar, wie etwa auf Hermann-Pauls Karikatur Après l'acquittement d'Esterhazy: Der Säbel vereint sich mit einem Sitzleder als Symbol der Beamten und Juristen, beides von einem Lichtschein umgeben. Vgl. HeRmanN-Paul: 200 dessins, Blatt 8. Vgl. dazu Hermann, Dreyfusaffäre, S. 110, Abb. 26. 


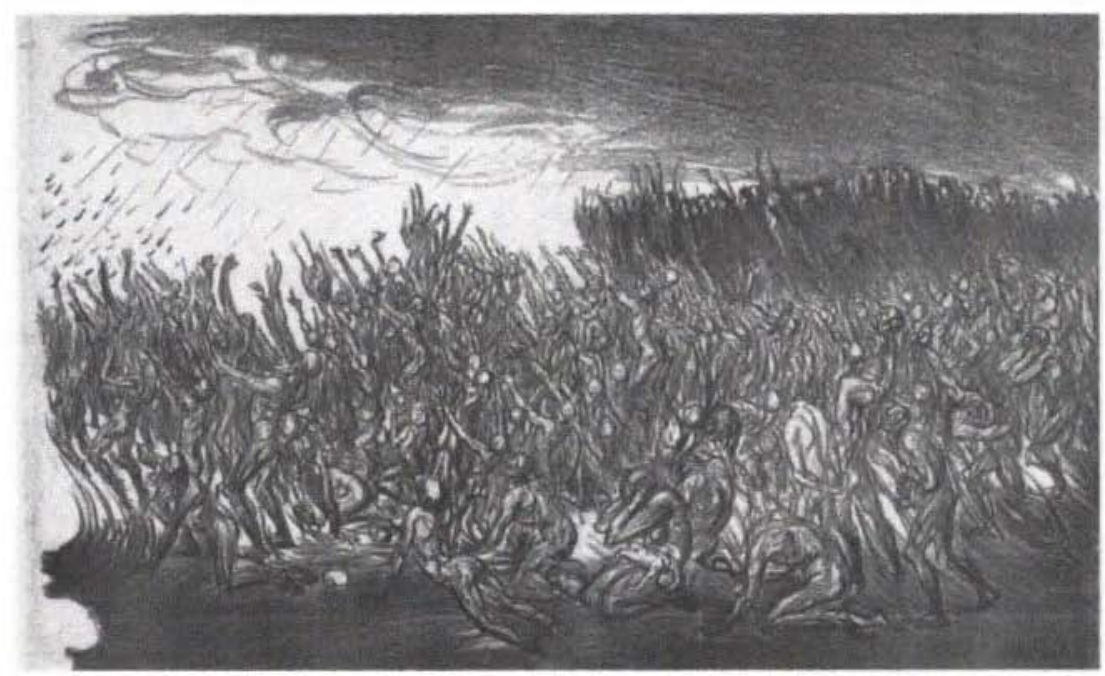

Abb. 80 Theophile Alexandre Steinlen: Justitia, in: L'Assiette au beurre, 26. 2.1902. Sammlung D.K.

wurden $^{189}$. Trotz der offenen Kritik an diesem Fall und anderen Unregelmäßigkeiten unterstellte die sozialistische Bildpresse eine Verschwörung zwischen Justiz und Kirche, die angesichts der realen Vorkommnisse absurd scheint: Der seinerzeit engagierte dreyfusard Ibels greift für L'Action quotidienne ${ }^{190}$ das Motiv der Wahrheit im Brunnen ${ }^{191}$ - au fond du puits - wieder auf. Die nackte Allegorie betrachtet die im knietiefen Wasser schwimmenden Hüte eines Richters und eines Priesters, die ihrerseits beide ängstlich über den Rand lugen:

"LA Vérite: Ce n'est pas la premiere fois que la toque de Themis et le chapeau de Basile se trouvent ici reunis! « Die Unauflösbarkeit dieser Verbindung rührt nicht zuletzt daher, daß die Sehnsucht nach der wahren Gerechtigkeit unverkennbar religiöse Züge annahm. Die übersteigerte Erlösungserwartung kommt auch in der von Steinlen gestalteten Nummer der

189 Bonnefous, Histoire politique, S. 173-175.

190 L'Action quotidienne. Supplement litteraire et artistique, 19.3.1910.

191 Eine Häufung des Motivs der aus dem Brunnen steigenden Wahrheit ist in der radikal antiklerikalen Zeitschrift La Calotte zu beobachten: Vgl. 12.7.1907: "L'HommE DES TENEBRES. - Mort! Oui, mort à la Verite! « (Ein Priesster ermordet die nackte Wahrheit auf dem Grund des Brunnens); 11.9.1908: Comment ils font la lumiere: Die aus dem Brunnen steigende Wahrheit wird von zwei Priestern mit dem Löschhut bedeckt: »BASILE. - Il n'y a encore que l'Eglise pour enseigner la verite«. 31.3.1911: L'Eteignour. Ein Priester versucht, die Fackel der allegorischen nackten Wahrheit mit dem Schriftzug Verite zu löschen: "Je n'arriverai donc jamais à eteindre son flambeau «; 3.11.1911: La Verite: Die mit dem Siegel aus dem Brunnen steigende nackte Wahrheit treibt die Priester zurück: »Arriere, noiraud infect, et place à la Verite!!!«. 
Assiette au beurre mit dem Motto Justice zum Ausdruck ${ }^{192}$ (Abb. 80): Seine Illustration Justitia zeigt die ausgebeutete, teils am Boden liegende Masse, die sich hoffnungsvoll dem sich aufhellenden Himmel zuwendet. Die Identität der Gerechtigkeit bleibt offen, wodurch ihr extrem aufgeladener VerheiBungscharakter noch gesteigert wird. Bereits 1896 läßt die Lithographie L'Aube von Jehannet für das Album des Temps nouveaux die Sonne Justice am dunkel verhangenen Himmel aufgehen ${ }^{193}$. Vier Jahre später erscheint als Blatt 21 des Albums Félix Vallottons La Débâcle ${ }^{194}$, in dem die Sonne der Justice ihren Sieg über Kirche, Militär und Justiz davonträgt. Leblos liegen die drei Gestalten am Boden, während die schwarze Wolke, aus der die Sonne Justice sich gerade befreit, zerreißt. Die siegreiche Sonne garantiert die Freiheit. Die Emanzipation der Freiheit von der Republik bereitet auch den Weg für eine neue Sonne, die ganz allein denen gehört, die bisher im Dunkeln waren.

192 L'Assiette au beurre No. 47, 26.2.1902 (= Justice. La vision de Victor Hugo).

193 Blatt 5 der Sammlung, angeboten ab 28.11.1896. Vgl. Dardel, Les Temps nouveaux, S. 52, Kat. 62 .

${ }^{194}$ Holzstich, ausgeführt von G. Berger nach dem Entwurf von Félix Vallotton. Ibid., S. 55, Kat. 80. Vgl. auch Kleeblatt, The Dreyfus Affair, S.255, Abb. 182. 
